\title{
Distribution, Migratory Behavior, and Habitat Use of Razorback Sucker (Xyrauchen texanus) in Lake Mohave, Arizona-Nevada
}

Open File Report 98-252

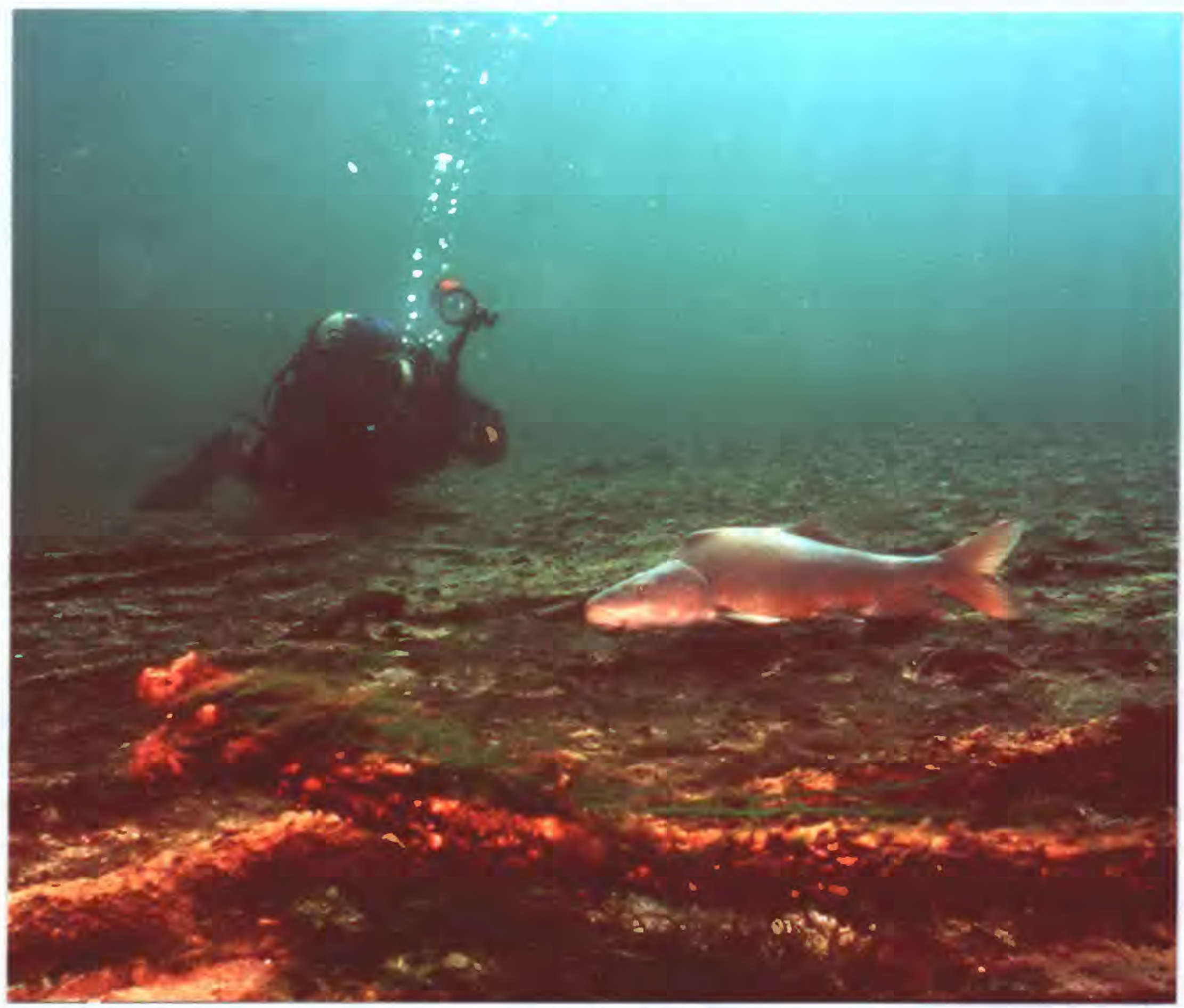

Photo courtesy of Greg Finnegan

U.S. Department of the Interior U.S. Geological Survey
Prepared in Cooperation with Arizona State University, Bureau of Reclamation, National Park Service, Fish and Wildlife Service, and Nevada Division of Wildlife

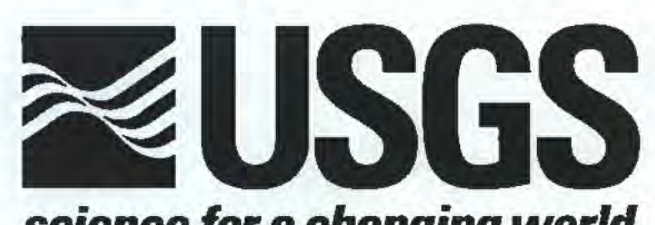




\title{
U.S. DEPARTMENT OF THE INTERIOR
}

\section{U.S. GEOLOGICAL SURVEY}

\section{Distribution, Migratory Behavior, and Habitat Use of Razorback Sucker (Xyrauchen texanus) in Lake Mohave, Arizona-Nevada}

\author{
By \\ ${ }^{1}$ Gordon Mueller, U.S. Geographical Survey \\ ${ }^{2}$ Dr. Paul Marsh and Glen W. Knowles, Arizona State University
}

Open-File Report 98-252

Prepared in cooperation with Arizona State University, Bureau of Reclamation, National Park Service, U.S. Fish and Wildlife Service, and Nevada Division of Wildlife.

This report is preliminary and has not been reviewed for conformity with U.S. Geological Survey editorial standards (or with the North American Stratigraphic Code). Any use of trade, product, or firm names is for descriptive purposes only and does not imply endorsement by the U.S.

Government.

'P.O. Box 25007 (D-8220), Denver, Colorado 80225

${ }^{2}$ Department of Biology, P.O.Box 871501, Tempe, Arizona 85287 
EXECUTIVE SUMMARY .................................................................. iii

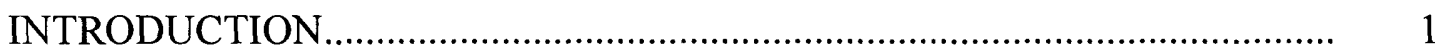

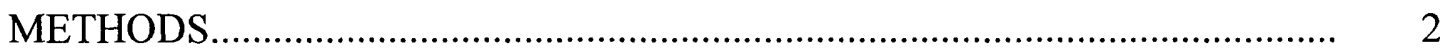

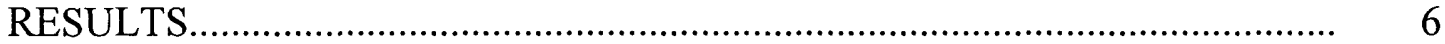

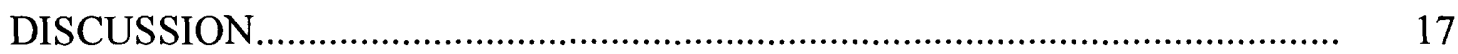

ACKNOWLEDGMENTS........................................................................ 22

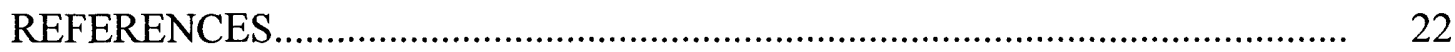

APPENDICES

A. Individual Fish Data................................................................................ 28

B. Telemetry Data Base ......................................................................... 31

C. Temperature and Depth Data................................................................... 60

D. Individual Movement Maps...................................................................

Number

1

Minimum, maximum, and average distance ( $\mathrm{m} /$ day) traveled by adult razorback suckers in Lake Mohave between November 1994 and July 1997.

TABLE

Monthly average movement rates ( $\mathrm{m} /$ day) for adult razorback suckers in Lake Mohave from November 1994 to July 1997 . 10

3

4
Minimum, maximum, and average distance ( $\mathrm{m} /$ day) traveled by juvenile (YOY) razorback suckers in Lake Mohave over a 50 day period in 1996.

Comparison of water temperature and depth occupied by adult razorback suckers in Lake Mohave from May through November 1995. 


\section{FIGURE}

Number

Segmented map of Lake Mohave showing the distribution

and location of the 71 GPS waypoints or listening stations

2-11 Movements of adult razorback suckers between GPS

waypoints in Lake Mohave, November 1994 to July 1997........ 8

12 The Maximum lineal distance traveled (range) by razorback suckers by river mile within Lake Mohave during November 1994 through July 1997.

13 Dispersal rate of young of the year razorback sucker

determined by externally attached sonic transmitters.

Average, maximum, and minimum body temperature range (month average) of adult razorback suckers compared to maximum reservoir temperatures of Lake Mohave, Arizona-Nevada from November 1994 to April 1996...............

15 Map showing areas where adult razorback suckers were detected in Lake Mohave during the spawning season (November through April), 1995 and 1996

16 Map showing areas where adult razorback suckers were detected in Lake Mohave during the non-spawning season (May through October) 1995, 1996, and 1997. 


\section{EXECUTIVE SUMMARY}

Lake Mohave currently supports the vast majority of wild razorback suckers in the Colorado River basin. The first few years following the closure of Davis Dam, ecological conditions allowed the survival of 100's of thousands of young razorback suckers in the new reservoir. This represented the last notable recruitment for the species. Measurable survival has not occurred following the establishment of the reservoir's sport fishery. Unfortunately, juveniles seek and use the same areas inhabited by large predators such as largemouth bass and channel catfish. As juveniles become sexually mature, increased activity may lead to additional losses from hydroelectric entrainment or water diversion.

Ten adult and six juvenile razorback sucker with sonic transmitters were released and tracked in Lake Mohave between November 1994 and July 1997 to determine habitat use and migratory behavior. Individual movements and ranges varied, but adults exhibited both pre- and post spawning migrations. Adults assembled in early December between river kilometer (RK) 26 and RK 90 (Horse Shoe Rapids) with spawning aggregations that often numbered in the hundreds. Tagged adults spawned between mid-January and March at multiple spawning sites.

Post-spawning movements were as prevalent as pre-spawning migrations as adults disbursed toward summer ranges. Six fish (60\%) used the area between RK 69 and RK 50 where hypolimnetic water released from Hoover Dam mixes with Lake Mohave waters. Two adults spent summers along the Nevada shoreline in Cottonwood Basin (RK 26 to RK 32) while the two remaining fish used both areas. Adult territorial ranges averaged $39 \mathrm{~km}(17.8$ to $72.4 \mathrm{~km})$ and were normally found between RK 26 (Nine Mile Cove) and RK 69 (Chalk Cliff Lights).

The reservoir's longitudinal thermal gradient did not influence geographical distribution. Fish were typically found within $50 \mathrm{~m}$ of shore and at depths between 3.1 and $16.8 \mathrm{~m}$. Although razorback suckers moved vertically in the water column, no correlation was found for depth with time of day. Adults utilized a wide thermal range and may regulate body temperature with depth. Fish inhabited shallower depths in early summer (June) and autumn (October) compared to the warmer months of July and August. Body temperatures of razorback suckers typically ranged between 18 and $22{ }^{\circ} \mathrm{C}$ when surface water temperature in the reservoir peaked at $30^{\circ} \mathrm{C}$ during the summer.

Adult razorback suckers return annually to select spawning sites along the wave-washed rubble shoreline. However, nine of 10 sonic-tagged fish were found at several spawning areas, regardless of where they were initially captured. After spawning, some individuals appeared to also have fidelity to specific areas of Lake Mohave during the non-spawning season, suggesting they may exhibit a home range. 
Hourly movement rates showed females were significantly $(\mathrm{P}=.05)$ more active during spawning than males. Apparently male razorback suckers congregate and remain on, or close to, spawning sites throughout the spawning season. Females on the other hand joined the males only when ready to spawn and left the site when the spawning act was completed. They appeared to wander between specific spawning groups and may spawn with various males that would contribute to genetic diversity.

Preliminary information on juveniles suggested they are cover oriented and exhibit migratory behavioral quite different than adults. Juveniles traveled substantial distances $(>5 \mathrm{~km})$ immediately following release, but with time their movements became less erratic and more closely associated with shore and protective cover. Juveniles typically found refuge in shallow, vegetated coves where they often remained sedentary for days and some for weeks. One young razorback sucker (3-yr) became quite active during the 1995 spawning season, traveling downstream to within $3 \mathrm{~km}$ of Davis Dam and then moving upstream to within $8 \mathrm{~km}$ of Hoover Dam, a minimum distance of $145 \mathrm{~km}$.

Lake Mohave serves as the largest refugium for adult razorback sucker. It provides additional research opportunities that merit consideration. Further research is recommended on predator/prey relationships between the early life stages of razorback sucker and introduced predators. The migratory behavior of sub- or young adults also needs to be examined to determine if that life stage is more susceptible to entrainment, passage, or stranding. Lastly, we suggest investigations into the influence that reservoir fluctuations have on predatory distribution and densities in shallower habitats used by juvenile razorback suckers. In sight into these interactions may increase stocking survival by introducing fish at times or locations where predators may be inactive or disbursed. 


\section{INTRODUCTION}

Most research on wild razorback suckers has dealt with adults, and much of the research focused on the relic population in Lake Mohave (Minckley 1983, Langhorst and Marsh 1986, Marsh 1987, Mueller 1989, Bozek et al. 1990, Minckley et al. 1991, Mueller 1995, Marsh 1997) and a small population found in the Green River, Utah (McAda and Wydoski 1980, Tyus 1987, Tyus and Karp 1990, Modde 1996, Modde et al. 1996, Modde and Wick 1997). Less is known about early life stages. Detection, movement, and behavior of larval suckers has been reported Minckley (1983), Langhorst and Marsh (1986), Horn et al. (1994), Mueller et al. (1995), and Muth (1995). Recent information on wild juveniles has been limited to a few, rare collections (Marsh and Minckley 1989a, Minckley et al. 1991, Gutermuth et al. 1994, Modde 1996, Mueller 1996, Modde and Wick 1997, Holden et al. 1997).

Most observations have occurred during the spawning period when razorbacks are most easily found and captured. Razorback suckers in Lake Mohave aggregate along shoreline between January through March to spawn over wave-washed alluvial terraces of sands and gravels. The majority of spawning occurs in the main basin of the reservoir but, occasionally, small spawning aggregations are observed in the upstream riverine portion of the reservoir (Minckley 1983, Mueller 1989). Some studies in the Upper Basin (Tyus 1987, Tyus and Karp 1990) suggested razorbacks exhibited fidelity to a specific spawning site, but these data have been inconclusive.

Less information is available on habitat use during non-spawning periods. Following spawning, Lake Mohave suckers were generally thought to disperse. Many can be found downstream of Hoover Dam (RK 97-103) and large schools have been seen on the surface of the main reservoir (Mike Burrell-NDOW personal communique). It was unknown whether these areas represent important summer habitat or if individual fish have specific home ranges.

Razorbacks are long-lived, many over 35 years of age and believed to be nearing the end of their estimated lifespan (Minckley et al. 1991). Population estimates conducted during the past decade has shown a 60 percent decline in the reservoir's population (Marsh 1995). While adults are still common, juvenile suckers are rarely collected. Information on juvenile razorback suckers is virtually nonexistent because of their scarcity. Nocturnal behavior and use of dense aquatic vegetation was reported for cove-reared fish (Mueller and Marsh 1993). Young suckers hid in aquatic vegetation during the day, but became active at night and less reclusive as they matured (Ryden and Pfeifer 1996). Modde (1996) reported collecting young razorback suckers from a depression wetland suggested that earlier speculations (Tyus and Karp 1990) of floodplain habitats may be important nursery habitat. To our knowledge, only six juvenile suckers have been collected from Lake Mohave in the past 20 years, and these may have been 
captive-reared fish from previous stockings (Marsh and Minckley 1989a).

The Native Fish Work Group formed as a coalition of concerned state and federal agencies for the purpose of stocking 50,000, juvenile razorback suckers to replace the old population that was dying out in Lake Mohave (Mueller 1995). Stocked fish are monitored to determine the appropriate sizes needed to ensure adequate survival. Preliminary information suggests that approximately $57 \%$ over $20 \mathrm{~cm}$ have survived (Marsh 1997). Predation is believed to be a major factor that limits recruitment from natural spawning. Survival is size dependent but other factors, such as time and location of stocking, cove availability, predator densities, and behavioral traits that could also impact survival.

The purpose of this study was to gain a better understanding of the migratory behavior and habitat used by juvenile and adult razorback suckers in a reservoir environment. As adults become rare and more difficult to capture, information regarding their movements and habitat use will become more important in monitoring populations. In addition, understanding habitat use and behavior of juveniles will allow assessment of predation, stocking protocols, and factors that can enhance survival and recovery.

\section{METHODS}

\section{Study Specimens}

Adults--Adults were trammel netted at Yuma and Tequila coves (Figure 1, RK 34\& 39) during November 6-7, 1994. Five males and five females were selected and held at each site for surgery the following morning. The Yuma Cove fish were surgically implanted and released on November 7 th and the Tequila Cove fish were implanted and released on November 8th. Adults averaged $609 \mathrm{~mm}(555-680 \mathrm{~mm})$ in total length and 2.78 kilograms $(1.75-4.21 \mathrm{~kg})$. Individual data pertaining to length, weight, PIT tag numbers, sonic transmitter code, release location, and distances moved are summarized in Appendix A.

Juveniles--Twenty five juvenile suckers were taken from grow-out ponds and held in holding facilities at the Bureau of Reclamation laboratories in Boulder City, Nevada. The fish were later transported by truck and by boat on November 22, 1994. Fish averaged $338 \mathrm{~mm}$ (315 to 392 $\mathrm{mm})$ and 369 grams $(296-598 \mathrm{~g})$. The juveniles were released in groups of four fish at: Red Light Cove (RK 10), Dandy Cove (RK 17), Owl Point (RK 45), Double Neck Cove (RK 71), and Cross Current Rapids (RK 92). Pertinent information is summarized in Appendix A.

\section{Telemetry Equipment}

We determined a 30+-cm sucker was capable of carrying a 6 gram, 16 X $55-\mathrm{mm}$ sonic transmitter (Sonotronics model CTT-83-2) (Knowles 1994). Appropriate transmitter size for 
juvenile suckers was determined by examining the volume of the abdominal cavity in museum specimens at Arizona State University. Transmitters ranged in size from $8 \times 35 \mathrm{~mm}$ to $18 \times 70$ $\mathrm{mm}$ with life spans ranging from 45 days to 48 months. While smaller transmitters are less stressful to fish, there is a substantial trade-off between transmitter size and performance with weaker signal strength and shorter the battery life with smaller transmitters.

Transmitters operated on a frequency of $73 \mathrm{kHz}$ and produced a code of pulses broken by pauses (e.g. 249 would be 2 pulses-pause, 4 pulses-pause, 9 pulses-pause, repeat sequence). Battery longevity was estimated to be about 14 months and signals had an average detection range of 1,000 meters. The transmitters also provided body temperature with an accuracy of $\pm 0.25^{\circ} \mathrm{C}$ through a measurable pulse interval.

\section{Surgical Procedures}

Surgical procedures were similar to Hart and Summerfelt (1975) and Tyus (1987). Fish were anesthetized in a tub containing approximately $80 \mathrm{~L}$ of a $0.1 \mathrm{~g} / \mathrm{L}$ mixture of tricaine methanesulfate (MS-222). When the fish lost equilibrium, it was positioned belly up in a specially designed surgical cradle. Water was passed over the gills to provide oxygen and to keep the body moist. Anesthetic bath was used during the first half and fresh water was used during the last half of the operation to minimize the effect of anesthesia and speed fish recovery.

Transmitters and passive integrated transponder (PIT) tags were sterilized in 70\% isopropyl alcohol and $10 \%$ betadine. A $30-40 \mathrm{~mm}$, medio-lateral incision was made slightly anterior and dorsal to the left pelvic fin. The transmitter was inserted toward the posterior of the abdominal cavity so that it rested on the pelvic girdle. The incision was sutured with 4-5 knots using 3-0 Ethilon black monofilament nylon and a FS-1 cutting needle.

The surgical process for individual fish required approximately 7-12 minutes. Anesthesia took affect in about 2-4 minutes and surgery normally required 3-5 minutes. The fish remained docile and incisions caused minimal bleeding. Following surgery, fish required from 1 to 10 minutes to recover from the anesthesia. Fish were released when they regained their motor skills.

\section{External Attachment}

Microtransmitters ( 8 X $35 \mathrm{~mm}, 45$ day) were externally mounted to five juvenile suckers on October 20, 1995. Equipment was sterilized in alcohol and the fishes dorsal keel was swabbed with betadyne. Two sutures were tied approximately $20 \mathrm{~mm}$ apart on each transmitter and their knots were glued. Needles were threaded through a plastic backing plate about $1 \mathrm{~cm}$ below the dorsal keel. The wound was treated with neosporium and the sutures were tied together with 2 square knots.

External attachment of sonic transmitters required approximately 30 seconds. Three fish were 
released with approximately 200 other juveniles in a small protected cove adjacent to Nellis Cove (RK 26). The remaining two fish were transported to a location cove near Sidewinder Cove (RK 14) on the Arizona side and released with another group of fish. The fish averaged $315 \mathrm{~mm}(303-328 \mathrm{~mm})$ in total length and weighed approximately 350 grams $(288-406 \mathrm{~mm})$. Specific information is summarized in Appendix A.

\section{Survey Design}

Weekly surveys were conducted by boat using a global positioning system (GPS). A transect grid was developed using 71 GPS way-points or "listening stations" (Figure 1). These waypoints were established at 1,600 meter intervals, which standardized our survey design and provided continuity and overlap (1,000 meter range). The pre-established way-points were programed into the GPS's navigational program. Surveyors simply navigated between waypoints, lowered a directional hydrophone into the water, and listened for transmitter signals.

Signals were detected using a DH-2 hand held, directional hydrophone, a USR-5W ultrasonic receiver, and headphones. The receiver had a digital readout that provided the time interval between signals, which correlated to the fishes body temperature.

Surveys required two days to cover the entire reservoir. Two complete surveys were conducted each week for 18 months. Alternate areas of Lake Mohave were examined during both day and night. When fish were detected, surveyors triangulated the fish as closely as possible without disturbing it. Fish location (latitude and longitude), body temperature, and estimated distance from shore were recorded. A Hydrolab was used to measure vertical water temperature profiles.

Battery life of several transmitters exceeded the 14 month life expectancy. Scheduled surveys continued until mid-April 1996, however, additional information was collected through July 1997 on an intermittent basis.

\section{Data Analysis}

Geographical information was provided using digitized shoreline profile maps of Lake Mohave and the geographical information program (GIS) ARCINFO (TM). Using ASCI files developed for each fish, the program calculated the distances between all locations where that particular fish was found. The output provided movement rates in $\mathrm{m} /$ day, total distance traveled, actual maps of movement, and seasonal distribution of fish (Appendices B \& D). Rate measurements and distances from shore were transformed into single classification frequency distributions. Each observed datum were summarized by particular classes. Movement rates $(\mathrm{m} /$ day) of both males and females were examined for the periods between January 31 and March 15 in 1995 and 1996, to determine if there were differences in movement patterns between sexes (F-test). 


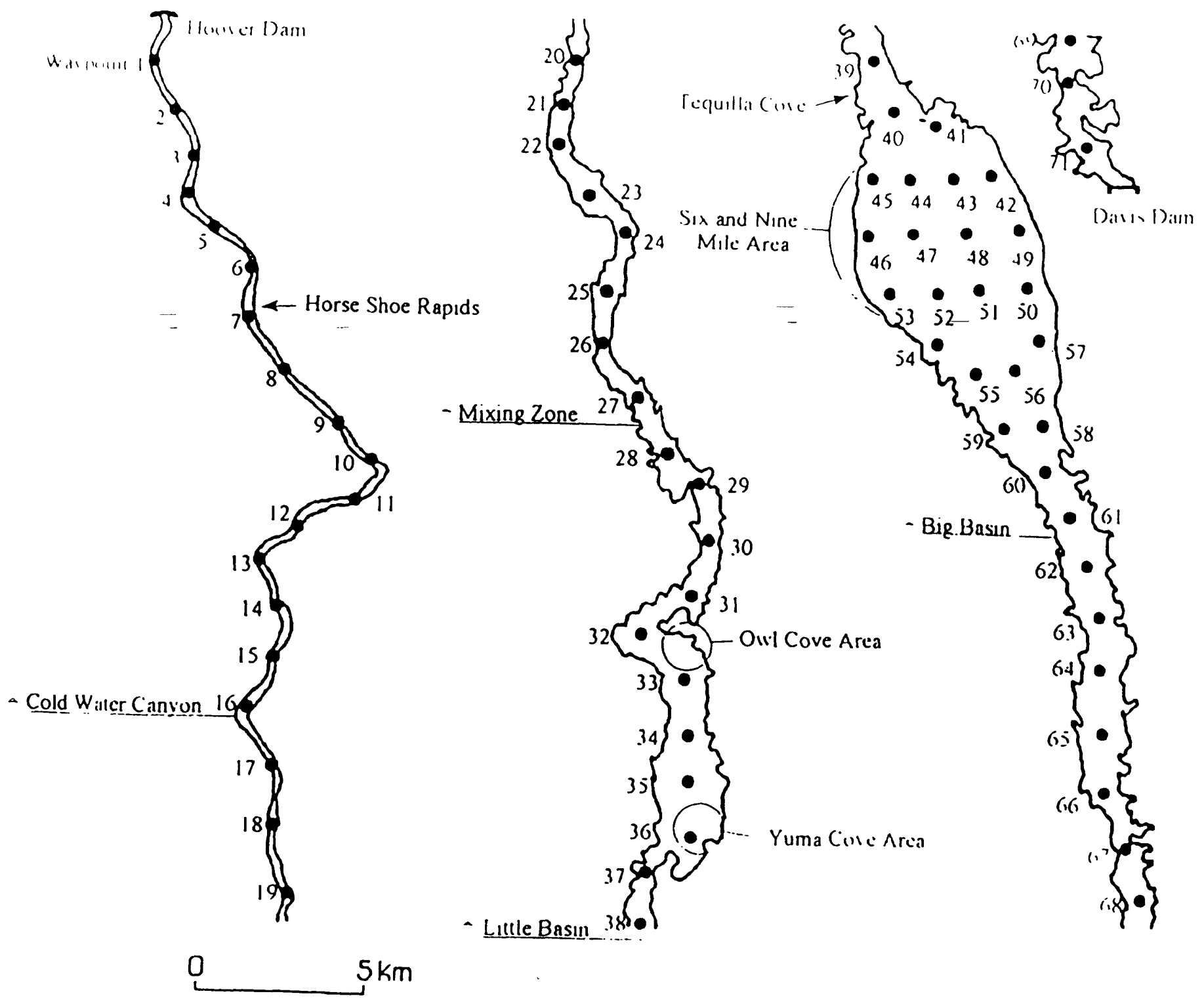

Figure 1. Segmented map of Lake Mohave showing the distribution and location of the 71 GPS waypoints or listening stations. 
To determine fidelity to inshore habitats, ARCINFO was used to determine the amount of area in the reservoir at specific distances from shore. Percentiles of available surface habitat were compared to the percentile of fish use within specific zones via chi square test (Sokal and Rolf 1981).

Comparisons of shoreline habitat utilization, movement rates, and area affinity were divided into spawning and non-spawning periods. These periods were defined based on information and observations reported for razorback suckers in Lake Mohave (Minckley 1983, Minckley et al. 1991, Bozek et al. 1990, NFWG unpublished data). The spawning season can vary depending upon weather and flow conditions. Staging of spawning aggregations have been observed as early as November and larval suckers have been collected into April. For the purposes of this analysis, we defined the spawning period as being from November through April and the nonspawning period from May through October.

\section{RESULTS}

\section{Data Base}

The database is presented in Appendices A-D which details information on all 45 fish (20 adults plus 25 juveniles) used in the telemetry study. We felt analysis could be biased by unhealthy fish, so only movement data from the 10 adults and 1 juvenile that remained active through the initial 14 month period for the analysis. Nearly 2,000 detections of fish movement were recorded, of which 637 represented daily detections of the eleven surviving fish. Hourly tracking information added over 1,000 observations to the database. Over 800 recordings of body temperature in razorback suckers with 147 correlated to depth through vertical water temperature profiles acquired with the Hydrolab (Appendix C). These data represented our most accurate information on depths occupied by fish.

Information was also collected from the 5 juveniles that were externally tagged with 45 day transmitters. Four of the five fish were tracked for the duration of the transmitter life.

\section{Fish Movement}

Adults--Fish movements were not only variable but quite distinctive by sex and among individuals (Figures 2-11). Both males and females exhibited the ability to travel substantial distances in a short time span. One fish (\#348) traveled more than 17 kilometers in fewer than 24 hours while some fish remained in the same general locations for weeks. Adult daily movement rates averaged $527 \mathrm{~m} /$ day $(242-788 \mathrm{~m} /$ day $)$. Females exhibited a slightly higher rate $(\bar{x}=582 \mathrm{~m} /$ day) compared to males $(\bar{x}=445 \mathrm{~m} /$ day)(Table 1$)$. Maps of individual fish movements are summarized in Figures 2-12 and provided in detail in Appendix D. 
Table 1. Minimum, maximum, and average distance $(\mathrm{m} /$ day $)$ traveled by adult razorback suckers in Lake Mohave between November 1994 and July 1997.

\section{Fish \# of Min, Max. Avg. STD Total Distance \\ ID Obs ---(meters / day)--- Traveled (m)}

\begin{tabular}{|c|c|c|c|c|c|c|}
\hline \multicolumn{7}{|c|}{ Females--Total Record } \\
\hline 88 & 65 & 0 & 6,703 & 603 & 1,322 & 250,427 \\
\hline 276 & 71 & 21 & 3,502 & 606 & 708 & 352,544 \\
\hline 339 & 62 & 9 & 10,108 & 767 & 1,413 & 417,375 \\
\hline 375 & 54 & 4 & 2,368 & 417 & 544 & 249,681 \\
\hline 384 & 36 & 0 & 6,886 & 614 & 1,133 & 182,991 \\
\hline 465 & 65 & 9 & 6,558 & 485 & 851 & 264,277 \\
\hline \multicolumn{7}{|c|}{ Males--Total Record } \\
\hline 2228 & 51 & 3 & 15,607 & 788 & 2,280 & 231,470 \\
\hline 366 & 57 & 0 & 1,986 & 243 & 509 & 167,653 \\
\hline 348 & 65 & 0 & 17,353 & 509 & 2,154 & 181,680 \\
\hline 258 & 57 & 0 & 1,635 & 242 & 334 & 120,942 \\
\hline
\end{tabular}

Spawning Movements --Movements of fish during the peak of spawning, January 31 to March 15 were examined for both 1995 and 1996 . We compared the daily average movements (m/day) for each sex. Parametric comparison of male and female movement rates indicated females were significantly (Anova/ $\mathrm{F}_{1,8}=6.79, \mathrm{P}=0.0314$ ) more active than males. During this 6-week period, females exhibited individual movement rates of 721, 444, 453, 412, 444, $284 \mathrm{~m} /$ day, which was slightly lower than their year-round total $(\bar{x}=460$ versus $582 \mathrm{~m} /$ day $)$ average. The four males on the other hand averaged $409,281,32$, and $31 \mathrm{~m} /$ day, all below their annual average $(\bar{x}=188$ versus $445 \mathrm{~m} /$ day).

Range--Fish were found occupying areas that encompassed known spawning sites and summer habitats (Figure 12). The average linear range of the 10 adults was about $39 \mathrm{~km}$ (18 to $72 \mathrm{~km}$ ). Females ranged further than males, both up and down reservoir. Their range averaged $42 \mathrm{~km}$ (29-72 km) compared to $35 \mathrm{~km}(18-51 \mathrm{~km})$ for males. 
Fish \#258(male)

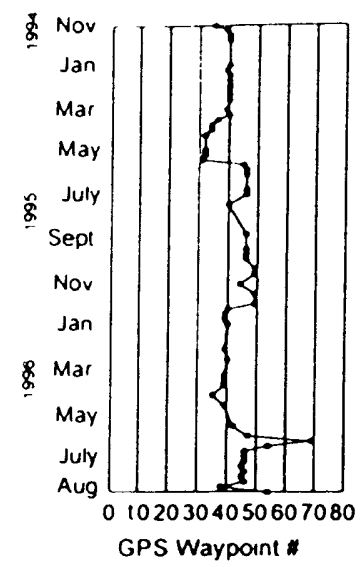

Fish $\# 348$ (male)

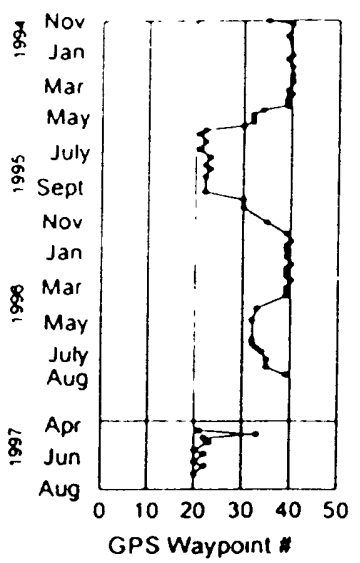

Fish \#366 (male)

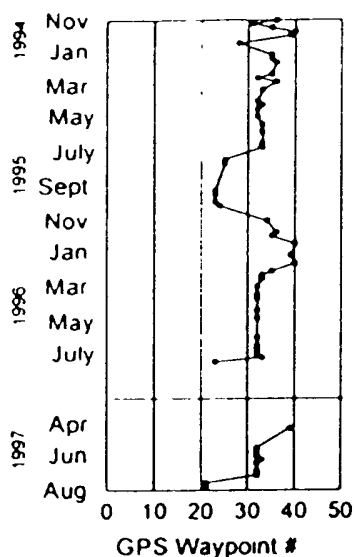

Fish $\# 2228$ (male)

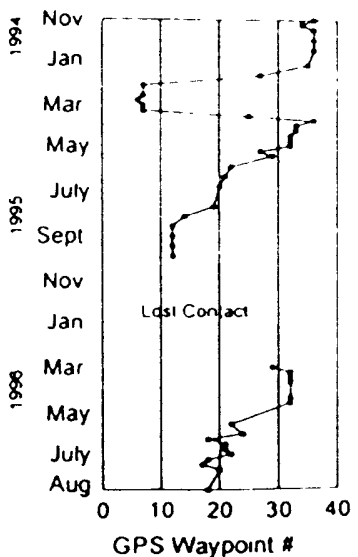

Fish \#88(female)

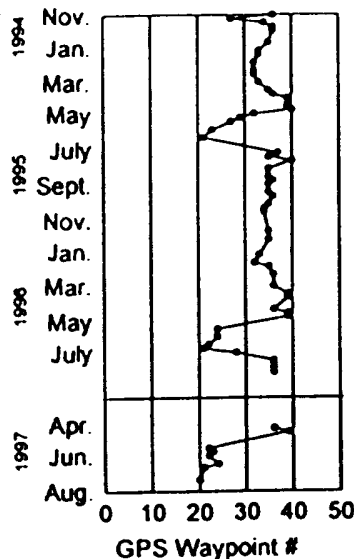

Fish \#375(female)

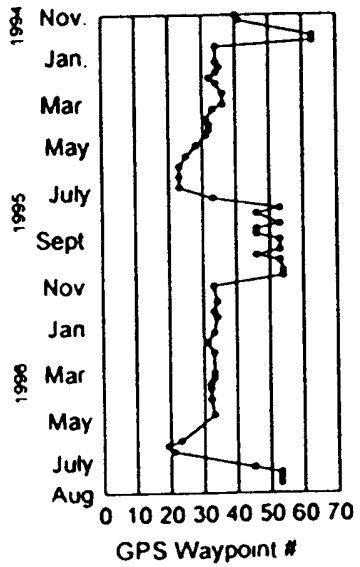

Fish \#276(female)

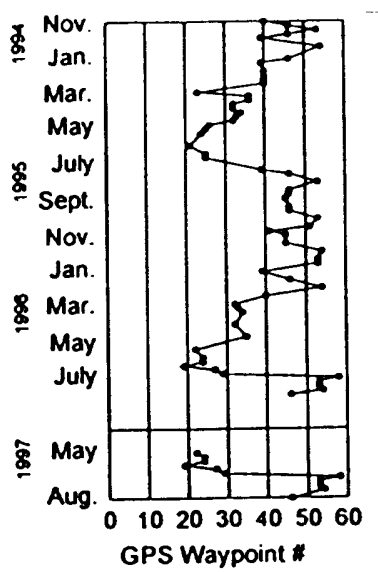

Fish \#384(female)

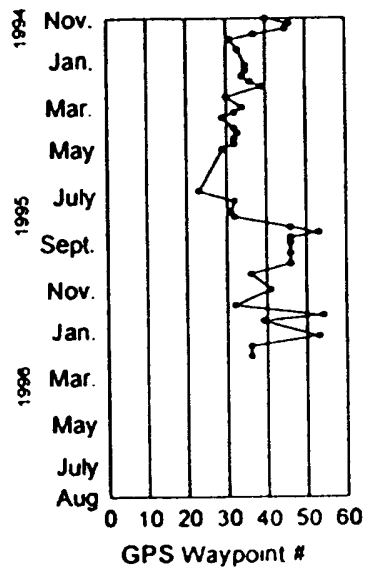

Fish \#339(female)

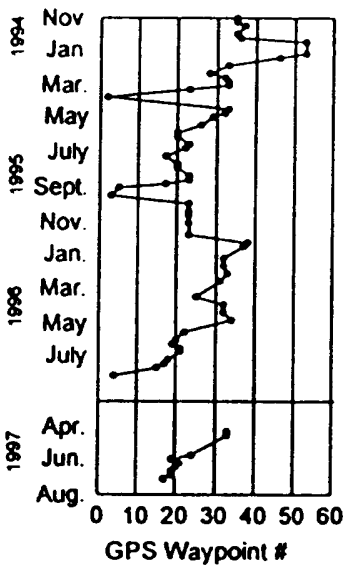

Fish \#465(female)

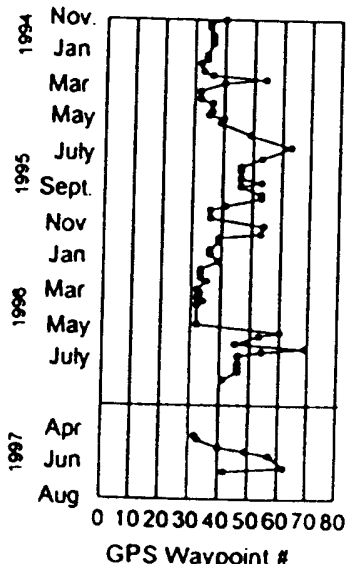

Figures 2-11. Movements of individual adult razorback suckers between GPS waypoints in Lake Mohave, November 1994 to July 1997. 


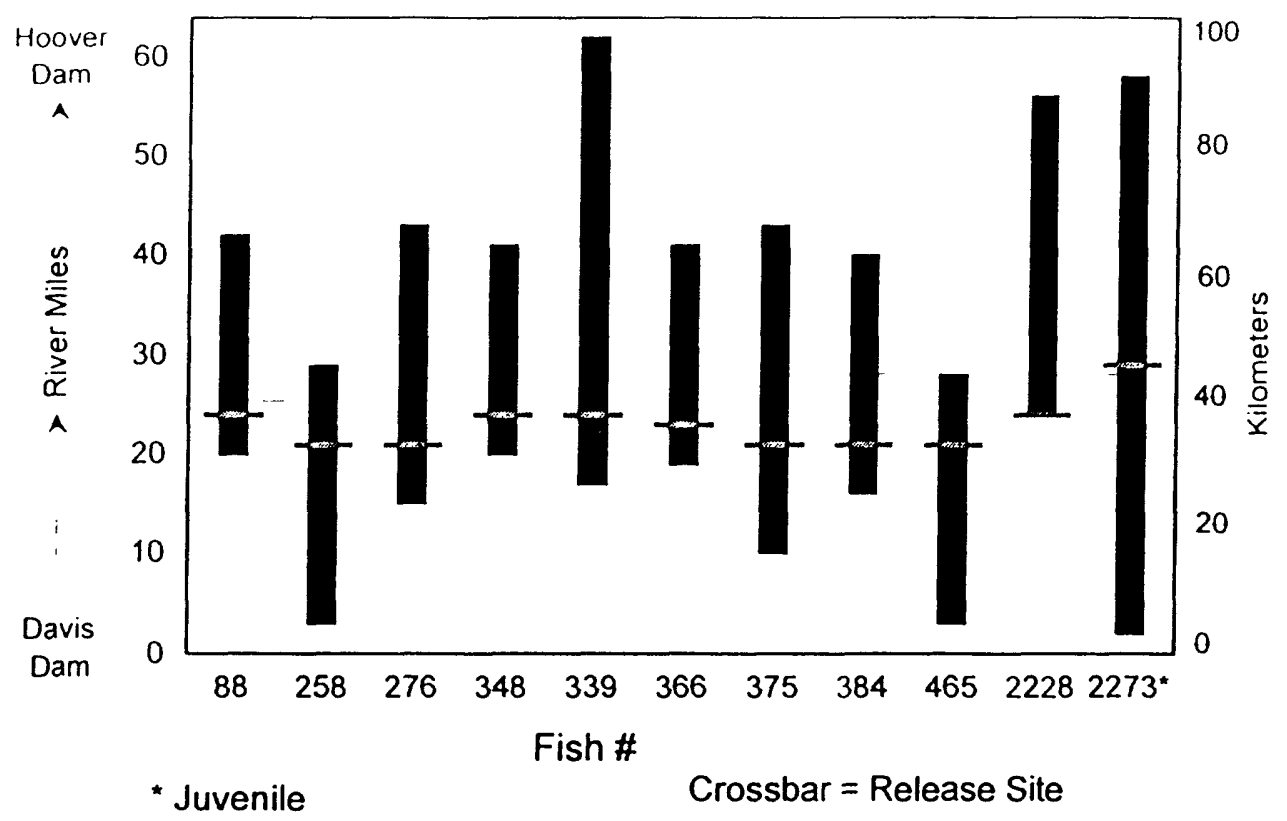

Figure 12. The maximum lineal distance (range) traveled by Razorbacks Suckers by River Kilometer within Lake Mohave during November 1994 through July 1997.

Hourly and Monthly Movement Rates Data were examined to determine trends in hourly or seasonal movement by adult razorback suckers. No significant trends were identified. Hourly data suggested fish might be slightly more active during mid-morning (9:00 to 10:00 am) in the summer. A similar analysis was preformed for the monthly averages but variability was high. However, months when individual fish movement exceeded $1,000 \mathrm{~m} /$ day, occurred immediately after release and following both spawning periods (Table 2). 
Table 2. Monthly average movement rates ( $\mathrm{m} /$ day) for adult razorback suckers in Lake Mohave from November 1994 to July 1997.

$\begin{array}{llrrc}\text { Month } & \text { Julian Day } & \begin{array}{c}\text { Average } \\ \text { STD }\end{array} & \text { Obs \# } \\ \text { Nov-1994 } & 34639 & 1,216 & 1,658 & 16 \\ \text { December } & 34669 & 488 & 563 & 25 \\ \text { January 1995 } & 34700 & 350 & 431 & 32 \\ \text { February } & 34731 & 345 & 525 & 25 \\ \text { March } & 34759 & 1,100 & 2,703 & 35 \\ \text { April } & 34790 & 309 & 515 & 33 \\ \text { May } & 34820 & 445 & 770 & 24 \\ \text { June } & 34851 & 463 & 593 & 28 \\ \text { July } & 34881 & 679 & 1,256 & 27 \\ \text { August } & 34912 & 686 & 2,030 & 23 \\ \text { September } & 34943 & 157 & 214 & 24 \\ \text { October } & 34973 & 307 & 541 & 24 \\ \text { November } & 35004 & 333 & 380 & 21 \\ \text { December } & 35034 & 521 & 773 & 21 \\ \text { January 1996 } & 35065 & 199 & 261 & 17 \\ \text { February } & 35096 & 262 & 390 & 10 \\ \text { March } & 35125 & 247 & 335 & 30 \\ \text { April } & 35156 & 479 & 1,407 & 18 \\ \text { May } & 35186 & 1,730 & 2,179 & 6 \\ \text { June } & 35217 & 475 & 453 & 40 \\ \text { July } & 35247 & 533 & 641 & 33 \\ \text { April 1997 } & 35521 & 2,338 & 5,017 & 11 \\ \text { May } & 35551 & 510 & 399 & 14 \\ \text { June } & 35582 & 576 & 806 & 17 \\ \text { July } & 35612 & 477 & 685 & 6\end{array}$

Juveniles The juvenile (\#2273) exhibited a very different trend. Shortly after release at Owl Point (RK 47) the juvenile (a 2 yr-old) was found $2 \mathrm{~km}$ from the release site in a shallow, vegetated cove. The fish remained relatively stationary for 21 weeks and then slowly moved down toward Arizona Bay (RK 40). In November 1995, its movements increased dramatically, traveling a minimum of $145 \mathrm{~km}$. The fish moved to within $3 \mathrm{~km}$ of Davis Dam and then was found within $8 \mathrm{~km}$ of Hoover Dam when surveys resumed in 1997 (Appendices B \& D).

Movements of the 5 (YOY) juveniles were highly erratic following release when fish swam around and across the reservoir's pelagic zone. Migratory rates for all 5 fish exceeded 1,000 $\mathrm{m} /$ day (range 1,193 to $3,750 \mathrm{~m} /$ day) during the first 10 days following release (Figure 13). After the second week, fish moved along the shore and were found in protected coves (Table 3). Average movement rates for 5 juvenile razorback suckers in Lake Mohave was between 319 and $1,011 \mathrm{~m} /$ day for a 50 -day period following stocking. 


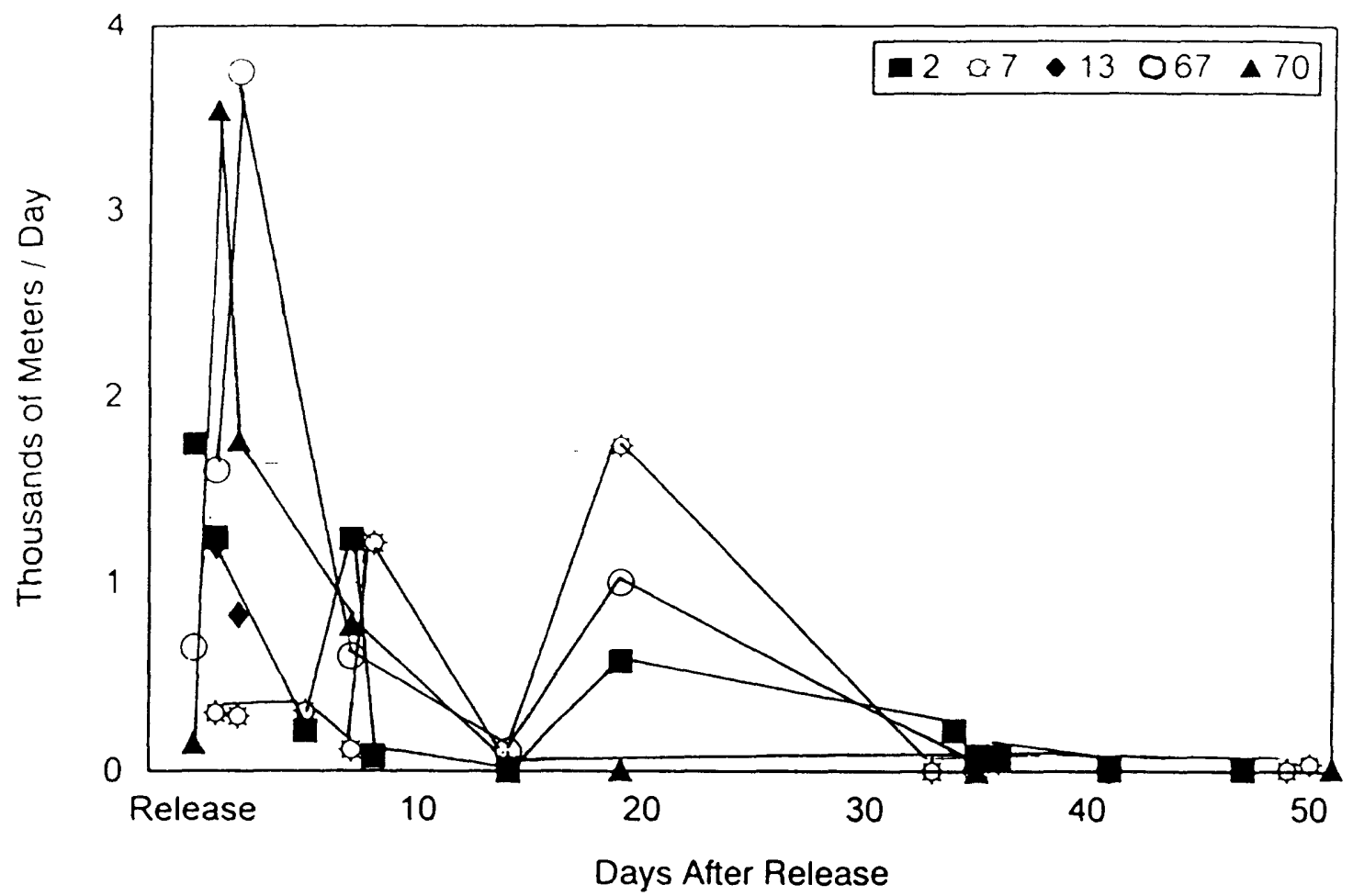

Figure 13. Dispersal rate of young of the year razorback suckers determined by externally attached sonic transmitters.

Table 3. Minimum, maximum, and average distance $(\mathrm{m} / \mathrm{day})$ traveled by juvenile (YOY) razorback suckers in Lake Mohave over a 50 day period in 1996.

\begin{tabular}{|c|c|c|c|c|c|c|}
\hline $\begin{array}{l}\text { Fish } \\
\text { ID }\end{array}$ & $\underset{\#}{\text { OBs }}$ & Min, & $\begin{array}{l}\text { Max. } \\
\text { ters / d }\end{array}$ & $\begin{array}{l}\text { Avg. } \\
\text { y)--- }\end{array}$ & STD & $\begin{array}{r}\text { Total Distance } \\
\text { Traveled (m) }\end{array}$ \\
\hline 2 & 12 & 4 & 1,741 & 457 & 579 & 12,685 \\
\hline 7 & 13 & 3 & 1,733 & 319 & 515 & 12,243 \\
\hline 13 & 2 & 830 & 1,193 & 1,011 & 181 & 2,023 \\
\hline 67 & 8 & 11 & 3,750 & 969 & 1,169 & 15,293 \\
\hline 70 & 10 & 0 & 3,541 & 630 & 1,109 & 9,788 \\
\hline
\end{tabular}




\section{Habitat Use}

Temperature Preference--Body temperatures varied according to the location of fish within the reservoir. Water temperatures above Willow Beach had a narrow range $\left(12-16^{\circ} \mathrm{C}\right)$ regardless of season because of the cold hypolimnetic releases from Lake Mead. However, further downstream the lake stratified during the summer, with water temperatures ranging from 15 to nearly $30^{\circ} \mathrm{C}$.

Temperature data were obtained from 570 fish contacts over the first 15 month period following tagging and release. Razorback suckers were found through a wide temperature range ( 12 to 28 ${ }^{\circ} \mathrm{C}$ ) (Figure 14). However during the summer, adults preferred temperatures that averaged between 18 to $22^{\circ} \mathrm{C}$. They seldom were found in water temperatures $>25^{\circ} \mathrm{C}$. Hourly tracking indicated that fish moved vertically in the water column but there were no correlations for depth with time of day. Temperature data for juvenile $\# 2273$ demonstrated that this fish preferred shallow, warm, protected coves (Appendices B \& D)

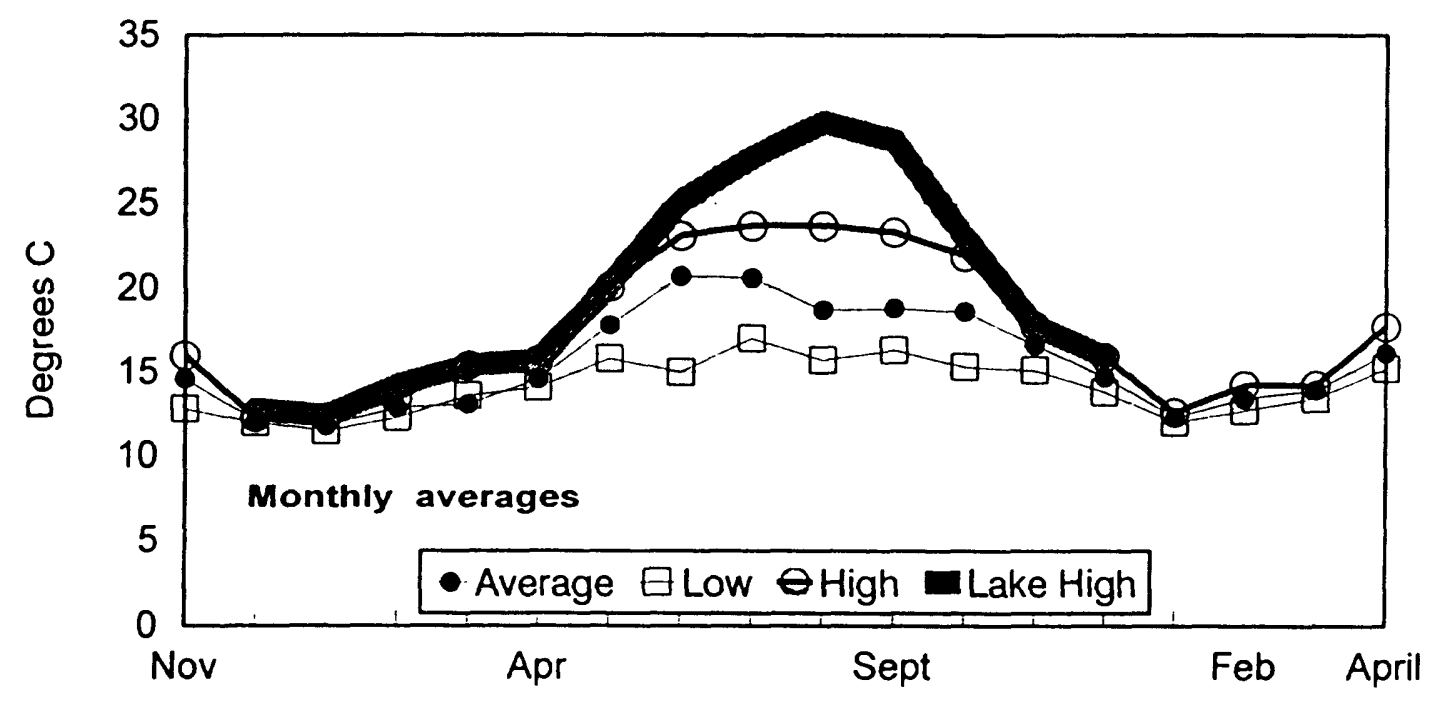

Figure 14. Average, maximum, and minimum body temperature range (monthly average) of adult razorback suckers compared to maximum reservoir temperatures found in Lake Mohave, Arizona-Nevada from December 1994 to February 1996. 
Table 4 presents the average depths and ranges for the 10 adult and one juvenile fish. While the depths are highly variable, the seasonal temperatures recorded for these fish were not, averaging between 18.0 and $20.9^{\circ} \mathrm{C}$ for the adults.

The thermal characteristics of Lake Mohave varied, with the lower portions of the reservoir being strongly stratified. Accordingly, water temperature at a specific depth also varied depending upon where the measurements were taken. For instance, a fish seeking out a temperature of $18^{\circ} \mathrm{C}$ during the summer would find that thermal regime close to the surface at RK 72, while at RK 32 that temperature would be found at a depth nearer to $10 \mathrm{~m}$. We simply did not collect the data required to describe the thermal dynamics of the entire reservoir or attempt to make correlations of depth and temperature by month. Both are highly variable, but it appeared that adults may have had a stronger preference toward water temperature, rather than depth (Table 4).

Shoreline Fidelity--Both juvenile and adult razorback suckers exhibited a significant fidelity for inshore habitats during the entire year $(\mathrm{P}<.001$, Chi Square test $)$. Fish were typically found within $50 \mathrm{~m}$ of shore. Fidelity was most pronounced during the spawning season when average distance from the shoreline was less than $30 \mathrm{~m}$. Fish tended to move off-shore following spawning (July-November) in concert with warming surface water temperatures.

Depth--We collected 147 vertical temperature profiles at the exact location where fish were detected. These data were collected from May through November of 1995, when the reservoir was thermally stratified and represents our most accurate information on depth. The temperature data suggested fish were usually found at depths less than $10 \mathrm{~m}$, but on one occasion a fish was deeper than $30 \mathrm{~m}$. Individual fish were found at average depths that varied between 3.1 and $16.8 \mathrm{~m}$ (Table 4). Seasonally, fish moved closer to the surface during early summer and then migrated deeper during mid-summer (Appendix C). As surface water temperatures cooled in late summer, fish once again moved closer to the surface at depths averaging $<15 \mathrm{~m}$.

Geographical Fidelity--There were definite areas of the reservoir where adults preferred to spawn and reside during non-spawning periods of the year (Figures $15 \& 16$ ). Adults seldom were detected downstream of South Basin Light (RK 21) or upstream of Monkey Hole (RK 77). In Cottonwood Basin, there was strong preference to the Nevada west shoreline between Nine Mile and Six Mile coves. This area was used during the spawning season by three fish (\#339, 465, 384 ) and during the summer by five fish ( $\# 375,258,276,384,465)$. Tequila Cove (RK 34) was visited by all spawners except for fish \#2228. The most heavily used area in the reservoir was between RK 39 and RK 47. The Arizona shoreline was used extensively by all fish during the spawning season and adults were seldom found along the more vegetated Nevada shoreline. This vegetated portion of the lake was initially used for several weeks by juvenile $\# 2273$. 
Table 4. Comparison of water temperature and depth occupied by adult razorback suckers in Lake Mohave from May through November, 1995.

\begin{tabular}{ccccc}
$\begin{array}{c}\text { Fish } \\
\#\end{array}$ & $\begin{array}{c}\text { Temperature } \\
\left({ }^{\circ} \mathbf{C}\right)\end{array}$ & $\begin{array}{c}\text { Range } \\
(\text { Min-Max) }\end{array}$ & $\begin{array}{c}\text { Depth* } \\
(\mathbf{m})\end{array}$ & $\begin{array}{c}\text { Range } \\
(\text { Min-Max })\end{array}$ \\
\hline 88 & 18.4 & $(14.6-27.4)$ & 12.8 & $(3-25)$ \\
258 & 18.0 & $(15.4-21.9)$ & 16.8 & $(8->30)$ \\
276 & 20.0 & $(16.1-24.8)$ & 8.4 & $(1-20)$ \\
339 & 19.7 & $(14.9-26.6)$ & 4.4 & $(1-7)$ \\
348 & 20.9 & $(14.3-25.8)$ & 5.6 & $(1-9)$ \\
366 & 18.7 & $(11.7-24.6)$ & 7.3 & $(3-12)$ \\
375 & 18.2 & $(15.0-27.2)$ & 13.3 & $(1-25)$ \\
384 & 20.5 & $(18.5-23.3)$ & 9.9 & $(1-16)$ \\
465 & 20.1 & $(17.7-22.1)$ & 9.1 & $(1-16)$ \\
2228 & 18.7 & $(14.1-22.7$ & 3.1 & $(1-6)$ \\
$2273 *$ & 23.5 & $(12.4-27.6)$ & 4.4 & $(1-16)$ \\
- & -9.4 &
\end{tabular}

*Average of weekly averages

The most popular 1-mile reach of the reservoir was at Owl Point (RK 45). This area was used by all ten of the study fish during spawning season (Figure 15) and by four fish $(88,348,366,375)$ during extended periods of the non-spawning season (Figure 16). Another major use area was located between Chalk Cliff Lights (RK 69) and Fire Mountain Lights (RK-60) and represented the cold/warm water interface where Hoover releases mix with the warm reservoir waters. Seven of the suckers $(348,366,2228,339,276,88,375)$ used this area during the summer. On one warm, calm day, we observed an average of 6 razorback suckers per kilometer at the surface in this area.

These areas played an important role in the home range of all ten adults. Some areas were used specifically for spawning while others were only used during non-spawning periods. Some areas, like Cottonwood Basin and Owl Point were used year round by some fish, while heavily used spawning areas, such as Tequila and Yuma coves were vacant during the summer. 


\section{Adult Fish Locations - Non-spawning Season Julian Dates 34820-36003, 35186-35369, and 35551-35734}

Lake Mohave Razorback Sucker Telemetry Study
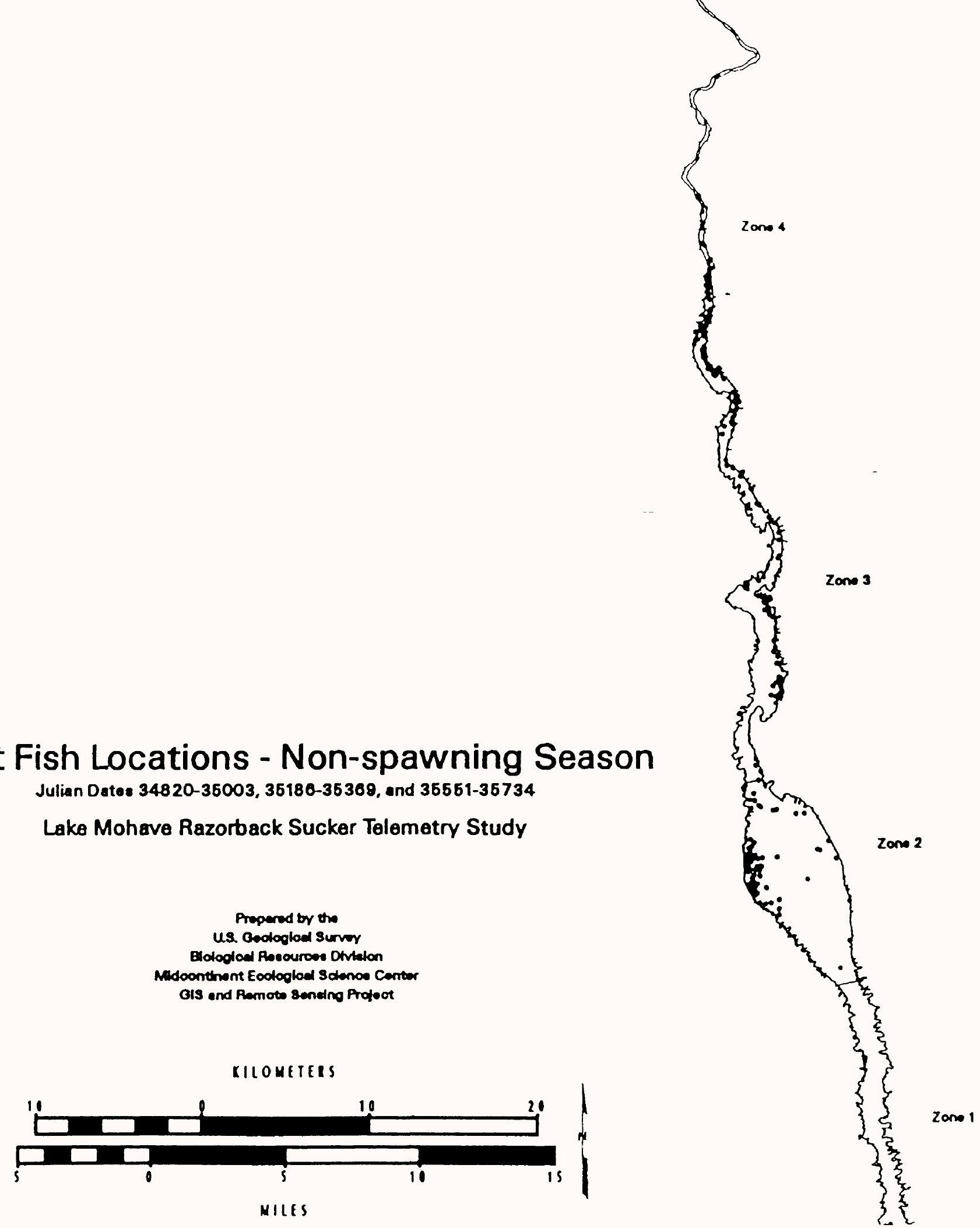

Figure 16. Map showing areas where adult razorback suckers were detected in Lake Mohave during the non-spawning season (May through October) 1995, 1996, and 1997. 


\section{DISCUSSION}

Lake Mohave may not be considered pristine habitat for a riverine species. However, opportunities to study behavioral and habitat use would be difficult in natural river settings. Studies in riverine systems have been challenged by the scarcity of fish and the logistics associated with remote riverine habitats. Our fish numbers were not significantly different from previous research, but study conditions were unparalleled that provided us an unprecedented database. Reservoir water visibility exceeded $10 \mathrm{~m}$, which unlike river conditions, allowed researchers to easily find spawning congregations, observe spawning, document reproduction (collect sucker larvae), and observe individual fish. These fish had a much broader and less fluctuating range of physical parameters to choose from compared to riverine conditions. Lake temperatures ranged from 12 to $30^{\circ} \mathrm{C}$, flows ranged from none to $3 \mathrm{~m} / \mathrm{sec}$, depths could exceed $40 \mathrm{~m}$, and fish had the opportunity to use both littoral and pelagic habitats.

It's noteworthy that the only significant recruitment recorded in recent history occurred in reservoir, rather than river habitats (Minckley et al. 1991). Lake Mohave once was the prominent nursery for 95 percent of the wild razorback suckers that still survive. This fact illustrates the adaptability of the razorback sucker to use a wide range of physical habitat conditions. While adults have successfully spawned in a variety of conditions ranging from small ponds to cold hypolimnetic tailwaters (Minckley et al. 1991, Mueller 1989, 1995), there is no measurable recruitment suggesting their young do not survive. The dependency of young suckers on shallow, warm, shoreline habitats make them highly susceptible to nonnative predators. Unfortunately, the fish has failed to cope with exotic predator introductions. This sobering fact has until recently been ignored or discounted in an arena where fishing license sales primarily funds management programs.

\section{Adults}

Both adults and juveniles used the broad, shallow, shoreline habitats found in Arizona and Cottonwood basins and generally avoided the deeper, canyon habitat typical of the lower reservoir. Fish were seldom tracked together until the spawning season (McAda and Wydoski 1980). Adult razorbacks were quite mobile, but exhibited movement rates and ranges similar to those reported in riverine habitats (Tyus 1987, Kaeding and Osmundson 1988, Marsh and Minckley 1989b, Tyus and Karp 1990, Ryden and Pfeifer 1995 and 1996, Burdick and Bonar 1997, Modde and Wick 1997). Adults exhibited various degrees of sedentary and roaming behavior similar to those reported for other stream fish (Funk 1955).

Spawning Migrations--Spawning razorback suckers migrate (Jordan 1891, Hubbs and Miller 1953, Sigler and Miller 1963, Tyus 1987, Tyus and Karp 1990, Minckley et al. 1991, Modde and Wick 1997). We observed prespawning movements both up- and down-lake that were similar to movements reported in the Green River (Modde and Wick 1997, Tyus and Karp 1990, Tyus 1987). Some spawners traveled up to $50 \mathrm{~km}$ prior to, and during spawning, to form or join 
large spawning aggregations.

It has been speculated that spawning migrations may be triggered by the ascending spring hydrograph (Tyus 1987, Tyus and Karp 1990). However, under reservoir conditions where flow has a minimal influence, we found suckers exhibited the same reproductive characteristics, behavioral traits, and migrations as reported for riverine populations.

Another attribute unique to the reservoir population is the spawning duration. Spawning in the Green and Colorado rivers has been reported to take between 4 and 6 weeks (Tyus 1987, Tyus and Karp 1990, Modde and Wick 1997) while reservoir spawning continued for 10 to 14 weeks (Medel-Ulmer 1983, Langhorst and Marsh 1986, Mueller 1989, Minckley et al. 1991). Spawning is usually associated with fish ovulation and gamete release and is normally reported in terms of days and even weeks. However, an examination of migration trends (Figures 2-12) suggests a broader interpretation is needed. Pre- and active spawning may actually last up to 6 months. Razorbacks migrate and stage near spawning sites as early as November and stay in those areas until late March or April. This suggests that non-hydraulic factors, such as temperature and photoperiod (Minckley et al. 1991), may not only trigger spawning, but conceivably may also influence its duration.

Spawning Site Fidelity--Tyus and Karp (1990) reported spawning site fidelity in the Green River basin and suggested the population structure might be segmented and made up of multiple "stocks." Later Scholz (et al. 1992) and Modde (et al. 1996) suggested there was evidence that fish might be imprinted to specific sites, but the results of those imprinting studies were inconclusive. Modde and Wick (1997) later suggested razorback suckers might actually spawn at several sites in the Green River. Studies of the Colorado squawfish suggest these native fish exhibit a fidelity for a particular river reach but may select spawning sites with certain characteristics based on stream flow (Osmundson et al. 1997).

The extended spawning season and survey conditions allowed us to more closely monitor individual movements. We found spawners to be highly social, forming aggregations numbering hundreds and possibly thousands of fish (Minckley et al. 1991). Adults returned annually to popular spawning sites, but, they also used other spawning sites as well. While we cannot confirm that spawning actually occurred, there is a high probability based on the presence of sucker larvae (Burke unpublished data) and the known fecundity of the species (Minckley 1983, Minckley et al. 1991). Females may produce an average of 100,000 ova, but release only a few eggs during separate spawning events. Our data show that spawning females are more mobile than males. Ripe males remain at specific spawning sites while females join them when they are ready to release their eggs (Mueller 1989), a common behavior among other catostomids (Moyle 1976). Females that ovulate over an extended period could spawn with numerous males at different locations. This behavior, combined with larval dispersal helps explain the high genetic variability described in this population (Dowling et al. 1996).

Post-Spawning--We found post-spawning migrations were as prevalent (distance and rate) as 
pre-spawning migrations. Valdez and Wick (1983), Tyus and Karp (1989) and Modde and Wick (1997) reported that following spawning, razorback suckers moved into flooded lowlands which were speculated to provide more abundant food and warmer habitats. Holden (et al. 1997) reported similar movements in Lake Mead where adult razorback suckers moved from spawning areas into the more productive inflow areas of Las Vegas Bay and the Overton Arm.

We witnessed a similar trend in Lake Mohave. The majority (60\%) of our fish migrated up reservoir after spawning toward the interface zone from Lake Mead. The reservoir provides warmer temperatures elsewhere, but, this mixing zone is limnologically more productive (Baker and Paulson 1980). Algal production in this cold-warm water interface is quite noticeable compared to other areas of the reservoir. Marsh (1987) reported that razorback suckers pursued a diet of planktonic crustaceans, diatoms, filamentous algae and benthic materials that are present in the mixing area. Wydoski and Wick (1998) suggested adult razorback suckers may feed on zooplankton in highly productive floodplains to regain their body condition after spawning. In Lake Mohave, adults were more active $(\mathrm{m} / \mathrm{d})$ after spawning and were found closest $(<6 \mathrm{~m})$ to the surface where plankton is most abundant. The need to recover body reserves after spawning may influence the their spatial distribution in the reservoir.

Some fish exhibited a strong spatial fidelity to specific locations in the reservoir while movement patterns for others were less obvious. For instance, the distance between spawning and summer resting areas for some fish $(348,258,375$, and 366$)$ averaged about $20 \mathrm{~km}$. Once located in either their spawning or summer habitats, some fish became sedentary, moving less than $\pm 2-5$ $\mathrm{km}$ for 1-2 months. The remaining six fish moved more with some roaming over $30 \mathrm{~km}$. Some of this movement may have been in response to changes in the location of the warm/cold interface zone. High discharges from Lake Mead and fluctuating reservoir elevations can cause this interface zone to migrate up and down the reservoir as much as $20 \mathrm{~km}$ and could influence fish distribution and movements (Baker and Paulson 1980).

We observed considerable territorial overlap during this study. Nine of the ten fish, regardless of whether they were captured initially in Yuma or Tequila Cove used both sites during the spawning season. The only exception was fish \#2228 whose spawning range was between Yuma Cove (RK 39) and Horseshoe Rapids (R). This fish appeared to spawn in both the warm and cold portions of the lake. While the spawning areas used by the majority of fish overlapped, the areas used by fish during the summer did not and, in some cases, were at opposite ends of the reservoir. This homing pattern of spawning and non-spawning populations was described by Gerking (1958) who stated; "Spawning migrations are directed toward a specific location.... (while) the fish are usually scattered over a wide area during the non-reproductive portion of life."

Adults in Lake Mohave were most active during late morning hours (9:00 a.m.-10:00 a.m.), especially during the spawning season. McAda and Wydoski (1980) found adults in a gravel pit most active during late evening (7:00 p.m.-9:00 p.m.) and late morning (10:00 a.m.-12:00 p.m.). 


\section{Juveniles}

The five juveniles equipped with external ( 45 day) transmitters were undoubtedly stressed during the first few days following stocking. Their behavior appeared abnormal, traveling both day and night through wide expanses of the reservoir's pelagic zone. After a few days, fish appeared to calm down and were found associated with shore, especially in shallow, vegetative coves. They skillfully hid in aquatic vegetation and usually moved nocturnally (Mueller and Marsh 1993).

Unfortunately, only one of the juveniles surgically implanted in this study retained its transmitter and remained active. We tracked juvenile $\# 2273$ for 20 months. One year following release, the juvenile became quite active, moving over $145 \mathrm{~km}$ around the entire reservoir. The fish came within $3 \mathrm{~km}$ of Davis Dam and then turned back upstream and traveled more than $80 \mathrm{~km}$ into the flowing portion of Lake Mohave. This behavior was quite different than the adults that had distinctly smaller ranges. However, there is a remote possibility the sucker was eaten by a large striped bass since an angler recently harvested a $30 \mathrm{~kg}$ striped bass that could have eaten a $50 \mathrm{~cm}$ razorback sucker. If this was the case, the observed movement was associated with the predator rather than the subadult razorback sucker.

Sufficient data is not yet available, but it seems logical to believe that young adults may be more active than older adults. Such behavior is reported for young flannelmouth suckers (Chart and Bergerson 1992) and young Colorado squawfish, two fishes that also evolved in this river system (Osmundson et al. 1997). Tyus (1990) speculated the migratory behavior for Colorado squawfish may have evolved in conjunction with long-distance larval drift, and Valdez (et al. 1982) further speculated that, "A net long-term movement of juveniles (squawfish) must occur to populate adult areas upstream, probably in the late young-adult stage,..." We believe similar evolutionary factors influenced the distribution and behavior of early life stages of this mainstem catostomid. If so, the implications could have significant implications for recovery efforts (Tyus 1997).

\section{Transmitters Retention}

Transmitter retention in adults was as good as, if not better than, similar studies (Creef and Clarkson 1993, Burdick and Bonar 1997, Holden et al. 1997 and Richard Bradford (AGFD personal communique). Fifty percent of the adults were still actively moving 14 months after being release. After 34 months, 6 transmitters and fish were still active. However, results with juvenile fish were disappointing. Only one of 20 surgically implanted juveniles remained active. Ryden (1997) reported similar problems but found that transmitter expulsion did not necessarily result in fish mortality because small razorback suckers shed surgically implanted transmitters and survived.

\section{Management Implications and Recommendations}


The adult razorback sucker population in Lake Mohave appears quite secure with regard to habitat requirements and the absence of major threats. The fish we studied generally remained in the center portion of the reservoir, away from the hazards of possible entrainment (Davis Dam) and remote enough to avoid propeller strike in high recreational use areas (marinas). Adult fish generally avoided deeper, canyon habitats which might lead them to Davis Dam.

However, young suckers are at risk to predation by nonnative fishes. Young use shallow, vegetated habitats that are also used by non-endemic predators such as red shiner (Notropis lurensis), green sunfish (Lepomis cyanellus), bluegill (Lepomis macrochirus), largemouth bass (Micropterus salmoides) and channel catfish (Ictalurus punctatus) (Tyus 1997). Predator distributions and densities, which historically were controlled by droughts and seasonally low flows, have been expanded due to channel degradation, reservoir fish populations, and sport -fishery management. We believe the establishment and spread of nonnative fish predators has literally turned nursery habitats into lethal traps for larvae and juveniles. This concept is supported by the boom and bust sucker populations which occurred following the inundation of lakes Mohave, Roosevelt, and Mead (Minckley 1983). Razorback suckers can successfully spawn over a wide range of habitat conditions, however, meaningful recruitment has only occurred in the relative absence of non-native predators (Minckley et al. 1991, Mueller 1995).

The second concern we have is in the migratory behavior of juvenile or young adults. The limited data we collected combined with the known migratory behavior of flannelmouth suckers and Colorado squawfish, suggests that after an initial period of growth, young suckers enter a roaming or dispersal life stage. The majority of wild juveniles captured downstream of Davis Dam in recent years have been from irrigation or delivery canals (St. Amant et al. 1974, Ulmer and Anderson 1985, USFWS 1981, Mueller 1996, Minckley et al. 1991). It has been speculated that the survival of these suckers was linked to annual drainage and low predator densities, but, the possibility exists that some fish entered the canals as roaming juveniles or young adults.

If so, and dependent upon the extent of these movements, such behavior could have serious ramifications to recovery efforts. With the potential loss of the core population in the lower basin, recovery may not be possible. Moyle and Nichols (1973) suggested that dams could effectively block community dispersal. Possibly the lower basin played a critical role as the systems most stable nursery habitat which produced the majority of young suckers that periodically repatriate marginal habitats further upstream. Augmentation efforts might also be affected if young fish movements make them more susceptible to entrainment, passage through dams, and stranding in large agricultural diversions.

We recommend that the following actions be considered:

1. Conduct further research on the migratory behavior of subadult fish. As fish become sexually mature, does their roaming behavior subject them to unacceptable losses through entrainment or passage into water diversions? 
2. Examine predator/prey relationships between early life stages of razorback sucker and introduced predators. Identify what habitat conditions and predatory thresholds would be necessary to insure some measurable level of razorback recruitment.

3. Review existing information and develop a stocking protocol for the lower basin which includes not only Lake Mohave but also other portions of the watershed. Prioritize the most likely areas in terms of habitat, stream length, and potential threats. Stock suckers as large as possible $(>40 \mathrm{~cm})$ at times when predators are less active (winter) and examine better methods of acclimation and release.

4. Examine the influence that reservoir fluctuations may have on the densities and distributions of potential predators. Assess whether current reservoir operations (or modifications) create shallow vegetated habitats which depress predator densities and would improve survival of stocked razorback suckers. .

\section{ACKNOWLEDGMENTS}

We thank numerous colleagues for their assistance on this project; Tom Burke (BOR), Kent Turner (NPS) and George Devine (FWS) contributed initial review and administrative support; Ty Wolters coordinated field surveys with numerous NPS and ASU staff; Mike Burrell (NDOW) assisted in the collection of adults, Bob Waltermire analyzed GIS and GPS data, and BOR supplied field equipment, support, and juvenile fish. Work was conducted under appropriate state and federal permits. Work was funded by USGS and technical and field assistance from ASU provided under Cooperative Agreement \#1445-0009-94-1108.

\section{REFERENCES}

Baker, J. R. and L. J. Paulson. 1980. Evaluation of impacts associated with reregulation of water levels in Lake Mohave. Technical Report \#4, Lake Mead Limnological Research Center, University of Nevada, Las Vegas, $22 \mathrm{pg}$.

Bozek, M. A., L. J. Paulson, and G. R. Wilde. 1990. Effects of ambient Lake Mohave temperatures on development, oxygen consumption, and hatching success of razorback sucker. Environmental Biology of Fishes 27:255-263.

Burdick, B .D. and R .B. Bonar. 1997. Experimental stocking of adult razorback suckers in the upper Colorado and Gunnison Rivers. Recovery Program Project Number 50. U.S.F.W.S, Colorado River Fishery Project, Grand Junction, Colorado. 
Chart, T. E., and E. P. Bergersen. 1992. Impact of mainstream impoundment on the distribution and movements of resident flannelmouth sucker (Catostomidae: Catostomus latipinnis) population in the White River, Colorado. The Southwestern Naturalist 37:9-15.

Creef, E. D. and R. W. Clarkson. 1993. Razorback sucker (Xyrauchen texanus) and Colorado squawfish (Ptychocheilus lucius) monitoring, Verde and Salt Rivers, Arizona, 1991-1993. Special Report, Arizona Game and Fish Department, Phoenix, Arizona.

Dowling, T. E., W. L. Minckley and P. C. Marsh. 1996. Mitochondrial DNA Diversity within and among populations of razorback sucker (Xyrauchen texanus) as determined by restriction endonuclease analysis. Copeia 1996 (3):542-550.

Funk, J .L. 1955. Movement of stream fishes in Missouri. Transactions of the American Fisheries Society 85:39-57.

Gerking, S. D. 1958. The restricted movement of fish populations. Biological Review 34:221242.

Gutermuth, F.B., L.D. Lentsch, D.R. Bestgen. 1994. Collection of age-0 razorback suckers (Xyrauchen texanus) in the lower Green River, Utah. The Southwestern Naturalist 39:389391.

Hart, R.C., and R.L. Summerfelt. 1975. Surgical procedures for implanting ultrasonic transmitters into flathead catfish (Pylodictis olivaris). Transactions of the American Fisheries Society 95:350-356.

Holden, P. B., P. D. Abate and J. B. Ruppert. 1997. Razorback sucker studies on Lake Mead, Nevada: 1996-1997 Annual Report, PR-578-1. Bio/West, Inc. 1063 West, 1400 North, Logan Utah.

Horn, J. M., P. C. Marsh, G. Mueller, and T. Burke. 1994. Predation by Odonate nymphs on larval razorback suckers (Xyrauchen texanus) under laboratory conditions. The Southwestern Naturalist 39(4):371-374.

Hubbs, C. L. and R. R. Miller. 1953. Hybridization in nature between the fish general Catostomus and Xyrauchen. Papers of the Michigan Academy of Science, Arts and Letters $38: 207-233$.

Jordan, D. S. 1891. Report of explorations in Utah and Colorado during the summer of 1889 , with an account of fishes found in each of the river basins examined. Bulletin of the U.S. Fish Commissioner 9:1-40. 
Kaeding, L. R. and D. B. Osmundson. 1988. A report on the studies of the endangered fishes of the upper Colorado river as part of conservation measures for the Green Mountain and Ruedi Reservoir water sales. Colorado River Fisheries Project, USFWS, Grand Junction, Colorado.

Knowles, G. W. 1994. Analysis of sonic transmitter fit in abdominal cavities of subadult razorback suckers Xyrauchen texanus. Arizona State University, Center or Environmental Studies, Tempe AZ 85287-3211.

Langhorst, D. R., and P. C. Marsh. 1986. Early life history of razorback sucker in Lake Mohave. Final Report to the U.S.B.R. Arizona State University, Tempe. 24 pp. + app.

McAda, C. W., and R. S. Wydoski. 1980. The razorback sucker, Xyrauchen texanus, in the upper Colorado River basin, 1974-1976. U.S.F.W.S. Technical Paper \# 99. U.S.F.W.S., Washington, D.C. $15 \mathrm{pp}$.

Marsh, P. C. 1987. Digestive tract contents of adult razorback suckers in Lake Mohave, Arizona-Nevada. Transaction of the American Fisheries Society 116:117-119.

Marsh, P. C. 1997. Razorback sucker monitoring in Lake Mohave, Arizona-Nevada, for the period 01 November to 31 October 1996. Submitted to BOR (Contract 1425-97-PG-3006390), Arizona State University, Center for Environmental Studies, Tempe, Arizona.

Marsh, P. C., and W. L. Minckley. 1989a. Observations on recruitment and ecology of razorback sucker: Lower Colorado River, Arizona-California-Nevada. Great Basin Naturalist 49, 71-78.

Marsh, P. C., and W. L. Minckley. 1989b. Radiotelemetry of razorback sucker in the Gila River, eastern Arizona. Proceedings of the 21st Annual Desert Fishes Council Meeting (16-18 Nov., 1989), Albuquerque, New Mexico.

Medel-Ulmer, L. 1983. Movement and reproduction of the razorback sucker (Xyrauchen texanus) inhabiting Senator Wash Reservoir, Imperial County, California. Proceedings of the Desert Fishes Council 12 (1980): 106 (Abstract).

Minckley, W. L. 1983. Status of the razorback sucker, Xyrauchen texanus (Abbott), in the lower Colorado River basin. The Southwestern Naturalist 28:165-187.

Minckley, W. L., P. C. Marsh, J. E. Brooks, J. E. Johnson, and B. L. Jensen. 1991. Management toward recovery of razorback sucker. In: Minckley and Deacon, editors. Battle Against Extinction: Native fish management in the American West. Tucson: University of Arizona Press. pp. 303-357. 
Modde, T. 1996. Juvenile razorback sucker (Xyrauchen texanus) in a managed wetland adjacent to the Green River. Great Basin Naturalist 56:375-376.

Modde, T., K. P. Burnham, and E. J. Wick. 1996. Population status of the razorback sucker in the middle Green River (U.S.A.). Conservation Biology 10 (1):110-119.

Modde, T., and E. J. Wick. 1997. Investigations of razorback sucker distribution, movements and habitats used during spring in the Green River, Utah. USFWS, Recovery Program Project Report \#49, Vernal, Utah.

Moyle, P. B. 1976. Inland Fishes of California. University of California Press, Berkeley and Los Angeles.

Moyle, P. B., and R. Nichols. 1973. Ecology of some native and introduced fishes of the SierraNevada foothills in central California. Copeia (3):478-490.

Mueller, G. 1989. Observations of spawning razorback sucker (Xyrauchen texanus) utilizing river habitat in the lower Colorado River, Arizona-Nevada. The Southwestern Naturalist $34: 147-149$.

Mueller, G. 1995. A program for maintaining the razorback sucker in Lake Mohave. American Fisheries Society Symposium 15:127-135.

Mueller, G. 1996. Establishment of a fish community in the Hayden-Rhodes and Salt-Gila Aqueducts, Arizona. North American Journal Fishery Management 16:795-804.

Mueller, G., and P. C. Marsh. 1993. Assessment of the effectiveness of the barrier net and summary of Scuba studies: February 1992 to June 1993. Bureau Of Reclamation Summary Report to the Native Fish Work Group, Boulder City, NV, 5 pp.

Muth, R. T. 1995. Development of a standardized monitoring program for Basin-wide evaluation of restoration activities for razorback sucker in the Green and Upper Colorado River systems. Final Report to the Recovery Implementation Program for the Endangered Fish Species in the Upper Colorado River Basin. Larval Fish Lab., Colorado State University, Fort Collins, Colorado.

Osmundson, D. B., and M. E. Tucker, B. D. Burdick, W. R. Elmblad, T. E. Chart. 1997. Nonspawning movements of sub-adult and adult Colorado Squawfish in the Upper Colorado River. in Studies of Colorado squawfish in the Upper Colorado River. Final Report. Colorado River Fishery Project, USDOI, FWS, Grand Junction, Colorado. 29 pp. 
Ryden, D. W., and F. K. Pfeifer. 1995. Monitoring of experimental stocked razorback sucker in the San Juan River. 1994 Annual Report. U.S.F.W.S., Colorado River Fishery Project, Grand Junction, Colorado.

Ryden, D. W., and F. K. Pfeifer. 1996. Monitoring of experimental stocked razorback sucker in the San Juan River. 1995 Annual Progress Report. U.S.F.W.S., Colorado River Fishery Project, Grand Junction, Colorado.

Ryden, D. W. 1997. Razorback sucker mortality and tag expulsion during radio implantation efforts, 1994-1996. Fish and Wildlife Service letter to Michelle Thieme (April 2, 1997), Colorado River Fishery Project, Grand Junction, Colorado.

St. Amant, J. A., R. Hulquist, C. Marshall, and A. Pickard. 1974. Fisheries section including information on fishery resources of the Coachella Canal study area. In Inventory of the fish and wildlife resources, recreational consumptive use, and habitat in and adjacent to the upper 49 miles and ponded areas of the Coachella Canal, pp. 64-88. Final Report for U.S. Bureau of Reclamation Contract 14-06-300-2555. California Department of Fish and Game, Sacramento.

Scholz, A. T., R. J. White, S. A. Horton, and W. A. Koehler. 1992. Measurement of egg and larval thyroxine concentration as an indicator of the critical period for imprinting in razorback sucker (Xyrauchen texanus Abbott): implications for endangered stocks in the Colorado River Basin. Colorado River Fisheries Project Technical Report 1, U.S.D.O.I., B.O.R., Salt Lake City, Utah.

Sigler, W. R., and R. R. Miller. 1963. Fishes of Utah. Utah State Department of Fish and Game, Salt Lake City. 203 pp.

Sokal, R. R., and F. J. Rolf. 1981. Biometry (2nd ed.). W.H. Freeman and Co., New York. $859 \mathrm{pp}$.

Tyus, H. M. 1987. Distribution, reproduction, and habitat use of razorback sucker in the Green River, Utah, 1979-1986. Transactions of the American Fisheries Society 116:111-116

Tyus, H. M. 1990. Potamodromy and reproduction of Colorado squawfish in the Green River basin, Colorado and Utah. Transactions of the American Fisheries Society 119: 10351047.

Tyus, H. M. 1997. Razorback Sucker (Xyrauchen texanus), Draft Recovery Plan. USFWS, Region 6, Denver, CO. 
Tyus, H. M., and C. A. Karp. 1990. Spawning and movements of razorback sucker, Xyrauchen texanus, in the Green River Basin of Colorado and Utah. The Southwestern Naturalist 35(4):427-433.

Ulmer, L., and K. R. Anderson. 1985. Management plan for the razorback sucker (Xyrauchen texanus) in California. California Department of Fish and Game, Region 5 information Bulletin 0013-10-1985, 1-26.

USFWS. 1981. Aquatic study of the lower Colorado River, aquatic study--Colorado river from Lees Ferry to souther International Boundary and selected tributaries, Arizona, California, and Nevada. Final report for USWPRS contract 9-07-03-X0066. USFWS, Phoenix, Arizona.

Valdez, R. A., P. G. Mangan, R. P. Smith and B. C. Nilson. 1982. Upper Colorado River investigation (Rifle, Colorado to Lake Powell, Utah). USFWS and BOR, Final Report Part 2, Colorado River Fishery Project, Salt Lake City, Utah.

Valdez, R. and E. Wick. 1983. Natural vs manmade backwaters as native fish habitat. Pages 519-536 in V. Adams and Lmarra, Editors. Aquatic Resources Management of the Colorado River Ecosystem. Ann Arbor Science, Ann Arbor, Michigan.

Wydoski, R.S. and E.D. Wick. 1998. Ecological value of floodplain habitats to razorback suckers in the Upper Colorado River Basin. Upper Colorado River Basin Recovery Program, USDOI, Fish and Wildlife Service, Denver, Colorado. 57 pp. (in review) 
Appendix A. Individual fish Data. 
Date Concerning Adult and Juvenile Telemetry Fish in Lake Mohave Fish * Sex * Release * PIT Tag * TL * Weight Range (RM-RM) \# (RK) $(\mathrm{mm}) \quad(\mathrm{g}) \quad(\mathrm{km})$

\begin{tabular}{|c|c|c|c|c|c|c|c|}
\hline 87 & Juv. & 11 & 1F78214F79 & 324 & 328 & 2 & $(10-11)$ \\
\hline$\underline{88}$ & $\mathbf{F}$ & 39 & 1F0B7A3A22 & 615 & 2,700 & 34 & $(32-66)$ \\
\hline 96 & Juv. & 26 & 1F7B600402 & 319 & 324 & 5 & $(26-31)$ \\
\hline 97 & $\mathrm{M}$ & 39 & 7F7D3D6310 & 566 & 2,170 & 3 & $(39-42)$ \\
\hline 249 & $\mathrm{M}$ & 34 & 7F7D7C665F & 563 & 1,990 & 6 & $(34-40)$ \\
\hline$\underline{258}$ & $\mathbf{M}$ & 34 & 7F7D7C3D7F & 595 & 2,260 & 18 & $(29-47)$ \\
\hline 267 & M & 34 & 7F7D78263D & 555 & 2,420 & 2 & $(32-34)$ \\
\hline$\underline{276}$ & $\mathbf{F}$ & 34 & 7F7D78316D & 654 & 3,610 & 43 & $(24-67)$ \\
\hline 285 & $\mathrm{~F}$ & 34 & 1F0E5E1A5B & 660 & 3,850 & 19 & $(24-43)$ \\
\hline 294 & $\mathrm{~F}$ & 39 & 7F7D3D5318 & 645 & 2,810 & 0 & (39) \\
\hline$\underline{339}$ & $\mathbf{F}$ & 39 & 7F7D7B333C & 666 & 3,330 & 72 & (27-99) \\
\hline$\underline{348}$ & $\mathbf{M}$ & 39 & 1F0A2C4269 & 526 & 1,750 & 39 & $(32-71)$ \\
\hline 357 & $\mathrm{M}$ & 39 & 7F7E430E15 & 585 & 2,410 & 1 & (39) \\
\hline$\underline{366}$ & $\mathbf{M}$ & 39 & 7F7D17123E & 588 & 2,290 & 31 & $(31-62)$ \\
\hline$\underline{375}$ & $\mathbf{F}$ & 34 & 7F7D7C3F34 & 680 & 3,350 & 48 & $(16-64)$ \\
\hline$\underline{384}$ & $\mathbf{F}$ & 34 & 1F0F31465B & 631 & 2,760 & 39 & $(26-65)$ \\
\hline 447 & $\mathrm{M}$ & 34 & 1F0A485D32 & 605 & 2,350 & 66 & $(32-98)$ \\
\hline 456 & $\mathrm{M}$ & 34 & 7F7B075039 & 582 & 2,310 & 13 & $(26-39)$ \\
\hline$\underline{465}$ & $\mathbf{F}$ & 34 & 7F7D3B724A & 614 & 2,940 & 29 & $(5-34)$ \\
\hline 555 & $\mathrm{~F}$ & 39 & $1 F 0 B 722143$ & 624 & 3,620 & 31 & $(34-65)$ \\
\hline$\underline{2228}$ & $\mathbf{M}$ & 39 & 1F0F143509 & 558 & 2,400 & 51 & $(39-90)$ \\
\hline 2237 & $\mathrm{~F}$ & 39 & 7F7D406F67 & 675 & 4,210 & 19 & $(27-46)$ \\
\hline 2246 & Juv. & 92 & 1F7B025212 & 350 & 380 & 8 & $(84-92)$ \\
\hline 2255 & Juv. & 71 & 1F78090D53 & 334 & 340 & 0 & (71) \\
\hline 2264 & Juv. & 47 & 1F7B4E4850 & 334 & 340 & 2 & $(47-49)$ \\
\hline$\underline{2273}$ & Juv. & 47 & 1F7B012D38 & 382 & 598 & 44 & $(3-47)$ \\
\hline 2327 & Juv. & 71 & 1F7A311323 & 332 & 338 & 2 & $(71-73)$ \\
\hline 2354 & Juv. & 47 & 1F7B0E3B1D & 315 & 296 & 1 & (47) \\
\hline 2363 & Juv. & 26 & $1 \mathrm{~F} 7 \mathrm{~A} 31674 \mathrm{~F}$ & 340 & 376 & 1 & $(26-27)$ \\
\hline 2426 & Juv. & 26 & $200 \mathrm{~A} 6 \mathrm{C} 303 \mathrm{~A}$ & 339 & 374 & 0 & (26) \\
\hline 2435 & Juv. & 11 & 1F7B0A5507 & 332 & 344 & 3 & $(8-11)$ \\
\hline 2444 & Juv. & 11 & 1F7B684836 & 336 & 348 & 8 & $(2-10)$ \\
\hline 2453 & Juv. & 92 & $1 \mathrm{~F} 77724 \mathrm{~A} 2 \mathrm{E}$ & 344 & 392 & 4 & $(87-91)$ \\
\hline 2525 & Juv. & 11 & 1F78403871 & 335 & 340 & 2 & $(10-12)$ \\
\hline 2534 & Juv. & 71 & 1F7A2C0437 & 340 & 358 & 0 & (71) \\
\hline 2543 & Juv. & 47 & $1 F 78117266$ & 341 & 400 & 2 & $(47-49)$ \\
\hline 2633 & Juv. & 91 & 1F78107762 & 338 & 375 & 11 & $(79-91)$ \\
\hline 3335 & Juv. & 71 & 1F7B092736 & 347 & 406 & 10 & $(61-71)$ \\
\hline 3344 & Juv. & 91 & 1F78107762 & 335 & 320 & 6 & $(85-91)$ \\
\hline 3434 & Juv. & 26 & 1F77775C17 & 350 & 400 & 2 & $(25-27)$ \\
\hline
\end{tabular}

High lighted $=$ Fish surviving $>14$ months. 
External Attachment of Sonic Transmitters to Juvenile Fish October 20, 1995

Lake Mohave, Arizona-Nevada

Range Data

Fish ${ }^{*}$ Sex $*$ Release*PIT Tag * TL * Weight Range (RK-RK)

$\begin{array}{lllll}\# & (\mathrm{RK}) & (\mathbf{m m}) & (\mathrm{g}) & (\mathbf{k m})\end{array}$

\begin{tabular}{llllllcl}
\hline $\mathbf{2}$ & Juv. & $\mathbf{2 5}$ & $\mathbf{2 0 3 7 2 4 5 C 2 9}$ & $\mathbf{3 0 9}$ & - & $\mathbf{8}$ & $\mathbf{( 2 5 - 3 3 )}$ \\
7 & Juv. & $\mathbf{2 5}$ & $\mathbf{2 0 3 7 1 1 2 D 6 B}$ & $\mathbf{3 1 6}$ & $\mathbf{2 8 8}$ & $\mathbf{1 1}$ & $\mathbf{( 2 5 - 3 6 )}$ \\
$\mathbf{1 3}$ & Juv. & $\mathbf{2 5}$ & $\mathbf{2 0 3 7 2 0 7 2 1 7}$ & $\mathbf{3 0 3}$ & - & $\mathbf{3}$ & $\mathbf{( 2 5 - 2 8 )}$ \\
$\mathbf{6 7}$ & Juv. & $\mathbf{1 6}$ & $\mathbf{2 0 3 7 0 C 2 7 7 6}$ & $\mathbf{3 2 8}$ & $\mathbf{4 0 6}$ & $\mathbf{5}$ & $\mathbf{( 2 5 - 3 0 )}$ \\
$\mathbf{7 0}$ & Juv. & $\mathbf{1 6}$ & $\mathbf{1 F 7 B 1 0 2 1 3 5}$ & $\mathbf{3 1 9}$ & $\mathbf{3 5 4}$ & $\mathbf{8}$ & $\mathbf{( 1 8 - 2 6 )}$ \\
\hline-
\end{tabular}


Appendix B. Telemetry Data 
LAKE MOHAVE RAZORBACK SUCKER TELEMIETRY STUDY Nov 1994 to July 1997

\begin{tabular}{|c|c|c|c|c|c|c|c|}
\hline Fish ID\# & DATE & TIME & WP & SHORE & TEMP $\mathrm{C}$ & LAT. & LONG. \\
\hline & (JULIAN) & $(24-h r)$ & & $1-10=\mathrm{X} 10 \mathrm{M}$ & & & \\
\hline & & & & $11=.100 \mathrm{~m}$ & & & \\
\hline 2 & 34996 & 0.5313 & 54 & 0 & & $35-24-18$ & $114-39-48$ \\
\hline 2 & 34997 & 0.0521 & 54 & 10 & & $35-24-36$ & $114-39-32$ \\
\hline 2 & 34998 & 0.0764 & 53 & & & $35-25-32$ & $114-39-41$ \\
\hline 2 & 34999 & 0.2986 & 47 & 11 & & $35-26-12$ & $114-39-37$ \\
\hline 2 & 35002 & 0.6146 & 47 & 11 & & $35-26-30$ & $114-39-50$ \\
\hline 2 & 35004 & 0.5660 & 40 & 1 & & $35-27-40$ & $114-40-37$ \\
\hline 2 & 35005 & 0.1007 & 40 & 4 & & $35-27-39$ & $114-40-34$ \\
\hline 2 & 35011 & 0.0694 & 40 & 2 & & $35-27-39$ & $114-40-35$ \\
\hline 2 & 35016 & 0.8750 & 47 & 11 & & $35-26-13$ & $114-39-46$ \\
\hline 2 & 35031 & 0.5451 & 41 & 11 & & $35-27-37$ & $114-38-26$ \\
\hline 2 & 35032 & 0.5660 & 41 & 11 & & $35-27-39$ & $114-38-24$ \\
\hline 2 & 35033 & 0.1146 & 41 & 11 & & $35-27-39$ & $114-38-21$ \\
\hline 2 & 35038 & 0.6736 & 42 & 11 & & $35-27-40$ & $114-38-22$ \\
\hline 2 & 35044 & 0.8646 & 42 & 10 & & $35-27-41$ & $114-38-24$ \\
\hline 2 & 35048 & 0.1354 & 42 & 10 & & $35-27-40$ & $114-38-24$ \\
\hline 2 & 35087 & 0.6771 & 42 & 11 & & $35-27-40$ & $114-38-24$ \\
\hline 7 & 34996 & 0.5313 & 54 & 0 & & $35-24-18$ & $114-39-48$ \\
\hline 7 & 34997 & 0.0521 & 54 & 3 & & $35-24-30$ & 114-39-32 \\
\hline 7 & 34998 & 0.5868 & 54 & 1 & & $35-24-20$ & $114-39-34$ \\
\hline 7 & 34999 & 0.2708 & 54 & 1 & & $35-24-27$ & $114-39-42$ \\
\hline 7 & 35002 & 0.6528 & 53 & 11 & & $35-24-58$ & $114-39-48$ \\
\hline 7 & 35004 & 0.4792 & 54 & 11 & & $35-24-51$ & $114-39-51$ \\
\hline 7 & 35005 & 0.1146 & 53 & 11 & & $35-25-17$ & $114-40-27$ \\
\hline 7 & 35011 & 0.1007 & 53 & 11 & & $35-25-14$ & $114-40-19$ \\
\hline 7 & 35016 & 0.9479 & 38 & 1 & & $35-29-55$ & $114-40-29$ \\
\hline 7 & 35030 & 0.6319 & 38 & 1 & & $35-29-54$ & $114-40-30$ \\
\hline 7 & 35032 & 0.5347 & 38 & 1 & & $35-29-54$ & $114-40-31$ \\
\hline 7 & 35033 & 0.1250 & 38 & 1 & & $35-29-54$ & $114-40-29$ \\
\hline 7 & 35038 & 0.6632 & 38 & 1 & & $35-29-55$ & $114-40-30$ \\
\hline 7 & 35046 & 0.7917 & 38 & 1 & & $35-29-53$ & $114-40-29$ \\
\hline 7 & 35047 & 0.1007 & 38 & 1 & & $35-29-54$ & $114-40-30$ \\
\hline 7 & 35074 & 0.7188 & 38 & 2 & & $35-29-55$ & $114-40-31$ \\
\hline 7 & 35087 & 0.7118 & 38 & 1 & & $35-29-54$ & $114-40-30$ \\
\hline 13 & 34996 & 0.5313 & 54 & 0 & & $35-24-18$ & $114-39-48$ \\
\hline 13 & 34997 & 0.0729 & 54 & 11 & & $35-24-37$ & $114-39-20$ \\
\hline 13 & 34998 & 0.0694 & 52 & & & $35-25-15$ & $114-39-29$ \\
\hline 13 & 34999 & 0.2847 & 53 & 11 & & $35-24-55$ & $114-39-51$ \\
\hline 67 & 34996 & 0.5972 & 57 & 0 & & $35-24-27$ & 114-36-35 \\
\hline 67 & 34997 & 0.0903 & 58 & 6 & & $35-24-06$ & $114-36-40$ \\
\hline 67 & 34998 & 0.1146 & 58 & & & $35-23-18$ & $114-37-04$ \\
\hline 67 & 34999 & 0.2778 & 54 & 11 & & $35-24-37$ & $114-38-57$ \\
\hline 67 & 35004 & 0.4861 & 53 & 11 & & $35-25-41$ & $114-40-30$ \\
\hline 67 & 35011 & 0.0903 & 46 & 11 & & $35-25-57$ & $114-40-08$ \\
\hline 67 & 35016 & 0.7917 & 59 & 11 & & $35-23-35$ & $114-38-31$ \\
\hline 67 & 35032 & 0.6667 & 59 & 11 & & $35-23-30$ & 114-38-24 \\
\hline 67 & 35038 & 0.6875 & 59 & 11 & & $35-23-32$ & $114-38-23$ \\
\hline 67 & 35044 & 0.7743 & 59 & 10 & & $35-23-31$ & $114-38-22$ \\
\hline 67 & 35048 & 0.2153 & 59 & 10 & & $35-23-32$ & $114-38-24$ \\
\hline 67 & 35075 & 0.4757 & 59 & 11 & & $35-23-34$ & $114-38-24$ \\
\hline 70 & 34996 & 0.5972 & 57 & 0 & & $35-24-27$ & $114-36-35$ \\
\hline
\end{tabular}




\begin{tabular}{|c|c|c|c|c|c|c|c|}
\hline LAKE MOH & AVE RAZOR & RBACK SUC & KER TELEN & AETR' & Nov 1 & 994 to July & 1997 \\
\hline Fish ID\# & DATE & TIME & WP & SHORE & TEMP $\mathrm{C}$ & LAT. & LONG. \\
\hline & (JULIAN) & $(24-h r)$ & & $1-10=X 10 M$ & & & \\
\hline & & & & $11=.100 \mathrm{~m}$ & & & \\
\hline 70 & 34997 & 0.0799 & 57 & 11 & & $35-24-27$ & $114-36-41$ \\
\hline 70 & 34998 & 0.1042 & 59 & 2 & & $35-22-55$ & 114-38-05 \\
\hline 70 & 34999 & 0.3160 & 60 & 11 & & $35-22-22$ & $114-37-08$ \\
\hline 70 & 35004 & 0.4167 & 62 & 2 & & $35-20-21$ & $114-36-22$ \\
\hline 70 & 35011 & 0.1528 & 62 & 2 & & $35-20-21$ & $114-36-22$ \\
\hline 70 & 35016 & 0.7708 & 62 & 3 & & $35-20-20$ & $114-36-21$ \\
\hline 70 & 35032 & 0.6806 & 62 & 3 & & $35-20-20$ & $114-36-22$ \\
\hline 70 & 35038 & 0.6979 & 70 & 2 & & $35-20-24$ & $114-36-25$ \\
\hline 70 & 35044 & 0.7569 & 62 & 2 & & $35-20-21$ & $114-36-22$ \\
\hline 70 & 35048 & 0.2292 & 62 & 2 & & $35-20-23$ & $114-36-23$ \\
\hline 70 & 35075 & 0.4549 & 62 & 2 & & $35-20-22$ & $114-36-23$ \\
\hline 87 & 34660 & 0.7014 & 66 & -1 & & $35-17-36$ & $114-35-12$ \\
\hline 87 & 34662 & 0.4167 & 65 & & & $35-17-29$ & $114-35-12$ \\
\hline 87 & 34673 & 0.6389 & 66 & 9 & 12.6 & $35-17-30$ & $114-35-31$ \\
\hline 87 & 34708 & 0.6736 & 66 & 5 & 11.2 & $35-17-35$ & $144-35-31$ \\
\hline 87 & 34711 & 0.3889 & 66 & 3 & 11.4 & $35-17-29$ & $114-35-35$ \\
\hline 87 & 34724 & 0.2993 & 66 & & & & \\
\hline 87 & 34736 & 0.6875 & 66 & 2 & 12.1 & $35-17-37$ & $114-35-32$ \\
\hline 87 & 34745 & 0.3958 & 65 & 2 & 12.4 & $35-17-43$ & $114-35-30$ \\
\hline 87 & 34752 & 0.2861 & 66 & & & & \\
\hline 87 & 34758 & 0.6806 & 66 & 1 & 13.1 & $35-17-35$ & $114-35-37$ \\
\hline 87 & 34767 & 0.3188 & 65 & 1 & 13.8 & $35-17-37$ & $114-35-36$ \\
\hline 87 & 34772 & 0.4826 & 65 & & 14 & $35-17-35$ & $114-35-33$ \\
\hline 87 & 34780 & 0.7535 & 65 & 1 & 14.4 & $35-17-36$ & $114-35-35$ \\
\hline 87 & 34787 & 0.5313 & 65 & & & $35-17-36$ & 114-35-35 \\
\hline 87 & 34792 & 0.6736 & 65 & 1 & 15.3 & $35-17-37$ & $114-35-35$ \\
\hline 87 & 34796 & 0.2153 & 65 & 1 & 15 & $35-17-34$ & $114-35-34$ \\
\hline 87 & 34820 & 0.7049 & 65 & 1 & 15.7 & $35-17-36$ & $114-35-34$ \\
\hline 87 & 34824 & 0.2674 & 65 & 1 & 15.5 & $35-17-36$ & $114-35-33$ \\
\hline 87 & 34850 & 0.7083 & 65 & 1 & 17.2 & $35-17-52$ & $114-35-35$ \\
\hline 87 & 34853 & 0.2569 & 65 & 1 & 16.7 & $35-17-35$ & 114-35-37 \\
\hline 87 & 34876 & 0.6667 & 65 & 1 & 17.7 & $35-17-36$ & $114-35-34$ \\
\hline 87 & 34904 & 0.6979 & 65 & 2 & 18 & $35-17-37$ & $114-35-36$ \\
\hline 87 & 34932 & 0.7014 & 65 & 2 & 18.9 & $35-17-37$ & $114-35-35$ \\
\hline 87 & 34960 & 0.6979 & 65 & 2 & 15 & $35-17-37$ & $114-35-35$ \\
\hline 87 & 34988 & 0.6875 & 65 & 2 & 19.6 & $35-17-37$ & $114-35-36$ \\
\hline 87 & 35016 & 0.7465 & 65 & 2 & 17.6 & $35-17-35$ & $114-35-36$ \\
\hline 87 & 35044 & 0.7396 & 65 & 1 & 15.7 & $35-17-35$ & $114-35-36$ \\
\hline 87 & 35087 & 0.5660 & 65 & 2 & 11.9 & $35-17-37$ & $114-35-35$ \\
\hline 88 & 34645 & 0.6667 & 36 & 1 & & $35-31-14$ & $114-39-25$ \\
\hline 88 & 34652 & 0.7458 & 27 & & 13.5 & $35-38-23$ & $114-40-47$ \\
\hline 88 & 34662 & 0.8125 & 34 & & 12.2 & & \\
\hline 88 & 34674 & 0.9500 & 36 & & 12.1 & $35-31-22$ & $114-37-35$ \\
\hline 88 & 34676 & 0.1354 & 36 & 9 & 12.1 & $35-31-43$ & $114-39-11$ \\
\hline 88 & 34688 & 0.7639 & 35 & & & & \\
\hline 88 & 34709 & 0.9514 & 33 & 11 & 12.1 & $35-34-01$ & $114-39-34$ \\
\hline 88 & 34712 & 0.1528 & 33 & & 12.2 & $35-34-26$ & $114-40-03$ \\
\hline 88 & 34724 & 0.7590 & 32 & & & & \\
\hline 88 & 34744 & 0.6986 & 32 & 1 & 13.5 & $35-35-09$ & $114-41-23$ \\
\hline 88 & 34752 & 0.6806 & 32 & & & & \\
\hline
\end{tabular}




\begin{tabular}{|c|c|c|c|c|c|c|c|}
\hline LAKE MOH & AVE RAZOP & RBACK SUC & KER TELEN & ETRY STU & Nov 1 & 994 to July & 1997 \\
\hline Fish ID\# & DATE & TIME & $W \bar{P}$ & SHORE & TEMP $\mathrm{C}$ & LAT. & LONG. \\
\hline & (JULIAN) & (24-hr) & & $1-10=X 10 M$ & & & \\
\hline & & & & $11=.100 \mathrm{~m}$ & & & \\
\hline 88 & 34759 & 0.8542 & 33 & 4 & 15.3 & $35-33-36$ & $114-39-29$ \\
\hline 88 & 34768 & 0.1750 & 35 & 10 & 13.9 & $35-32-52$ & $114-39-25$ \\
\hline 88 & 34780 & 0.6111 & 36 & 8 & 15.5 & $35-31-24$ & $114-39-20$ \\
\hline 88 & 34787 & 0.4236 & 39 & 1 & 14.8 & $35-28-34$ & $114-40-44$ \\
\hline 88 & 34796 & 0.1042 & 40 & 3 & 16.5 & $35-28-40$ & $114-40-40$ \\
\hline 88 & 34801 & 0.7361 & 40 & 1 & 15 & $35-28-31$ & $114-40-42$ \\
\hline 88 & 34808 & 0.7222 & 40 & 2 & 15.6 & $35-28-32$ & $114-40-41$ \\
\hline 88 & 34821 & 0.7361 & 32 & 8 & 19.4 & $35-34-40$ & $114-39-38$ \\
\hline 88 & 34823 & 0.1944 & 29 & 1 & 19 & $35-37-05$ & $114-39-20$ \\
\hline 88 & 34836 & 0.6771 & 27 & 3 & 14.6 & $35-38-52$ & $114-40-58$ \\
\hline 88 & 34852 & 0.2326 & 23 & 11 & 18.9 & $35-41-52$ & $114-41-40$ \\
\hline 88 & 34863 & 0.6042 & 21 & 5 & 20.7 & $35-43-27$ & $114-42-00$ \\
\hline 88 & 34864 & 0.5382 & 21 & 10 & 20.1 & $35-43-47$ & $114-41-55$ \\
\hline 88 & 34865 & 0.0972 & 21 & 8 & 19.9 & $35-43-41$ & $114-42-00$ \\
\hline 88 & 34891 & 0.6250 & 37 & 2 & 27.4 & $35-30-56$ & $114-40-53$ \\
\hline 88 & 34892 & 0.6597 & 37 & 2 & 27.4 & $35-30-55$ & $114-40-50$ \\
\hline 88 & 34905 & 0.7986 & 35 & 10 & 16.9 & $35-32-02$ & $114-39-15$ \\
\hline 88 & 34907 & 0.0799 & 36 & 11 & 16.8 & $35-$ & $114-39-14$ \\
\hline 88 & 34908 & 0.0799 & 40 & 11 & 17.5 & $35-28-20$ & $114-40-23$ \\
\hline 88 & 34920 & 0.5833 & 35 & 11 & 17 & $35-31-55$ & $114-39-18$ \\
\hline 88 & 34934 & 0.7188 & 35 & 9 & 16.7 & $35-32-00$ & $114-39-13$ \\
\hline 88 & 34935 & 0.1007 & 35 & 9 & 16.7 & $35-32-03$ & $114-39-13$ \\
\hline 88 & 34949 & 0.6111 & 35 & 11 & 17.7 & $35-32-05$ & $114-39-17$ \\
\hline 88 & 34961 & 0.6910 & 35 & 11 & 16.7 & $35-31-55$ & $114-39-24$ \\
\hline 88 & 34963 & 0.1007 & 36 & 11 & 17.3 & $35-31-49$ & $114-39-32$ \\
\hline 88 & 34974 & 0.6250 & 35 & 11 & 17.5 & $35-3$ & $114-39-31$ \\
\hline 88 & 34975 & 0.6771 & 35 & 9 & 17.2 & $35-31-55$ & $114-39-16$ \\
\hline 88 & 34976 & 0.0938 & 36 & 11 & 17 & $35-31-44$ & $114-39-19$ \\
\hline 88 & 34989 & 0.6597 & 34 & 5 & 20.5 & $35-33-16$ & $114-39-27$ \\
\hline 88 & 34991 & 0.1354 & 34 & 2 & 21.1 & $35-33-03$ & $114-39-24$ \\
\hline 88 & 35006 & 0.1215 & 35 & 11 & 18.1 & $35-32-46$ & $114-39-33$ \\
\hline 88 & 35032 & 0.5139 & 35 & 10 & 15.6 & $35-32-15$ & $114-39-17$ \\
\hline 88 & 35046 & 0.7569 & 35 & 11 & 13.8 & $35-32-54$ & $114-39-42$ \\
\hline 88 & 35047 & 0.1458 & 35 & 11 & 13.9 & $35-33-07$ & $114-39-43$ \\
\hline 88 & 35074 & 0.6979 & 33 & 11 & 12.4 & $35-33-53$ & $114-39-41$ \\
\hline 88 & 35088 & 0.6181 & 32 & 11 & 12.6 & $35-34-29$ & $114-39-55$ \\
\hline 88 & 35098 & 0.6458 & 35 & 8 & 12.3 & $35-32-28$ & $114-39-24$ \\
\hline 88 & 35101 & 0.7083 & 35 & 8 & 12.7 & $35-32-43$ & $114-39-28$ \\
\hline 88 & 35108 & 0.6736 & 34 & 4 & & $35-32-59$ & $114-39-30$ \\
\hline 88 & 35116 & 0.5139 & 36 & 11 & 1391 & $35-31-10$ & $114-39-38$ \\
\hline 88 & 35130 & 0.5000 & 36 & 5 & 1530 & $35-31-39$ & 114-39-09 \\
\hline 88 & 35137 & 0.8889 & 39 & 1 & & $35-28-32$ & $114-40-43$ \\
\hline 88 & 35144 & 0.6875 & 39 & 2 & & $35-28-32$ & $114-40-43$ \\
\hline 88 & 35172 & 0.3750 & 36 & & & $35-31-41$ & $114-39-11$ \\
\hline 88 & 35185 & 0.7153 & 39 & 3 & 1267 & $35-28-32$ & $114-40-43$ \\
\hline 88 & 35535 & 0.440278 & 36 & & & 353130 & 1143912 \\
\hline 88 & 35536 & 0.527083 & 39 & 15.7 & & 352835 & 1144040 \\
\hline 88 & 35574 & 0.479167 & 22 & 18.5 & 3 & 354234 & 1144205 \\
\hline 88 & 35578 & 0.479167 & 23 & 14.4 & & 354210 & 1144150 \\
\hline 88 & 35588 & 0.465278 & 22 & & & 354233 & 1144202 \\
\hline
\end{tabular}




\begin{tabular}{|c|c|c|c|c|c|c|c|}
\hline LAKE MOH & AVE RAZC & RBACK SUC & KER TELEM & IETRY STUE & Nov 1 & 994 to July & 1997 \\
\hline Fish ID\# & DATE & TIME & WP & SHORE & TEMP C & LAT. & LONG. \\
\hline & (JULIAN) & (24-hr) & & $1-10=X 10 M$ & & & \\
\hline & & & & $11=.100 \mathrm{~m}$ & & & \\
\hline 88 & 35598 & 0.395833 & 24 & & 3 & 354111 & 1144049 \\
\hline 88 & 35605 & 0.451389 & 21 & & 10 & 354352 & 1144148 \\
\hline 88 & 35619 & 0.416667 & 20 & 23.5 & & 354420 & 1144147 \\
\hline 96 & 34660 & 0.6111 & 54 & 1 & & $35-24-29$ & $114-39-40$ \\
\hline 96 & 34662 & 0.3681 & 54 & 9 & 13.8 & $35-24-43$ & $114-39-51$ \\
\hline 96 & 34673 & 0.7569 & 43 & 11 & 11.9 & $35-27-11$ & $114-39-14$ \\
\hline 96 & 34677 & 0.1944 & 44 & 11 & 12.3 & $35-27-05$ & $114-39-17$ \\
\hline 96 & 34688 & 0.4375 & 44 & & & & \\
\hline 96 & 34708 & 0.8194 & 44 & 11 & 11.3 & $35-27-08$ & 114-39-16 \\
\hline 96 & 34711 & 0.2438 & 43 & 11 & 11.4 & $35-27-11$ & $114-39-18$ \\
\hline 96 & 34724 & 0.4167 & 44 & & & & \\
\hline 96 & 34736 & 0.8333 & 44 & 11 & 11.8 & $35-27-12$ & $114-39-33$ \\
\hline 96 & 34752 & 0.3750 & 44 & 11 & & & \\
\hline 96 & 34758 & 0.7986 & 44 & 11 & 12.8 & $35-27-12$ & $114-39-21$ \\
\hline 96 & 34767 & 0.2118 & 44 & 11 & 13.3 & $35-27-08$ & $114-39-20$ \\
\hline 96 & 34772 & 0.6146 & 44 & 11 & 13.9 & $35-27-08$ & 114-39-33 \\
\hline 96 & 34780 & 0.6806 & 44 & 11 & 14.1 & $35-27-10$ & 114-39-35 \\
\hline 96 & 34787 & 0.4583 & 44 & & & $35-27-08$ & $114-39-28$ \\
\hline 96 & 34792 & 0.7639 & 44 & 11 & 13.9 & $35-27-05$ & $114-39-24$ \\
\hline 96 & 34796 & 0.1285 & 44 & 11 & 14.1 & $35-27-12$ & $114-39-28$ \\
\hline 96 & 34820 & 0.7882 & 44 & 11 & 14.6 & $35-27-14$ & $114-39-32$ \\
\hline 96 & 34850 & 0.7951 & 44 & 11 & 15.5 & $35-27-09$ & $114-39-30$ \\
\hline 96 & 34853 & 0.1389 & 44 & 11 & 15.5 & $35-27-13$ & 114-39-29 \\
\hline 96 & 34876 & 0.7743 & 44 & 11 & 16 & $35-27-06$ & $114-39-24$ \\
\hline 96 & 34904 & 0.8299 & 44 & 11 & 16.6 & $35-27-11$ & 114-39-26 \\
\hline 96 & 34932 & 0.8403 & 44 & 11 & 17.2 & $35-27-12$ & $114-39-27$ \\
\hline 96 & 34960 & 0.8194 & 44 & 11 & 17.1 & $35-27-10$ & $114-39-26$ \\
\hline 96 & 34988 & 0.7986 & 44 & 11 & 16.5 & $35-27-06$ & $114-39-29$ \\
\hline 96 & 35016 & 0.8958 & 44 & 11 & 16.3 & $35-27-08$ & $114-39-28$ \\
\hline 96 & 35044 & 0.8472 & 44 & 11 & 14.7 & $35-27-11$ & $114-39-26$ \\
\hline 97 & 34645 & 0.6319 & 36 & 1 & & $35-31-14$ & $114-39-25$ \\
\hline 97 & 35032 & 0.4965 & 34 & 1 & 16.1 & $35-33-16$ & $114-39-57$ \\
\hline 97 & 35047 & 0.1528 & 34 & 1 & 14.9 & $35-33-15$ & $114-39-56$ \\
\hline 249 & 34646 & 358 & 39 & 1 & & $35-28-32$ & $114-40-48$ \\
\hline 249 & 34652 & 0.8278 & 35 & & & & \\
\hline 249 & 34662 & 0.8194 & 35 & & & & \\
\hline 249 & 34737 & 0.9306 & 34 & 2 & 13.1 & $35-32-30$ & $114-40-16$ \\
\hline 249 & 34744 & 0.6458 & 35 & 2 & 13.4 & $35-32-34$ & $114-40-18$ \\
\hline 249 & 34752 & 0.6944 & 35 & & & & \\
\hline 249 & 34759 & 0.8875 & 35 & 3 & 15.2 & $35-32-25$ & $114-40-21$ \\
\hline 249 & 34768 & 0.1458 & 35 & 4 & 14.7 & $35-32-27$ & $114-40-20$ \\
\hline 249 & 34780 & 0.5938 & 35 & 10 & 15.4 & $35-32-26$ & $114-40-23$ \\
\hline 249 & 34793 & 0.8264 & 35 & 6 & 14.6 & $35-32-28$ & $114-40-24$ \\
\hline 249 & 34795 & 0.1146 & 35 & 3 & 14.9 & $35-32-26$ & $114-40-21$ \\
\hline 249 & 34801 & 0.7639 & 35 & 3 & 15.4 & $35-32-26$ & $114-40-25$ \\
\hline 258 & 34646 & 0.4167 & 39 & 1 & & $35-28-32$ & $114-40-48$ \\
\hline 258 & 34653 & 0.6597 & 39 & & 15.5 & $35-28-22$ & $114-40-29$ \\
\hline 258 & 34662 & 0.2708 & 39 & & & & \\
\hline 258 & 34673 & 0.8125 & 40 & 3 & 12.3 & $35-28-31$ & $114-40-39$ \\
\hline 258 & 34708 & 0.8750 & 40 & 2 & 11.4 & $35-28-30$ & $114-40-38$ \\
\hline
\end{tabular}




\begin{tabular}{|c|c|c|c|c|c|c|c|}
\hline AKE MOHK & IAVE RAZOF & RBACK SUC & KER TELEN & TETRY STU & Nov 1 & 994 to July & 1997 \\
\hline Fish ID\# & DATE & TIME & WP & SHORE & TEMP $\mathrm{C}$ & LAT. & LONG. \\
\hline & (JULIAN) & $(24-h r)$ & & $1-10=X 10 \mathrm{M}$ & & & \\
\hline & & & & $11=.100 \mathrm{~m}$ & & & \\
\hline 258 & 34711 & 0.1944 & 39 & 3 & 11.6 & $35-28-29$ & $114-40-39$ \\
\hline 258 & 34724 & 0.4375 & 40 & & & & \\
\hline 258 & 34736 & 0.8813 & 40 & 2 & 12 & $35-28-32$ & $114-40-39$ \\
\hline 258 & 34744 & 0.5694 & 40 & 2 & 13 & $35-28-34$ & $114-40-46$ \\
\hline 258 & 34752 & 0.3931 & 40 & & & & \\
\hline 258 & 34758 & 0.8611 & 40 & & & $35-28-33$ & $114-40-42$ \\
\hline 258 & 34767 & 0.1410 & 40 & 2 & 14.5 & $35-28-30$ & $114-40-42$ \\
\hline 258 & 34772 & 0.6403 & 40 & & & $35-28-31$ & $114-40-44$ \\
\hline 258 & 34787 & 0.0556 & 35 & & & & \\
\hline 258 & 34793 & 0.8090 & 34 & 11 & 13.8 & $35-32-45$ & $114-39-44$ \\
\hline 258 & 34795 & 0.1319 & 34 & 11 & 14.5 & $35-32-42$ & $114-39-53$ \\
\hline 258 & 34808 & 0.6319 & 32 & 11 & 14 & $35-35-06$ & $114-40-20$ \\
\hline 258 & 34821 & 0.7188 & 31 & 11 & 16.2 & $35-35-12$ & $114-40-02$ \\
\hline 258 & 34823 & 0.1563 & 32 & 10 & 15.5 & $35-35-05$ & $114-40-28$ \\
\hline 258 & 34835 & 0.5938 & 32 & 5 & 16.2 & $35-35-12$ & $114-40-18$ \\
\hline 258 & 34836 & 0.7222 & 32 & 11 & 15.7 & $35-34-58$ & $114-40-34$ \\
\hline 258 & 34837 & 0.1042 & 32 & 11 & 15.4 & $35-35-03$ & $114-40-28$ \\
\hline 258 & 34853 & 0.1563 & 46 & 11 & 20.7 & $35-26-35$ & $114-40-34$ \\
\hline 258 & 34876 & 0.7535 & 46 & 11 & 21.9 & $35-26-16$ & $114-40-06$ \\
\hline 258 & 34892 & 0.7049 & 46 & 11 & 17.5 & $35-25-59$ & $114-40-07$ \\
\hline 258 & 34904 & 0.8507 & 40 & 11 & 16.5 & $35-27-54$ & $114-40-07$ \\
\hline 258 & 34936 & 0.2153 & 46 & 11 & 17.3 & $35-26-14$ & $114-40-16$ \\
\hline 258 & 34960 & 0.8090 & 46 & 11 & 17.3 & $35-25-53$ & $114-40-21$ \\
\hline 258 & 34964 & 0.2083 & 46 & 11 & 17.9 & $35-25-53$ & $114-40-37$ \\
\hline 258 & 34975 & 0.7188 & 46 & 11 & 17.2 & $35-26-00$ & $114-40-11$ \\
\hline 258 & 34988 & 0.7778 & 49 & 11 & 20.1 & $35-26-28$ & $114-37-47$ \\
\hline 258 & 34992 & 0.1563 & 49 & 11 & 19.6 & $35-26-30$ & $114-37-53$ \\
\hline 258 & 35004 & 0.5347 & 44 & 11 & 16.5 & $35-27-16$ & $114-39-37$ \\
\hline 258 & 35016 & 0.8681 & 49 & 11 & 17.8 & $35-26-28$ & $114-37-54$ \\
\hline 258 & 35032 & 0.6042 & 49 & 11 & 16.6 & $35-26-32$ & $114-37-52$ \\
\hline 258 & 35044 & 0.8958 & 39 & 3 & & $35-28-33$ & $114-40-42$ \\
\hline 258 & 35048 & 0.1146 & 39 & 2 & & $35-28-32$ & $114-40-41$ \\
\hline 258 & 35087 & 0.6944 & 39 & 3 & & $35-28-32$ & $114-40-44$ \\
\hline 258 & 35098 & 0.4792 & 39 & 2 & & $35-28-31$ & $114-40-42$ \\
\hline 258 & 35101 & 0.7465 & 39 & 1 & 12.6 & $35-28-35$ & $114-40-42$ \\
\hline 258 & 35116 & 0.4861 & 40 & 2 & & $35-28-34$ & $114-40-44$ \\
\hline 258 & 35130 & 0.5347 & 39 & 1 & 1422 & $35-28-31$ & $114-40-42$ \\
\hline 258 & 35137 & 0.8889 & 39 & 1 & 1352 & $35-28-32$ & $114-40-43$ \\
\hline 258 & 35144 & 0.6875 & 39 & 2 & 1258 & $35-28-32$ & $114-40-43$ \\
\hline 258 & 35173 & 0.6875 & 35 & 11 & 1237 & $35-32-06$ & $114-39-14$ \\
\hline 258 & 35185 & 0.7153 & 39 & 3 & 1202 & $35-28-32$ & $114-40-43$ \\
\hline 267 & 34646 & 0.3715 & 39 & 1 & & $35-28-32$ & $114-40-48$ \\
\hline 267 & 34653 & 0.6597 & 39 & 10 & 14.7 & $35-28-16$ & $114-39-49$ \\
\hline 267 & 34662 & 0.2847 & 40 & & & & \\
\hline 267 & 34673 & 0.7986 & 40 & 10 & 12.1 & $35-28-18$ & $114-39-48$ \\
\hline 267 & 34677 & 0.1590 & 40 & 11 & 12.1 & $35-28-16$ & 114-39-54 \\
\hline 267 & 34688 & 0.4653 & 40 & & & & \\
\hline 267 & 34708 & 0.8542 & 40 & 11 & 11.3 & $35-28-14$ & $114-40-00$ \\
\hline 267 & 34711 & 0.2153 & 40 & 11 & 11.5 & $35-28-18$ & 114-39-55 \\
\hline 267 & 34724 & 0.4375 & 40 & & & & \\
\hline
\end{tabular}




\begin{tabular}{|c|c|c|c|c|c|c|c|}
\hline LAKE MOH & AVE RAZOF & RBACK SUC & KER TELEN & YETRY STU & Nov 1 & 994 to July & 1997 \\
\hline Fish ID\# & DATE & TIME & WP & SHORE & TEMP $\mathrm{C}$ & LAT. & LONG. \\
\hline & (JULIAN) & (24-hr) & & $1-10=X 10 M$ & & & \\
\hline & & & & $11=.100 \mathrm{~m}$ & & & \\
\hline 267 & 34736 & 0.8750 & 40 & 10 & 11.9 & $35-28-32$ & $114-40-01$ \\
\hline 267 & 34744 & 0.6042 & 40 & 3 & 12.8 & $35-28-30$ & $114-40-44$ \\
\hline 267 & 34752 & 0.3889 & 40 & & & & 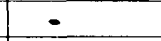 \\
\hline 267 & 34758 & 0.8403 & 40 & 11 & 12.9 & $35-28-26$ & 114-39-59 \\
\hline 267 & 34767 & 0.1528 & 40 & 11 & 13.6 & $35-28-19$ & $114-39-59$ \\
\hline 267 & 34772 & 0.6444 & 40 & 11 & 14.2 & $35-28-19$ & $114-39-56$ \\
\hline 267 & 34780 & 0.6597 & 40 & 11 & 15.1 & $35-28-23$ & $114-39-59$ \\
\hline 267 & 34787 & 0.4375 & 40 & & 14.6 & $35-28-21$ & $114-39-55$ \\
\hline 267 & 34792 & 0.7778 & 40 & 11 & 13.9 & $35-28-19$ & $114-40-01$ \\
\hline 267 & 34796 & 0.1076 & 40 & 11 & 14.3 & $35-28-26$ & 114-39-57 \\
\hline 267 & 34820 & 0.8056 & 40 & 11 & 15 & $35-28-22$ & $114-39-56$ \\
\hline 267 & 34850 & 0.8090 & 40 & 11 & 15.5 & $35-28-27$ & $114-40-00$ \\
\hline 267 & 34853 & 0.1215 & 40 & 11 & 15.7 & $35-28-25$ & $114-39-55$ \\
\hline 267 & 34876 & 0.7917 & 40 & 11 & 14.7 & $35-28-19$ & $114-40-01$ \\
\hline 267 & 34904 & 0.8646 & 40 & 11 & 17 & $35-28-18$ & $114-39-57$ \\
\hline 267 & 34932 & 0.8542 & 40 & 11 & 17.6 & $35-28-24$ & $114-40-01$ \\
\hline 267 & 34960 & 0.8403 & 40 & 11 & 17.4 & $35-28-18$ & $114-39-57$ \\
\hline 267 & 34988 & 0.8125 & 40 & 11 & 17.2 & $35-28-24$ & $114-40-01$ \\
\hline 267 & 35016 & 0.9340 & 40 & 11) & 17.1 & $35-28-24$ & $114-40-01$ \\
\hline 267 & 35044 & 0.8715 & 40 & 10 & 14.5 & $35-28-23$ & 114-40-01 \\
\hline 276 & 34646 & 0.4097 & 39 & 1 & & $35-28-32$ & $114-40-48$ \\
\hline 276 & 34653 & 0.7292 & & 11 & 16 & $35-24-50$ & $114-40-07$ \\
\hline 276 & 34662 & 0.3403 & 53 & & & & \\
\hline 276 & 34673 & 0.7500 & 47 & 11 & 12.2 & $35-26-10$ & $114-40-18$ \\
\hline 276 & 34677 & 0.1319 & 39 & 9 & 12 & $35-28-44$ & 114-39-59 \\
\hline 276 & 34688 & 0.3681 & 54 & & & & \\
\hline 276 & 34708 & 0.8125 & 46 & 11 & 11.9 & $35-26-53$ & $114-40-11$ \\
\hline 276 & 34711 & 0.1944 & 39 & 3 & 11.6 & $35-28-29$ & $114-40-39$ \\
\hline 276 & 34724 & 0.4375 & 40 & & & & \\
\hline 276 & 34736 & 0.8813 & 40 & 2 & 12 & $35-28-32$ & $114-40-39$ \\
\hline 276 & 34744 & 0.5694 & 40 & 2 & 13 & $35-28-34$ & $114-40-46$ \\
\hline 276 & 34752 & 0.3931 & 40 & & & & \\
\hline 276 & 34759 & 0.7292 & 23 & 5 & 13.5 & $35-41-22$ & $114-40-51$ \\
\hline 276 & 34768 & 0.1139 & 36 & 4 & 14.5 & $35-31-25$ & 114-39-22 \\
\hline 276 & 34773 & 0.8056 & 36 & 11 & 15.4 & $35-31-28$ & $114-39-20$ \\
\hline 276 & 34780 & 0.5472 & 32 & 10 & 15.4 & $35-34-37$ & $114-40-13$ \\
\hline 276 & 34787 & 0.0139 & 32 & 2 & 13.2 & $35-39-39$ & $114-40-01$ \\
\hline 276 & 34793 & 0.8125 & 34 & 11 & 14.1 & $35-32-49$ & 114-39-31 \\
\hline 276 & 34795 & 0.1667 & 33 & 3 & 15 & 35-33-59 & 114-39-23 \\
\hline 276 & 34808 & 0.6354 & 32 & 11 & 14.2 & $35-34-36$ & $114-40-24$ \\
\hline 276 & 34821 & 0.6632 & 26 & 10 & 17.3 & $35-38-57$ & $114-41-13$ \\
\hline 276 & 34823 & 0.2465 & 25 & 11 & 17.3 & $35-40-13$ & $114-41-17$ \\
\hline 276 & 34836 & 0.6250 & 24 & 11 & 16.1 & $35-41-01$ & $114-40-54$ \\
\hline 276 & 34852 & 0.2743 & 20 & 11 & 17 & $35-44-23$ & $114-41-48$ \\
\hline 276 & 34864 & 0.6007 & 25 & 4 & 21 & $35-40-30$ & $114-40-57$ \\
\hline 276 & 34877 & 0.6979 & 23 & 3 & 24.8 & $35-41-44$ & $114-41-17$ \\
\hline 276 & 34879 & 0.3021 & 25 & 10 & 23.9 & $35-40-21$ & 114-41-01 \\
\hline 276 & 34904 & 0.8681 & 39 & 11 & 17.1 & $35-29-15$ & $114-40-17$ \\
\hline 276 & 34908 & 0.1285 & 46 & 11 & 18.8 & $35-26-00$ & $114-40-46$ \\
\hline 276 & 34920 & 0.6701 & 53 & 11 & 18.1 & $35-25-37$ & $114-40-30$ \\
\hline
\end{tabular}


LAKE MOHAVE RAZORBACK SUCKER TELEMETRY STUDY Nov 1994 to July 1997

\begin{tabular}{|c|c|c|c|c|c|c|c|}
\hline Fish ID\# & DATE & TIME & WP & SHORE & TEMP C & LAT. & LONG. \\
\hline & (JULIAN) & $(24-h r)$ & & $1-10=X 10 M$ & & & \\
\hline & & & & $11=.100 \mathrm{~m}$ & & & \\
\hline 276 & 34922 & 0.0972 & 53 & 11 & 18 & $35-25-35$ & $114-40-32$ \\
\hline 276 & 34932 & 0.7847 & 46 & 11 & 18.6 & $35-25-51$ & $114-40-36$ \\
\hline 276 & 34936 & 0.1528 & 46 & 11 & 19.4 & $35-26-01$ & $114-40-41$ \\
\hline 276 & 34949 & 0.6528 & 46 & 11 & 22.3 & $35-26-45$ & $114-40-24$ \\
\hline 276 & 34960 & 0.8056 & 46 & 11 & 20.5 & $35-25-53$ & $114-40-23$ \\
\hline 276 & 34964 & 0.1667 & 53 & 10 & 22.4 & $35-25-24$ & $114-40-40$ \\
\hline 276 & 34975 & 0.7326 & 53 & 11 & 17.4 & $35-25-24$ & $114-40-28$ \\
\hline 276 & 34988 & 0.7639 & 51 & 11 & 20.6 & $35-25-33$ & $114-38-17$ \\
\hline 276 & 34992 & 0.1181 & 41 & 11 & 20.5 & $35-27-39$ & $114-38-43$ \\
\hline 276 & 35004 & 0.5278 & 45 & 11 & 16.8 & $35-26-44$ & $114-40-17$ \\
\hline 276 & 35016 & 0.8854 & 45 & 11 & 17 & $35-27-28$ & $114-40-22$ \\
\hline 276 & 35032 & 0.6458 & 54 & 10 & 16.7 & $35-24-22$ & $114-39-19$ \\
\hline 276 & 35044 & 0.8194 & 53 & 11 & 14.4 & $35-25-17$ & $114-40-11$ \\
\hline 276 & 35048 & 0.1944 & 53 & 11 & 15 & $35-25-07$ & $114-40-20$ \\
\hline 276 & 35075 & 0.5278 & 39 & 2 & & $35-28-33$ & $114-40-43$ \\
\hline 276 & 35087 & 0.6528 & 46 & 11 & 12 & $35-25-48$ & $114-40-34$ \\
\hline 276 & 35099 & 0.4514 & 53 & 5 & 12.3 & $35-25-05$ & $114-40-26$ \\
\hline 276 & 35101 & 0.7882 & 54 & 2 & 13 & $35-24-43$ & $114-40-10$ \\
\hline 276 & 35110 & 0.9375 & 54 & 2 & & $35-24-52$ & $114-40-22$ \\
\hline 276 & 35116 & 0.4861 & 40 & 2 & & $35-28-34$ & $114-40-44$ \\
\hline 276 & 35130 & 0.4583 & 32 & 11 & 1368 & $35-34-45$ & $114-40-41$ \\
\hline 276 & 35137 & 0.8194 & 33 & 5 & 1292 & $35-33-44$ & $114-39-29$ \\
\hline 276 & 35144 & 0.6597 & 34 & 11 & 1255 & $35-32-42$ & $114-39-30$ \\
\hline 276 & 35173 & 0.6319 & 32 & 6 & 1153 & $35-34-40$ & $114-39-47$ \\
\hline 276 & 35185 & 0.6667 & 35 & 6 & 1181 & $35-32-25$ & $114-39-19$ \\
\hline 276 & 35535 & 0.447917 & 35 & 14.4 & & 353240 & 1143919 \\
\hline 276 & 35537 & 0.479167 & 37 & 16.9 & & 353253 & 1143934 \\
\hline 276 & 35574 & 0.694444 & 24 & 19.2 & 11 & 354055 & 1144048 \\
\hline 276 & 35574 & 0.444444 & 25 & 19.1 & 10 & 354029 & 1144057 \\
\hline 276 & 35578 & 0.423611 & 27 & & 5 & 353835 & 1144041 \\
\hline 276 & 35584 & 0.368056 & 33 & & 7 & 353421 & 1143939 \\
\hline 276 & 35588 & 0.451389 & 23 & 20.4 & & 354148 & 1144119 \\
\hline 276 & 35598 & 0.395833 & 24 & 20 & 10 & 354043 & 1144100 \\
\hline 285 & 34646 & 0.3819 & 39 & 1 & & $35-28-32$ & $114-40-48$ \\
\hline 285 & 34653 & 0.7569 & 56 & & 15.7 & & \\
\hline 285 & 34674 & 0.8889 & 33 & 11 & 12.4 & & \\
\hline 285 & 34676 & 0.1944 & 34 & 11 & 12.7 & $35-33-39$ & $114-40-04$ \\
\hline 285 & 34688 & 0.7569 & 34 & & & & \\
\hline 285 & 34709 & 0.9792 & 34 & 11 & 12.1 & $35-33-44$ & 114-40-04 \\
\hline 285 & 34712 & 0.1250 & 34 & 10 & 12.1 & $35-33-41$ & $114-40-02$ \\
\hline 285 & 34724 & 0.7708 & 33 & & & & \\
\hline 285 & 34744 & 0.6597 & 34 & 11 & 13.3 & $35-33-46$ & $114-40-06$ \\
\hline 285 & 34752 & 0.6875 & 34 & & & & \\
\hline 285 & 34759 & 0.8611 & 33 & 11 & 14.3 & $35-33-44$ & $114-40-10$ \\
\hline 285 & 34768 & 0.1944 & 34 & 7 & 14 & $35-33-46$ & $114-40-06$ \\
\hline 285 & 34773 & 0.7882 & 34 & 11 & 13.9 & $35-33-46$ & $114-40-05$ \\
\hline 285 & 34780 & 0.5729 & 34 & 11 & 15.1 & $35-33-39$ & $114-40-03$ \\
\hline 285 & 34793 & 0.7917 & 33 & 11 & 14.1 & $35-33-40$ & $114-40-06$ \\
\hline 285 & 34795 & 0.1493 & 34 & 11 & 14.4 & $35-33-32$ & $114-39-54$ \\
\hline 285 & 34802 & 0.3056 & 34 & 11 & 14.4 & $35-33-39$ & $114-40-05$ \\
\hline
\end{tabular}




\begin{tabular}{|c|c|c|c|c|c|c|c|}
\hline LAKE MOH & AVE RAZO & RBACK SUC & KER TELEM & IETRY STUE & Nov 1 & 994 to July & 1997 \\
\hline Fish ID\# & DATE & TIME & WP & SHORE & TEMP C & LAT. & LONG. \\
\hline & (JULIAN) & $(24-h r)$ & & $1-10=X 10 \mathrm{M}$ & & & \\
\hline & & & & $11=.100 \mathrm{~m}$ & & & \\
\hline 285 & 34821 & 0.7500 & 33 & 11 & 16.8 & $35-33-41$ & $114-40-07$ \\
\hline 285 & 34850 & 0.8333 & 34 & 11 & 17.5 & $35-33-42$ & $114-40-00$ \\
\hline 285 & 34852 & 0.1076 & 34 & 11 & 17.8 & $35-33-41$ & $114-40-05$ \\
\hline 285 & 34877 & 0.7847 & 34 & 11 & 19.7 & $35-33-42$ & $114-40-04$ \\
\hline 285 & 34905 & 0.7847 & 33 & 11 & 26.5 & $35-33-42$ & $114-40-02$ \\
\hline 285 & 34961 & 0.6736 & 33 & 11 & 21.9 & $35-33-39$ & $114-40-02$ \\
\hline 285 & 34989 & 0.6528 & 33 & 11 & 19.6 & $35-33-39$ & $114-40-05$ \\
\hline 285 & 35047 & 0.1597 & 34 & 10 & 13.9 & $35-33-39$ & $114-40-04$ \\
\hline 294 & 34645 & 0.5972 & 36 & 1 & & $35-31-14$ & $114-39-25$ \\
\hline 294 & 34653 & 0.6042 & 36 & & 14.3 & $35-31-14$ & $114-39-25$ \\
\hline 339 & 34645 & 0.6146 & 36 & 1 & & $35-31-14$ & $114-39-25$ \\
\hline 339 & 34652 & 0.8333 & 35 & & 13.8 & & \\
\hline 339 & 34653 & 0.6250 & 37 & 11 & 14 & $35-30-51$ & $114-40-32$ \\
\hline 339 & 34674 & 0.8958 & 35 & 2 & 12.1 & $35-32-51$ & $114-39-28$ \\
\hline 339 & 34676 & 0.1354 & 36 & 9 & 11.9 & $35-31-43$ & $114-39-11$ \\
\hline 339 & 34688 & 0.3750 & 53 & & & & \\
\hline 339 & 34708 & 0.7708 & 53 & 3 & 11.9 & $35-25-40$ & $114-40-43$ \\
\hline 339 & 34711 & 0.2917 & 46 & 3 & 11.2 & $35-25-17$ & $114-40-38$ \\
\hline 339 & 34724 & 0.7708 & 33 & & & & \\
\hline 339 & 34737 & 0.8542 & 28 & 2 & 12.6 & $35-37-48$ & 114-40-01 \\
\hline 339 & 34744 & 0.6875 & 32 & 2 & 13.4 & $35-35-32$ & $114-40-09$ \\
\hline 339 & 34752 & 0.6875 & 33 & & & & \\
\hline 339 & 34759 & 0.8333 & 33 & 11 & 15.4 & $35-34-01$ & $114-39-36$ \\
\hline 339 & 34768 & 0.3632 & 23 & 6 & 13 & $35-42-01$ & $114-42-07$ \\
\hline 339 & 34779 & 0.6215 & 2 & 4 & 12.5 & $35-59-30$ & $114-44-22$ \\
\hline 339 & 34802 & 0.3160 & 33 & 8 & 14.8 & $35-34-25$ & $114-39-43$ \\
\hline 339 & 34807 & 0.6111 & 32 & 3 & 14.7 & $35-34-34$ & 114-39-38 \\
\hline 339 & 34808 & 0.6458 & 32 & 7 & 14.7 & $35-34-39$ & $114-39-59$ \\
\hline 339 & 34810 & 0.0938 & 32 & 11 & 13.8 & $35-34-36$ & $114-40-00$ \\
\hline 339 & 34823 & 0.2049 & 29 & 3 & 17.6 & $35-37-16$ & $114-39-34$ \\
\hline 339 & 34836 & 0.6597 & 26 & 3 & 16.9 & $35-39-08$ & $114-41-15$ \\
\hline 339 & 34852 & 0.2882 & 20 & 5 & 17.4 & $35-44-47$ & $114-41-44$ \\
\hline 339 & 34864 & 0.5243 & 20 & 11 & 19.1 & $35-44-33$ & $114-41-48$ \\
\hline 339 & 34877 & 0.6979 & 23 & 3 & 25.1 & $35-41-44$ & $114-41-17$ \\
\hline 339 & 34879 & 0.3472 & 22 & 5 & 24.4 & $35-43-29$ & $114-42-06$ \\
\hline 339 & 34892 & 0.4757 & 17 & 4 & 21 & $35-47-25$ & $114-41-58$ \\
\hline 339 & 34905 & 0.6806 & 20 & 6 & 23.4 & $35-44-49$ & $114-41-56$ \\
\hline 339 & 34907 & 0.2257 & 20 & 10 & 26.6 & $35-44-46$ & $114-41-46$ \\
\hline 339 & 34920 & 0.4931 & 23 & 10 & 18.8 & $35-42-00$ & $114-41-30$ \\
\hline 339 & 34934 & 0.6319 & 17 & 2 & 14.3 & $35-47-45$ & $114-42-08$ \\
\hline 339 & 34935 & 0.2431 & 10 & 3 & 13.9 & $35-53-05$ & $114-40-40$ \\
\hline 339 & 34949 & 0.4514 & 5 & 4 & 14 & $35-56-20$ & 114-43-31 \\
\hline 339 & 34963 & 0.2917 & 3 & 4 & 13.4 & $35-59-03$ & $114-44-37$ \\
\hline 339 & 34975 & 0.5972 & 23 & 4 & 16.1 & $35-42-02$ & $114-41-34$ \\
\hline 339 & 34989 & 0.5903 & 23 & 3 & 14.9 & $35-42-14$ & $114-41-53$ \\
\hline 339 & 34991 & 0.1910 & 23 & 11 & 14.9 & $35-41-52$ & $114-41-36$ \\
\hline 339 & 35004 & 0.6563 & 23 & 7 & 15.5 & $35-41-50$ & $114-41-31$ \\
\hline 339 & 35032 & 0.4132 & 23 & 10. & 13.3 & $35-41-54$ & $114-41-40$ \\
\hline 339 & 35046 & 0.7813 & 38 & 11 & 15.4 & $35-29-50$ & $114-40-51$ \\
\hline 339 & 35047 & 0.1076 & 37 & 10 & 14.5 & $35-31-21$ & $114-40-02$ \\
\hline
\end{tabular}




\begin{tabular}{|c|c|c|c|c|c|c|c|}
\hline LAKE MOH & AVE RAZOF & BACK SUC & KER TELEN & METRY STU & Nov 1 & 994 to July & 1997 \\
\hline Fish ID\# & DATE & TIME & WP & SHORE & TEMP C & LAT. & LONG. \\
\hline & (JULIAN) & (24-hr) & & $1-10=X 10 M$ & & & \\
\hline & & & & $11=.100 \mathrm{~m}$ & & & \\
\hline 339 & 35074 & 0.6840 & 32 & 7 & 12.5 & $35-34-38$ & $114-40-03$ \\
\hline 339 & 35088 & 0.6111 & 32 & 5 & 12.5 & $35-34-44$ & $114-40-12$ \\
\hline 339 & 35101 & 0.6667 & 33 & 2 & 12.5 & $35-33-59$ & $114-39-22$ \\
\hline 339 & 35108 & 0.6458 & 32 & 5 & & $35-34-24$ & $114-39-45$ \\
\hline 339 & 35116 & 0.5764 & 31 & 8 & 1295 & $35-35-25$ & $114-39-27$ \\
\hline 339 & 35144 & 0.5972 & 25 & 9 & 1319 & $35-40-04$ & $114-41-06$ \\
\hline 339 & 35152 & 0.3542 & 32 & 3 & 1305 & $35-34-40$ & $114-40-10$ \\
\hline 339 & 35173 & 0.6528 & 32 & 7 & 1196 & $35-34-30$ & $114-39-43$ \\
\hline 339 & 35185 & 0.6528 & 34 & 3 & 1210 & $35-33-07$ & $114-39-26$ \\
\hline 339 & 35535 & 0.471528 & 33 & 14.2 & 2 & 353421 & 1143940 \\
\hline 339 & 35537 & 0.519444 & 33 & 15.3 & & 353416 & 1143933 \\
\hline 339 & 35578 & 0.444444 & 24 & 18.9 & 10 & 354102 & 1144048 \\
\hline 339 & 35588 & 0.493056 & 19 & 18 & & 354532 & 1144148 \\
\hline 339 & 35598 & 0.423611 & 21 & 16.7 & 2 & 354359 & 1144144 \\
\hline 339 & 35605 & 0.458333 & 20 & 20.6 & & 354454 & 1144145 \\
\hline 339 & 35613 & 0.4375 & 19 & & & 354509 & 1144152 \\
\hline 339 & 35619 & 0.430556 & 19 & 20.8 & 1 & 354541 & 1144143 \\
\hline 339 & 35626 & 0.430556 & 17 & 21.3 & 4 & 354713 & 1144200 \\
\hline 348 & 34645 & 0.6528 & 36 & 1 & & $35-31-14$ & $114-39-25$ \\
\hline 348 & 34653 & 0.7743 & 50 & & & & \\
\hline 348 & 34662 & 0.2708 & 39 & & & & \\
\hline 348 & 34677 & 0.1389 & 39 & 9 & 12 & $35-28-34$ & $114-40-38$ \\
\hline 348 & 34708 & 0.8681 & 40 & 2 & 11.8 & $35-28-33$ & $114-40-44$ \\
\hline 348 & 34711 & 0.1944 & 39 & 3 & 11.6 & $35-28-29$ & $114-40-39$ \\
\hline 348 & 34724 & 0.4375 & 40 & & & & \\
\hline 348 & 34736 & 0.8819 & 40 & 2 & 12 & $35-28-32$ & $114-40-39$ \\
\hline 348 & 34744 & 0.5694 & 40 & 2 & 13 & $35-28-34$ & $114-40-46$ \\
\hline 348 & 34752 & 0.3931 & 40 & & & & \\
\hline 348 & 34758 & 0.8611 & 40 & & & $35-28-33$ & $114-40-42$ \\
\hline 348 & 34767 & 0.1410 & 40 & 2 & 14.3 & $35-28-30$ & $114-40-42$ \\
\hline 348 & 34772 & 0.6403 & 40 & & & $35-28-31$ & $114-40-44$ \\
\hline 348 & 34780 & 0.6563 & 40 & 5 & 16.5 & $35-28-35$ & $114-40-42$ \\
\hline 348 & 34787 & 0.4236 & 39 & 2 & & $35-28-34$ & $114-40-44$ \\
\hline 348 & 34792 & 0.7917 & 39 & 3 & 14.6 & $35-29-42$ & $114-40-22$ \\
\hline 348 & 34795 & 0.1424 & 34 & 3 & 15.2 & $35-33-16$ & $114-39-24$ \\
\hline 348 & 34802 & 0.3368 & 32 & 10 & 15.1 & $35-34-39$ & $114-40-04$ \\
\hline 348 & 34807 & 0.6076 & 32 & 4 & 14.9 & $35-34-39$ & $114-39-42$ \\
\hline 348 & 34808 & 0.6493 & 32 & 2 & 14.5 & $35-34-42$ & $114-39-50$ \\
\hline 348 & 34810 & 0.1076 & 32 & 3 & 14 & $35-34-40$ & $114-39-56$ \\
\hline 348 & 34821 & 0.7396 & 32 & 4 & 19.6 & $35-34-38$ & $114-39-39$ \\
\hline 348 & 34823 & 0.1285 & 32 & 3 & 19.5 & $35-34-41$ & $114-39-55$ \\
\hline 348 & 34836 & 0.7014 & 30 & 11 & 17.9 & $35-36-31$ & $114-39-12$ \\
\hline 348 & 34851 & 0.6111 & 22 & 3 & 18.8 & $35-42-36$ & $114-42-01$ \\
\hline 348 & 34852 & 0.2604 & 21 & 5 & 14.3 & $35-44-03$ & $114-41-44$ \\
\hline 348 & 34864 & 0.5521 & 22 & 4 & 20.8 & $35-42-42$ & $114-42-07$ \\
\hline 348 & 34877 & 0.6667 & 21 & 3 & 21.5 & $35-43-36$ & $114-41-47$ \\
\hline 348 & 34879 & 0.3264 & 22 & 7 & 21.2 & $35-43-14$ & $114-42-11$ \\
\hline 348 & 34890 & 0.7014 & 23 & 2 & 26.5 & $35-42-08$ & $114-41-47$ \\
\hline 348 & 34892 & 0.5486 & 23 & 6 & 24.9 & $35-42-01$ & $114-41-31$ \\
\hline 348 & 34893 & 0.1007 & 23 & 6 & 19.1 & $35-41-43$ & $114-41-14$ \\
\hline
\end{tabular}


LAKE MOHAAVE RAZORBACK SUCKER TELEMETRY STUPY Nov 1994 to July 1997

\begin{tabular}{|c|c|c|c|c|c|c|c|}
\hline Fish ID\# & DATE & TIME & WP & SHORE & TEMP C & LAT. & LONG. \\
\hline & (JULIAN) & $(24-h r)$ & & $1-10=X 10 M$ & & & \\
\hline & & & & $11=.100 \mathrm{~m}$ & & & \\
\hline 348 & 34905 & 0.7118 & 23 & 1 & 25.8 & $35-42-18$ & $114-41-57$ \\
\hline 348 & 34907 & 0.1944 & 23 & 2 & 22.1 & $35-42-10$ & $114-41-47$ \\
\hline 348 & 34920 & 0.4861 & 22 & 7 & 23 & $35-42-37$ & $114-42-04$ \\
\hline 348 & 34949 & 0.5313 & 22 & 4 & 24.5 & $35-42-27$ & $114-42-05$ \\
\hline 348 & 34963 & 0.1563 & 30 & 6 & 23.3 & $35-35-59$ & $114-39-11$ \\
\hline 348 & 34975 & 0.6354 & 30 & 5 & 19.2 & $35-35-55$ & $114-39-14$ \\
\hline 348 & 35003 & 0.6215 & 35 & 11 & 15.2 & $35-32-14$ & $114-39-21$ \\
\hline 348 & 35004 & 0.6007 & 35 & 9 & 18.6 & $35-32-14$ & $114-39-13$ \\
\hline 348 & 35006 & 0.1007 & 35 & 7 & 18.5 & $35-32-10$ & $114-39-07$ \\
\hline 348 & 35032 & 0.5451 & 39 & 11 & 16.2 & $35-28-33$ & $114-40-35$ \\
\hline 348 & 35044 & 0.8958 & 39 & 2 & 15.9 & $35-28-33$ & $114-40-42$ \\
\hline 348 & 35048 & 0.1146 & 39 & 4 & & $35-28-32$ & $114-40-41$ \\
\hline 348 & 35075 & 0.5278 & 39 & 2 & & $35-28-33$ & $114-40-43$ \\
\hline 348 & 35087 & 0.6944 & 39 & 3 & & $35-28-32$ & $114-40-44$ \\
\hline 348 & 35098 & 0.4792 & 39 & 2 & & $35-28-33$ & $114-40-47$ \\
\hline 348 & 35099 & 0.4375 & 39 & 3 & & $35-28-33$ & $114-40-47$ \\
\hline 348 & 35101 & 0.7465 & 39 & 2 & 12.7 & $35-28-30$ & $114-40-41$ \\
\hline 348 & 35116 & 0.4861 & 40 & 2 & & $35-28-34$ & $114-40-44$ \\
\hline 348 & 35130 & 0.5347 & 39 & 1 & 1473 & $35-28-31$ & $114-40-42$ \\
\hline 348 & 35137 & 0.8889 & 39 & 1 & & $35-28-32$ & $114-40-43$ \\
\hline 348 & 35144 & 0.6875 & 39 & 2 & & $35-28-32$ & $114-40-43$ \\
\hline 348 & 35173 & 0.6597 & 33 & 8 & 1225 & $35-34-14$ & $114-39-30$ \\
\hline 348 & 35185 & 0.5903 & 32 & 2 & & $35-34-40$ & $114-39-41$ \\
\hline 348 & 35534 & 0.423611 & 21 & 23.3 & 2 & 354308 & 1144203 \\
\hline 348 & 35535 & 0.464583 & 33 & 15.8 & & 353401 & 1143920 \\
\hline 348 & 35537 & & 32 & 17.2 & 2 & 353442 & 1143959 \\
\hline 348 & 35574 & 0.493056 & 22 & 18.9 & 1 & 354249 & 1144202 \\
\hline 348 & 35578 & 0.465278 & 23 & & 2 & 354208 & 1144146 \\
\hline 348 & 35588 & 0.486111 & 20 & 21.4 & & 354500 & 1144146 \\
\hline 348 & 35598 & 0.409722 & 22 & 21 & 1 & 354224 & 1144200 \\
\hline 348 & 35605 & 0.458333 & 20 & & 1 & 354445 & 1144142 \\
\hline 357 & 34645 & 0.6076 & 36 & 1 & & $35-31-14$ & $114-39-25$ \\
\hline 357 & 34653 & 0.5799 & 35 & 10 & & $35-31-56$ & $114-40-05$ \\
\hline 357 & 34662 & 0.8194 & 35 & & & & \\
\hline 357 & 34674 & 0.9028 & 35 & & & & \\
\hline 357 & 34688 & 0.7639 & 35 & & & & \\
\hline 357 & 34711 & 0.1736 & 36 & 11 & 12.2 & $35-31-58$ & $114-40-04$ \\
\hline 357 & 34724 & 0.7917 & 35 & & & & \\
\hline 357 & 34737 & 0.9792 & 36 & 11 & 13.1 & $35-31-53$ & $114-40-05$ \\
\hline 357 & 34752 & 0.7014 & 36 & 11 & & & \\
\hline 357 & 34768 & 0.1250 & 35 & 11 & 14.1 & $35-32-04$ & $114-39-47$ \\
\hline 357 & 34773 & 0.7917 & 35 & 11 & 14 & $35-32-01$ & $114-40-04$ \\
\hline 357 & 34780 & 0.6042 & 35 & 11 & 15 & $35-32-00$ & $114-40-08$ \\
\hline 357 & 34787 & 0.0556 & 35 & & & & \\
\hline 357 & 34793 & 0.8299 & 35 & 11 & 14.2 & $35-32-02$ & $114-40-05$ \\
\hline 357 & 34795 & 0.1076 & 35 & 11 & 14.1 & $35-32-06$ & $114-39-57$ \\
\hline 357 & 34821 & 0.7813 & 35 & 11 & 15.5 & $35-32-03$ & $114-40-05$ \\
\hline 357 & 34850 & 0.8299 & 35 & 11 & 16.3 & $35-32-03$ & $114-40-07$ \\
\hline 357 & 34852 & 0.1007 & 35 & 11 & 15.9 & $35-32-02$ & $114-40-09$ \\
\hline 357 & 34876 & 0.8264 & 35 & 11 & 16.8 & $35-32-00$ & $114-40-06$ \\
\hline
\end{tabular}




\begin{tabular}{|c|c|c|c|c|c|c|c|}
\hline LAKE MOH & AVE RAZOP & RBACK SUC & KER TELEN & METRY STU & Nov 1 & 994 to July & 1997 \\
\hline Fish ID\# & DATE & TIME & WP & SHORE & TEMP $\mathrm{C}$ & LAT. & LONG. \\
\hline & (JULIAN) & (24-hr) & & $1-10=X 10 \mathrm{M}$ & & & \\
\hline & & & & $11=.100 \mathrm{~m}$ & & & \\
\hline 357 & 34905 & 0.8125 & 35 & 11 & 18.6 & $35-32-02$ & $114-40-08$ \\
\hline 357 & 34961 & 0.6840 & 35 & 11 & 18.1 & $35-32-00$ & $114-40-07$ \\
\hline 357 & 34989 & 0.6667 & 35 & 11 & 17.8 & $35-31-59$ & $114-40-08$ \\
\hline 357 & 35047 & 0.1319 & 35 & 11 & 14.5 & $35-31-59$ & $114-40-07$ \\
\hline 366 & 34645 & 0.5729 & 36 & 1 & & $35-31-14$ & $114-39-25$ \\
\hline 366 & 34652 & 0.7708 & 31 & & 13.4 & $35-34-58$ & $114-39-32$ \\
\hline 366 & 34662 & 0.8194 & 35 & & & & \\
\hline 366 & 34673 & 0.8125 & 40 & & & $35-28-31$ & $114-40-39$ \\
\hline 366 & 34677 & 0.1319 & 39 & 9 & 12 & $35-28-34$ & $114-40-38$ \\
\hline 366 & 34688 & 0.7292 & 28 & & & & \\
\hline 366 & 34709 & 0.0417 & 36 & 5 & 11.9 & $35-31-29$ & $114-39-05$ \\
\hline 366 & 34711 & 0.1319 & 35 & 5 & 11.7 & $35-31-39$ & $114-39-09$ \\
\hline 366 & 34724 & 0.8042 & 36 & & & & \\
\hline 366 & 34737 & 0.9514 & 35 & & 13.6 & $35-32-41$ & $114-39-14$ \\
\hline 366 & 34744 & 0.6736 & 32 & 3 & 13.3 & $35-43-56$ & $114-40-15$ \\
\hline 366 & 34752 & 0.7014 & 36 & & & & \\
\hline 366 & 34768 & 0.2194 & 33 & 2 & 14.5 & $35-34-35$ & $114-39-37$ \\
\hline 366 & 34774 & 0.6528 & 31 & 10 & 15.7 & $35-34-36$ & $114-39-43$ \\
\hline 366 & 34793 & 0.7743 & 32 & 6 & 14.3 & $35-34-37$ & $114-39-39$ \\
\hline 366 & 34795 & 0.1806 & 32 & 11 & 15 & $35-34-33$ & $114-39-51$ \\
\hline 366 & 34802 & 0.3264 & 32 & 5 & 15.1 & $35-34-37$ & $114-39-42$ \\
\hline 366 & 34807 & 0.6111 & 32 & 3 & & $35-34-34$ & $114-39-38$ \\
\hline 366 & 34808 & 0.6528 & 32 & 5 & 14.8 & $35-34-36$ & $114-39-40$ \\
\hline 366 & 34810 & 0.1146 & 32 & 2 & 14.2 & $35-34-37$ & $114-39-40$ \\
\hline 366 & 34821 & 0.7396 & 32 & 2 & 20 & $35-34-38$ & $114-39-34$ \\
\hline 366 & 34823 & 0.1458 & 32 & 2 & 19.6 & $35-34-37$ & $114-39-35$ \\
\hline 366 & 34836 & 0.7917 & 32 & 1 & 20.8 & $35-34-35$ & $114-39-35$ \\
\hline 366 & 34852 & 0.1181 & 33 & 10 & 22.1 & $35-34-30$ & $114-39-49$ \\
\hline 366 & 34877 & 0.7743 & 33 & 10 & 17.2 & $35-34-13$ & $114-39-39$ \\
\hline 366 & 34879 & 0.2569 & 33 & 8 & 24.6 & $35-34-12$ & $114-39-38$ \\
\hline 366 & 34905 & 0.7292 & 25 & 3 & 20.1 & $35-40-16$ & $114-40-54$ \\
\hline 366 & 34907 & 0.1771 & 25 & 3 & 18.9 & $35-40-17$ & $114-40-58$ \\
\hline 366 & 34961 & 0.6111 & 23 & 11 & 16.8 & $35-41-55$ & $114-41-35$ \\
\hline 366 & 34963 & 0.1979 & 23 & 8 & 15.9 & $35-41-56$ & $114-41-32$ \\
\hline 366 & 34975 & 0.5903 & 23 & 11 & 15.2 & $35-41-53$ & $114-41-41$ \\
\hline 366 & 34989 & 0.6007 & 24 & 3 & 17 & $35-41-18$ & $114-40-50$ \\
\hline 366 & 35004 & 0.6111 & 34 & 5 & 18.1 & $35-33-20$ & $114-39-32$ \\
\hline 366 & 35030 & 0.6146 & 36 & 3 & 16.5 & $35-31-35$ & $114-39-11$ \\
\hline 366 & 35032 & 0.5208 & 36 & 5 & 15.8 & $35-31-36$ & $114-39-11$ \\
\hline 366 & 35044 & 0.8958 & 39 & 3 & & $35-28-33$ & $114-40-42$ \\
\hline 366 & 35048 & 0.1146 & 39 & 2 & & $35-28-32$ & $114-40-41$ \\
\hline 366 & 35075 & 0.5278 & 39 & 2 & & $35-28-33$ & $114-40-43$ \\
\hline 366 & 35087 & 0.6944 & 39 & 3 & & $35-28-32$ & $114-40-44$ \\
\hline 366 & 35101 & 0.6910 & 35 & 2 & 12.5 & $35-32-40$ & 114-39-09 \\
\hline 366 & 35108 & 0.6458 & 32 & 4 & & $35-34-44$ & $114-40-20$ \\
\hline 366 & 35116 & 0.5347 & 33 & 11 & 1362 & $35-34-02$ & $114-39-30$ \\
\hline 366 & 35130 & 0.4653 & 32 & 2 & 1510 & $35-34-41$ & $114-39-46$ \\
\hline 366 & 35144 & 0.6319 & 32 & 2 & 1314 & $35-34-36$ & 114-39-37 \\
\hline 366 & 35152 & 0.3889 & 32 & 2 & 1389 & $35-34-37$ & $114-39-36$ \\
\hline 366 & 35173 & 0.6528 & 32 & 1 & 1084 & $35-34-34$ & $114-39-34$ \\
\hline
\end{tabular}


LAKE MOHAVE RAZORBACK SUCKER TELEMETRY STUPY Nov 1994 to July 1997

\begin{tabular}{|c|c|c|c|c|c|c|c|}
\hline Fish ID\# & DATE & TIME & WP & SHORE & TEMP C & LAT. & LONG. \\
\hline & (JULIAN) & $(24-h r)$ & & $1-10=X 10 M$ & & & \\
\hline & & & & $11=.100 \mathrm{~m}$ & & & \\
\hline 366 & 35185 & 0.5903 & 32 & 1 & 1259 & $35-34-37$ & $114-39-38$ \\
\hline 366 & 35534 & 0.81875 & 39 & & & & \\
\hline 366 & 35571 & 0.784722 & 32 & & 2 & 353432 & 1143946 \\
\hline 366 & 35573 & 0.8125 & 32 & 20.6 & 1 & 353433 & 1143943 \\
\hline 366 & 35578 & 0.375 & 32 & & 1 & 353440 & 1143936 \\
\hline 366 & 35584 & 0.375 & 33 & & & 353431 & 1143942 \\
\hline 366 & 35588 & 0.388889 & 32 & & & 353435 & 1143945 \\
\hline 366 & 35597 & 0.569444 & 32 & & 1 & 353438 & 1143943 \\
\hline 366 & 35598 & 0.354167 & 32 & & 1 & 353439 & 1143933 \\
\hline 366 & 35605 & 0.361111 & 32 & & 1 & 353442 & 1144002 \\
\hline 366 & 35613 & 0.416667 & 21 & & 1 & 354308 & 1144203 \\
\hline 366 & 35619 & 0.409722 & 21 & & 5 & 354341 & 1144156 \\
\hline 375 & 34646 & 0.4306 & 39 & 1 & & $35-28-32$ & $114-40-48$ \\
\hline 375 & 34653 & 0.6736 & 41 & & 15.9 & $35-27-49$ & $114-38-58$ \\
\hline 375 & 34673 & 0.6604 & 63 & 9 & 12.5 & $35-20-06$ & $114-36-14$ \\
\hline 375 & 34677 & 0.3576 & 63 & 5 & 12 & $35-19-32$ & $114-35-54$ \\
\hline 375 & 34688 & 0.7569 & 34 & & & & \\
\hline 375 & 34709 & 0.9931 & 34 & 5 & 12.1 & $35-33-32$ & $114-40-04$ \\
\hline 375 & 34711 & 0.1389 & 35 & 5 & 11.8 & $35-31-41$ & $114-39-08$ \\
\hline 375 & 34724 & 0.7590 & 32 & & & & \\
\hline 375 & 34737 & 0.9028 & 34 & 11 & 13 & $35-32-40$ & $114-39-54$ \\
\hline 375 & 34752 & 0.7014 & 36 & & & & \\
\hline 375 & 34759 & 0.9097 & 36 & 2 & 14.7 & $35-31-23$ & $114-39-17$ \\
\hline 375 & 34768 & 0.2313 & 32 & 10 & 14.2 & $35-34-45$ & $114-40-17$ \\
\hline 375 & 34774 & 0.5521 & 32 & 3 & 14.3 & $35-34-39$ & $114-39-41$ \\
\hline 375 & 34779 & 0.7986 & 31 & 6 & 15.7 & $35-35-31$ & $114-39-16$ \\
\hline 375 & 34787 & 0.0139 & 32 & 2 & & $35-34-40$ & $114-40-09$ \\
\hline 375 & 34793 & 0.7639 & 32 & 9 & 13.7 & $35-34-41$ & $114-40-14$ \\
\hline 375 & 34795 & 0.2083 & 32 & 11 & 15 & $35-34-47$ & $11 \overline{14-40-23}$ \\
\hline 375 & 34808 & 0.6181 & 31 & 11 & 14 & $35-35-18$ & $114-39-51$ \\
\hline 375 & 34821 & 0.6771 & 28 & 7 & 18.4 & $35-37-42$ & $114-40-03$ \\
\hline 375 & 34836 & 0.6528 & 25 & 11 & 15.2 & $35-39-58$ & $114-41-22$ \\
\hline 375 & 34864 & 0.5868 & 23 & 11 & 15 & $35-41-51$ & $114-41-37$ \\
\hline 375 & 34877 & 0.6875 & 22 & 10 & 15.2 & $35-42-02$ & $114-41-46$ \\
\hline 375 & 34879 & 0.3125 & 23 & 10 & 14.9 & $35-42-04$ & $114-41-54$ \\
\hline 375 & 34892 & 0.6076 & 33 & 7 & 27.2 & $35-34-02$ & $114-39-30$ \\
\hline 375 & 34904 & 0.7674 & 53 & 11 & 17.2 & $35-25-29$ & $114-40-26$ \\
\hline 375 & 34908 & 0.1597 & 46 & 11 & 16.9 & $35-25-42$ & $114-40-26$ \\
\hline 375 & 34920 & 0.6701 & 53 & 11 & 17.4 & $35-25-37$ & $114-40-29$ \\
\hline 375 & 34932 & 0.7917 & 46 & 11 & 18.5 & $35-26-03$ & $114-40-42$ \\
\hline 375 & 34936 & 0.1979 & 46 & 11 & 19.5 & $35-25-59$ & $114-40-39$ \\
\hline 375 & 34947 & 0.6458 & 46 & 10 & 18.8 & $35-26-46$ & $114-40-34$ \\
\hline 375 & 34949 & 0.6771 & 53 & 11 & 18.8 & $35-25-20$ & $114-40-24$ \\
\hline 375 & 34960 & 0.7639 & 53 & 11 & 17.8 & $35-25-19$ & $114-40-28$ \\
\hline 375 & 34964 & 0.1458 & 46 & 11 & 17.7 & $35-26-21$ & $114-40-23$ \\
\hline 375 & 34975 & 0.7396 & 53 & 11 & 17.6 & $35-25-15$ & $114-40-25$ \\
\hline 375 & 34988 & 0.7431 & 54 & 11 & 20.5 & $35-24-37$ & $114-39-27$ \\
\hline 375 & 34992 & 0.1875 & 54 & 3 & 20.7 & $35-24-25$ & $114-39-27$ \\
\hline 375 & 35004 & 0.6215 & 33 & 6 & 18 & $35-34-13$ & $114-39-39$ \\
\hline 375 & 35032 & 0.5000 & 34 & 5 & 15.4 & $35-33-08$ & $114-40-03$ \\
\hline
\end{tabular}




\begin{tabular}{|c|c|c|c|c|c|c|c|}
\hline LAKE MOH & AVE RAZOF & RBACK SUC & KERR TELEN & METRY STU & Nov 1 & 994 to July & 1997 \\
\hline Fish ID\# & DATE & TIME & WP & SHORE & TEMP C & LAT. & LONG. \\
\hline & (JULIAN) & (24-hr) & & $1-10=X 10 M$ & & & \\
\hline & & & & $11=.100 \mathrm{~m}$ & & & \\
\hline 375 & 35046 & 0.7326 & 33 & 11 & 13.8 & $35-33-35$ & $114-39-41$ \\
\hline 375 & 35047 & 0.1667 & 34 & 11 & 13.8 & $35-33-37$ & $114-39-54$ \\
\hline 375 & 35074 & 0.6944 & 33 & 4 & 12.8 & $35-33-57$ & $114-40-08$ \\
\hline 375 & 35088 & 0.6007 & 31 & 4 & 12.5 & $35-35-20$ & $114-40-00$ \\
\hline 375 & 35101 & 0.6736 & 33 & 1 & 12.8 & $35-34-03$ & $114-39-26$ \\
\hline 375 & 35110 & 0.9375 & 54 & 2 & & $35-24-53$ & $114-40-22$ \\
\hline 375 & 35130 & 0.4861 & 33 & 6 & 1518 & $35-34-14$ & $114-39-30$ \\
\hline 375 & 35137 & 0.8194 & 32 & & & $35-34-39$ & $114-39-45$ \\
\hline 375 & 35144 & 0.6319 & 32 & 3 & 1418 & $35-34-39$ & $114-39-44$ \\
\hline 375 & 35152 & 0.3819 & 32 & 7 & 1409 & $35-34-38$ & $114-39-43$ \\
\hline 375 & 35173 & 0.6250 & 32 & 10 & 1240 & $35-34-38$ & $114-39-54$ \\
\hline 375 & 35185 & 0.6458 & 33 & 3 & 1327 & $35-34-09$ & $114-39-28$ \\
\hline 384 & 34646 & 0.4444 & 39 & 1 & & $35-28-32$ & $114-40-48$ \\
\hline 384 & 34653 & 0.7431 & & 9 & 16 & $35-24-46$ & $114-40-00$ \\
\hline 384 & 34662 & 0.2847 & 40 & & & & \\
\hline 384 & 34676 & 0.2431 & 31 & & 12.2 & $35-35-03$ & $114-39-43$ \\
\hline 384 & 34688 & 0.7500 & 33 & & & & \\
\hline 384 & 34709 & 0.0625 & 36 & 10 & 11.8 & $35-31-23$ & $114-39-23$ \\
\hline 384 & 34711 & 0.1458 & 36 & 5 & 11.7 & $35-31-22$ & $114-39-20$ \\
\hline 384 & 34724 & 0.8042 & 36 & & & & \\
\hline 384 & 34736 & 0.9076 & 39 & 3 & 12.3 & $35-29-43$ & $114-40-19$ \\
\hline 384 & 34752 & 0.6667 & 30 & & & & \\
\hline 384 & 34759 & 0.8681 & 34 & 11 & 15 & $35-33-20$ & 114-39-29 \\
\hline 384 & 34768 & 0.3028 & 31 & 11 & 14.3 & $35-35-13$ & $114-39-36$ \\
\hline 384 & 34774 & 0.5313 & 32 & 8 & 14.7 & $35-34-40$ & $114-40-02$ \\
\hline 384 & 34779 & 0.7604 & 29 & 4 & 15.4 & $35-37-17$ & 114-39-29 \\
\hline 384 & 34793 & 0.7674 & 32 & 11 & 14.1 & $35-34-37$ & 114-39-51 \\
\hline 384 & 34795 & 0.1840 & 32 & 8 & 15.1 & $35-34-43$ & $114-40-11$ \\
\hline 384 & 34802 & 0.5382 & 32 & 10 & 15.7 & $35-34-34$ & $114-39-50$ \\
\hline 384 & 34808 & 0.6389 & 32 & 10 & 14.3 & $35-34-39$ & $114-40-10$ \\
\hline 384 & 34821 & 0.6944 & 29 & 3 & 18.3 & $35-37-08$ & 114-39-27 \\
\hline 384 & 34877 & 0.6875 & 22 & 8 & 22.9 & $35-42-08$ & $114-41-52$ \\
\hline 384 & 34892 & 0.5938 & 32 & 8 & 20.5 & $35-35-05$ & $114-40-30$ \\
\hline 384 & 34905 & 0.7604 & 31 & 11 & 20.8 & $35-35-19$ & $114-39-50$ \\
\hline 384 & 34907 & 0.1111 & 32 & 11 & 18.2 & $35-34-56$ & $114-40-29$ \\
\hline 384 & 34920 & 0.6458 & 46 & 11 & 18.5 & $35-26-29$ & $114-40-34$ \\
\hline 384 & 34932 & 0.7569 & 53 & 11 & 19.2 & $35-25-26$ & $114-40-18$ \\
\hline 384 & 34936 & 0.1806 & 46 & 11 & 20.4 & $35-26-34$ & $114-40-38$ \\
\hline 384 & 34949 & 0.6597 & 46 & 11 & 21.1 & $35-26-22$ & $114-40-34$ \\
\hline 384 & 34964 & 0.2188 & 46 & 11 & 22.4 & $35-26-13$ & $114-40-37$ \\
\hline 384 & 34975 & 0.7222 & 46 & 11 & 23.3 & $35-25-52$ & $114-40-12$ \\
\hline 384 & 34991 & 0.1042 & 36 & 3 & 20.5 & $35-31-27$ & 114-39-13 \\
\hline 384 & 35004 & 0.5590 & 41 & 11 & & $35-27-45$ & 114-39-43 \\
\hline 384 & 35032 & 0.4549 & 32 & 11 & 15.1 & 35-34-09 & $114-40-07$ \\
\hline 384 & 35044 & 0.8056 & 54 & 3 & 15.9 & $35-24-47$ & $114-40-10$ \\
\hline 384 & 35048 & 0.1146 & 39 & 2 & & $35-28-32$ & $114-40-41$ \\
\hline 384 & 35075 & 0.5069 & 53 & 11 & 12.3 & $35-25-19$ & $114-40-27$ \\
\hline 384 & 35088 & 0.6597 & 36 & 7 & 12.1 & $35-31-27$ & $114-39-19$ \\
\hline 384 & 35101 & 0.7153 & 36 & 2 & 13.7 & $35-31-23$ & $114-39-20$ \\
\hline 447 & 34646 & 0.4583 & 39 & 1 & & $35-28-32$ & $114-40-48$ \\
\hline
\end{tabular}




\begin{tabular}{|c|c|c|c|c|c|c|c|}
\hline LAKE MOH & AVE RAZOF & RBACK SUC & KER TELEN & AETRY STUR & Nov 1 & 994 to July & 1997 \\
\hline Fish ID\# & DATE & TIME & WP & SHORE & TEMP C & LAT. & LONG. \\
\hline & (JULIAN) & (24-hr) & & $1-10=X 10 M$ & & & \\
\hline & & & & $11=.100 \mathrm{~m}$ & & & \\
\hline 447 & 34662 & 0.7083 & 8 & & 13.3 & & \\
\hline 447 & 34688 & 0.6042 & 3 & & & & \\
\hline 447 & 34709 & 0.0278 & 35 & 5 & 11.8 & $35-31-59$ & $114-39-05$ \\
\hline 447 & 34724 & 0.8042 & 36 & & & & \\
\hline 447 & 34768 & 0.3222 & 29 & 1 & 13.6 & $35-37-07$ & $114-39-20$ \\
\hline 447 & 34773 & 0.7361 & 30 & 5 & 14.7 & $35-35-52$ & $114-39-11$ \\
\hline 447 & 34780 & 0.5590 & 33 & 11 & 15.5 & $35-34-02$ & $114-39-28$ \\
\hline 447 & 34786 & 0.9722 & 31 & 2 & & $35-35-04$ & $114-39-52$ \\
\hline 447 & 34802 & 0.5313 & 31 & 5 & 15.1 & $35-35-15$ & $114-40-14$ \\
\hline 447 & 34808 & 0.6875 & 33 & 11 & 14.5 & $35-34-03$ & $114-39-36$ \\
\hline 447 & 34820 & 0.8125 & 40 & 3 & 17.1 & $35-28-35$ & $114-40-43$ \\
\hline 447 & 34824 & 0.1146 & 40 & 2 & 18.6 & $35-28-31$ & $114-40-42$ \\
\hline 456 & 34646 & 0.4375 & 39 & 1 & & $35-28-32$ & $114-40-48$ \\
\hline 456 & 34653 & 0.6951 & 45 & & 16 & $35-26-49$ & $114-40-31$ \\
\hline 456 & 34662 & 0.3125 & 46 & & & & \\
\hline 456 & 34673 & 0.7986 & 40 & 9 & 12.5 & $35-27-53$ & $114-40-20$ \\
\hline 456 & 34677 & 0.2188 & 45 & 9 & 12 & $35-27-21$ & $114-40-27$ \\
\hline 456 & 34688 & 0.3750 & 53 & & & & \\
\hline 456 & 34708 & 0.7569 & 54 & 3 & 11.6 & $35-24-57$ & $114-40-21$ \\
\hline 456 & 34711 & 0.2778 & 45 & 5 & 11.3 & $35-26-30$ & $114-40-46$ \\
\hline 456 & 34724 & 0.4028 & 46 & & & & \\
\hline 456 & 34736 & 0.8194 & 46 & 11 & 13.2 & $35-26-13$ & $114-40-41$ \\
\hline 456 & 34745 & 0.3333 & 45 & 4 & 12.1 & $35-27-11$ & $114-40-36$ \\
\hline 456 & 34752 & 0.3931 & 40 & & & & \\
\hline 456 & 34767 & 0.1076 & 37 & 3 & 14.6 & $35-30-30$ & $114-40-54$ \\
\hline 465 & 34646 & 0.4722 & 39 & 1 & & $35-28-32$ & $114-40-48$ \\
\hline 465 & 34652 & 0.8250 & 35 & & & & \\
\hline 465 & 34653 & 0.5917 & 35 & & 13.9 & $35-31-41$ & $114-39-26$ \\
\hline 465 & 34662 & 0.8194 & 35 & & & & \\
\hline 465 & 34674 & 0.9306 & 36 & 9 & 12.1 & $35-31-35$ & $114-39-12$ \\
\hline 465 & 34676 & 0.1458 & 36 & 9 & & $35-31-35$ & $114-39-13$ \\
\hline 465 & 34688 & 0.7778 & 36 & & & & \\
\hline 465 & 34709 & 0.9653 & 34 & 11 & 12 & $35-33-49$ & 114-39-59 \\
\hline 465 & 34712 & 0.1250 & 34 & 10 & 12.1 & $35-33-41$ & $114-40-00$ \\
\hline 465 & 34724 & 0.7590 & 32 & & & & \\
\hline 465 & 34737 & 0.8958 & 33 & & 13.2 & $35-34-07$ & 114-39-35 \\
\hline 465 & 34744 & 0.6299 & 36 & 3 & 13.2 & $35-31-29$ & $114-38-50$ \\
\hline 465 & 34752 & 0.3382 & 54 & & & & \\
\hline 465 & 34758 & 0.8611 & 40 & & & $35-28-33$ & $114-40-42$ \\
\hline 465 & 34768 & 0.2396 & 32 & 11 & 14 & $35-34-27$ & $114-40-20$ \\
\hline 465 & 34774 & 0.5486 & 32 & 5 & 14 & $35-34-36$ & $114-39-36$ \\
\hline 465 & 34780 & 0.5472 & 32 & 8 & 15.5 & $35-34-38$ & $114-40-12$ \\
\hline 465 & 34787 & 0.0556 & 35 & & & & \\
\hline 465 & 34795 & 0.0938 & 36 & 5 & 13.7 & $35-31-42$ & $114-39-10$ \\
\hline 465 & 34801 & 0.7535 & 36 & 10 & 14.3 & $35-31-37$ & $114-39-10$ \\
\hline 465 & 34808 & 0.6979 & 35 & 11 & 14.4 & $35-32-01$ & $114-39-11$ \\
\hline 465 & 34820 & 0.8125 & 40 & 3 & 16.7 & $35-28-35$ & $114-40-43$ \\
\hline 465 & 34824 & 0.1111 & 40 & 2 & 18.7 & $35-28-28$ & $114-40-46$ \\
\hline 465 & 34853 & 0.1840 & 49 & 3 & 21.8 & $35-26-45$ & $114-37-25$ \\
\hline 465 & 34880 & 0.2361 & 63 & 8 & 24.4 & $35-19-43$ & $114-36-06$ \\
\hline
\end{tabular}




\begin{tabular}{|c|c|c|c|c|c|c|c|}
\hline LAKE MOH & AVE RAZOF & RBACK SUC & KER TELEM & AETRY STU & Nov 1 & 994 to July & 1997 \\
\hline Fish ID\# & DATE & TIME & WP & SHORE & TEMP $\mathrm{C}$ & LAT. & LONG. \\
\hline & (JULIAN) & (24-hr) & & $1-10=X 10 \mathrm{M}$ & & & \\
\hline & & & & $11=.100 \mathrm{~m}$ & & & \\
\hline 465 & 34892 & 0.7188 & 53 & 11 & 21 & $35-25-19$ & $114-40-29$ \\
\hline 465 & 34904 & 0.8160 & 46 & 11 & 18.9 & $35-26-20$ & $114-40-36$ \\
\hline 465 & 34908 & 0.1389 & 46 & 11 & 19.2 & $35-26-02$ & $114-40-46$ \\
\hline 465 & 34920 & 0.6563 & 46 & 11 & 17.9 & $35-25-54$ & $114-40-36$ \\
\hline 465 & 34932 & 0.7639 & 53 & 8 & 22.1 & $35-25-11$ & $114-40-34$ \\
\hline 465 & 34936 & 0.1667 & 46 & 11 & 19 & $35-26-15$ & $114-40-35$ \\
\hline 465 & 34949 & 0.6875 & 54 & 11 & 19.2 & $35-24-47$ & $114-40-00$ \\
\hline 465 & 34960 & 0.7674 & 53 & 11 & 18.8 & $35-25-26$ & $114-40-34$ \\
\hline 465 & 34975 & 0.7951 & 41 & 11 & 17.7 & $35-27-47$ & $114-39-38$ \\
\hline 465 & 34988 & 0.8438 & 36 & 6 & 20.6 & $35-31-36$ & $114-39-10$ \\
\hline 465 & 34991 & 0.1111 & 36 & 3 & 20.7 & $35-31-40$ & $114-39-11$ \\
\hline 465 & 35004 & 0.4736 & 54 & 11 & 19.1 & $35-24-37$ & $114-39-39$ \\
\hline 465 & 35016 & 0.8264 & 53 & 2 & 18.1 & $35-25-26$ & $114-40-46$ \\
\hline 465 & 35032 & 0.5521 & 39 & 11 & 16.3 & $35-28-21$ & $114-40-30$ \\
\hline 465 & 35046 & 0.7674 & 36 & 2 & 14 & $35-31-26$ & $114-39-16$ \\
\hline 465 & 35047 & 0.1215 & 36 & 6 & 13.9 & $35-31-39$ & $114-39-11$ \\
\hline 465 & 35075 & 0.5278 & 39 & 2 & & $35-28-33$ & $114-40-43$ \\
\hline 465 & 35088 & 0.6285 & 33 & 8 & 12.4 & $35-34-01$ & $114-39-32$ \\
\hline 465 & 35098 & 0.6563 & 35 & 5 & 12 & $35-32-43$ & $114-39-29$ \\
\hline 465 & 35101 & 0.7049 & 35 & 5 & 12.5 & $35-32-39$ & $114-39-16$ \\
\hline 465 & 35108 & 0.6806 & 34 & 5 & & $35-32-21$ & $114-39-20$ \\
\hline 465 & 35116 & 0.5417 & 32 & 10 & 1290 & $35-34-27$ & $114-39-44$ \\
\hline 465 & 35130 & 0.4722 & 33 & 11 & 1414 & $35-33-59$ & $114-39-33$ \\
\hline 465 & 35137 & 0.8194 & 32 & 2 & 1315 & $35-34-37$ & $114-39-42$ \\
\hline 465 & 35144 & 0.6597 & 34 & 5 & 1283 & $35-32-42$ & $114-39-19$ \\
\hline 465 & 35152 & 0.3750 & 32 & 11 & 1319 & $35-34-34$ & $114-39-52$ \\
\hline 465 & 35173 & 0.7153 & 39 & 3 & 1208 & $35-28-33$ & $114-40-43$ \\
\hline 465 & 35185 & 0.5764 & 32 & 2 & 1271 & $35-34-41$ & $114-39-44$ \\
\hline 465 & 35535 & 0.457639 & 32 & 13.8 & & 353254 & 1143925 \\
\hline 465 & 35537 & 0.520833 & 33 & & & 353401 & 1143931 \\
\hline 465 & 35571 & 0.902778 & 40 & & & & \\
\hline 465 & 35575 & 0.395833 & 49 & & 8 & 352612 & 1143708 \\
\hline 465 & 35577 & 0.875 & 57 & & 7 & 352450 & 1143638 \\
\hline 465 & 35595 & 0.895833 & 62 & 22.3 & 1 & 352024 & 1143632 \\
\hline 465 & 35604 & 0.958333 & 41 & & & & \\
\hline 555 & 34645 & 0.6840 & 36 & 1 & & $35-31-14$ & $114-39-25$ \\
\hline 555 & 34652 & 0.7083 & 22 & & 13.5 & $35-43-03$ & $114-42-18$ \\
\hline 555 & 34662 & 0.7778 & 24 & & 13.1 & & \\
\hline 555 & 34674 & 0.8056 & 25 & 1 & 13.2 & $35-40-31$ & $114-40-56$ \\
\hline 555 & 34676 & 0.3021 & 25 & 3 & 13 & $35-40-27$ & $114-40-52$ \\
\hline 555 & 34688 & 0.7083 & 24 & & & & \\
\hline 555 & 34709 & 0.8403 & 25 & 3 & 12.3 & $35-40-30$ & $114-40-55$ \\
\hline 555 & 34712 & 0.2361 & 25 & 3 & 12.3 & $35-40-27$ & $114-40-54$ \\
\hline 555 & 34724 & 0.7153 & 25 & & & & \\
\hline 555 & 34737 & 0.8333 & 25 & 2 & 13 & $35-40-30$ & $114-40-53$ \\
\hline 555 & 34752 & 0.6389 & 25 & & & & \\
\hline 555 & 34759 & 0.7431 & 25 & 7 & 13.6 & $35-40-28$ & $114-40-53$ \\
\hline 555 & 34768 & 0.3493 & 25 & 8 & 13.2 & $35-40-31$ & $114-40-56$ \\
\hline 555 & 34773 & 0.6875 & 25 & & 13.1 & $35-40-27$ & $114-40-59$ \\
\hline 555 & 34779 & 0.7292 & 25 & 3 & 13.8 & $35-40-28$ & $114-40-57$ \\
\hline
\end{tabular}


LAKE MOHAVE RAZORBACK SUCKER TELEMIETRY STUDY Nov 1994 to July 1997

\begin{tabular}{|c|c|c|c|c|c|c|c|}
\hline Fish ID\# & DATE & TIME & WP & SHORE & TEMP C & LAT. & LONG. \\
\hline & (JULIAN) & $(24-h r)$ & & $1-10=X 10 M$ & & & \\
\hline & & & & $11=.100 \mathrm{~m}$ & & & \\
\hline 555 & 34786 & 0.9097 & 25 & 3 & 13.1 & $35-40-27$ & $114-40-58$ \\
\hline 555 & 34793 & 0.7118 & 25 & 5 & 13.4 & $35-40-31$ & $114-40-56$ \\
\hline 555 & 34795 & 0.2500 & 25 & 5 & 13.6 & $35-40-28$ & $114-40-56$ \\
\hline 555 & 34821 & 0.6597 & 25 & 4 & 14.8 & $35-40-26$ & $114-40-56$ \\
\hline 555 & 34851 & 0.6319 & 25 & 4 & 14.7 & $35-40-25$ & $114-40-56$ \\
\hline 555 & 34852 & 0.2188 & 25 & 4 & 14.7 & $35-40-25$ & $114-40-58$ \\
\hline 555 & 34877 & 0.7118 & 25 & 3 & 15.3 & $35-40-29$ & $114-40-57$ \\
\hline 555 & 34905 & 0.7257 & 25 & 2 & 17.1 & $35-40-26$ & $114-40-56$ \\
\hline 555 & 34961 & 0.6181 & 25 & 2 & 17 & $35-40-28$ & $114-40-56$ \\
\hline 555 & 34989 & 0.6076 & 25 & 2 & 15.2 & $35-40-29$ & $114-40-56$ \\
\hline 555 & 35046 & 0.6806 & 25 & 2 & 14 & $35-40-29$ & $114-40-55$ \\
\hline 2228 & 34645 & 0.6701 & 36 & 1 & & $35-31-14$ & $114-39-25$ \\
\hline 2228 & 34652 & 0.8125 & 34 & & 14 & & \\
\hline 2228 & 34653 & 0.5764 & 35 & 11 & 14 & $35-31-45$ & $114-39-51$ \\
\hline 2228 & 34662 & 0.8333 & 36 & & & & \\
\hline 2228 & 34674 & 0.9306 & 36 & 9 & 12.1 & $35-31-35$ & $114-39-12$ \\
\hline 2228 & 34676 & 0.1458 & 36 & 9 & & $35-31-35$ & $114-39-13$ \\
\hline 2228 & 34688 & 0.7799 & 36 & & & & \\
\hline 2228 & 34709 & 0.0417 & 36 & & 11.8 & $35-31-23$ & $114-39-15$ \\
\hline 2228 & 34711 & 0.1458 & 35 & 5 & 11.6 & $35-31-30$ & $114-39-15$ \\
\hline 2228 & 34724 & 0.7222 & 27 & & & & \\
\hline 2228 & 34737 & 0.7153 & 7 & 2 & 12.7 & $35-55-01$ & $114-42-28$ \\
\hline 2228 & 34752 & 0.5694 & 7 & 2 & 12.9 & $35-54-55$ & $114-42-26$ \\
\hline 2228 & 34759 & 0.6250 & 7 & 1 & 12.7 & $35-55-00$ & $114-42-35$ \\
\hline 2228 & 34768 & 0.4438 & 7 & 1 & 12.5 & $35-54-57$ & $114-42-34$ \\
\hline 2228 & 34773 & 0.5361 & 7 & 1 & 12.8 & $35-54-55$ & $114-42-31$ \\
\hline 2228 & 34779 & 0.7396 & 25 & 3 & 14.4 & $35-39-47$ & $114-41-10$ \\
\hline 2228 & 34780 & 0.6146 & 36 & 8 & 15.8 & $35-31-29$ & $114-39-18$ \\
\hline 2228 & 34787 & 0.0451 & 33 & & 13.2 & $35-35-54$ & $114-39-41$ \\
\hline 2228 & 34793 & 0.7882 & 33 & 11 & 15.4 & $35-34-04$ & $114-39-33$ \\
\hline 2228 & 34795 & 0.1597 & 33 & 11 & 14.9 & $34-07$ & $114-39-32$ \\
\hline 2228 & 34802 & 0.3299 & 32 & 4 & 15.1 & $35-34-43$ & $114-39-52$ \\
\hline 2228 & 34808 & 0.6458 & 32 & 3 & 14.8 & $35-34-41$ & $114-39-57$ \\
\hline 2228 & 34821 & 0.7431 & 32 & 7 & 19.3 & $35-34-38$ & $114-39-45$ \\
\hline 2228 & 34823 & 0.2257 & 27 & 2 & 18 & $35-38-44$ & $114-40-35$ \\
\hline 2228 & 34836 & 0.6875 & 29 & 3 & 18.3 & $35-37-05$ & $114-39-22$ \\
\hline 2228 & 34852 & 0.2500 & 22 & 5 & 18 & $35-42-53$ & $114-42-25$ \\
\hline 2228 & 34864 & 0.5347 & 21 & 11 & 20.9 & $35-43-42$ & $114-41-57$ \\
\hline 2228 & 34879 & 0.3611 & 20 & 9 & 22.7 & $35-44-44$ & $114-41-47$ \\
\hline 2228 & 34905 & 0.6736 & 19 & 4 & 22.6 & $35-45-39$ & $114-41-43$ \\
\hline 2228 & 34920 & 0.4444 & 14 & 5 & 14.1 & $35-50-08$ & $114-41-49$ \\
\hline 2228 & 34934 & 0.6042 & 12 & 5 & 14.3 & $35-51-37$ & $114-41-22$ \\
\hline 2228 & 34935 & 0.2014 & 12 & 10 & 14 & $35-51-36$ & $114-41-20$ \\
\hline 2228 & 34949 & 0.4861 & 12 & 6 & 14.2 & $35-51-36$ & $114-41-22$ \\
\hline 2228 & 34961 & 0.5486 & 12 & 7 & 14.6 & $35-51-37$ & $114-41-21$ \\
\hline 2228 & 34963 & 0.2465 & 12 & 6 & 14.2 & $35-51-39$ & $114-41-19$ \\
\hline 2228 & 34975 & 0.5382 & 12 & 4 & 13.8 & $35-51-40$ & $114-41-18$ \\
\hline 2228 & 34989 & 0.5382 & 12 & 7 & 14.3 & $35-51-39$ & $114-41-21$ \\
\hline 2228 & 35130 & 0.4306 & 29 & 1 & 1517 & $35-36-47$ & $114-38-59$ \\
\hline 2228 & 35137 & 0.8194 & 32 & 1 & 1443 & $35-34-39$ & $114-39-45$ \\
\hline
\end{tabular}




\begin{tabular}{|c|c|c|c|c|c|c|c|}
\hline LAKE MOHA & AVVE RAZOF & RBACK SUC & KER TELEI & METRY STU & Nov $1 \mathrm{~s}$ & 994 to July & 997 \\
\hline Fish ID\# & DATE & TIME & WP & SHORE & TEMP C & LAT. & LONG. \\
\hline & (JULIAN) & $(24-h r)$ & & $1-10=X 10 M$ & & & \\
\hline & & & & $11=.100 \mathrm{~m}$ & & & \\
\hline 2228 & 35144 & 0.6319 & 32 & 4 & 1452 & $35-34-40$ & $114-39-53$ \\
\hline 2228 & 35152 & 0.3681 & 32 & 2 & 1439 & $35-34-42$ & $114-39-53$ \\
\hline 2228 & 35173 & 0.6250 & 32 & 4 & 1277 & $35-34-39$ & $114-39-49$ \\
\hline 2228 & 35185 & 0.5903 & 32 & 2 & & $35-34-40$ & $114-39-41$ \\
\hline 2237 & 34645 & 0.6424 & 36 & 1 & & $35-31-14$ & $114-39-25$ \\
\hline 2237 & 34653 & 0.7083 & 53 & & 16.2 & $35-25-11$ & $114-40-27$ \\
\hline 2237 & 34662 & 0.8194 & 35 & & & & \\
\hline 2237 & 34674 & 0.9028 & 36 & 2 & 12 & $35-31-22$ & $114-39-18$ \\
\hline 2237 & 34676 & 0.1667 & 35 & 9 & 12.1 & $35-32-38$ & $114-39-20$ \\
\hline 2237 & 34688 & 0.7639 & 35 & & & & \\
\hline 2237 & 34711 & 0.1181 & 35 & 11 & 11.9 & $35-31-52$ & 114-39-09 \\
\hline 2237 & 34724 & 0.7431 & 31 & & & & \\
\hline 2237 & 34737 & 0.8889 & 31 & 3 & 13 & $35-35-01$ & $114-39-29$ \\
\hline 2237 & 34744 & 0.7125 & 31 & 4 & 13.3 & $35-34-58$ & $114-39-31$ \\
\hline 2237 & 34752 & 0.6729 & 31 & & & & \\
\hline 2237 & 34759 & 0.7917 & 31 & 5 & 14.6 & $35-34-58$ & $114-39-34$ \\
\hline 2237 & 34768 & 0.2569 & 31 & 10 & 13.7 & $35-34-57$ & $114-39-35$ \\
\hline 2237 & 34773 & 0.7500 & 31 & 10 & 14.2 & $35-35-00$ & 114-39-36 \\
\hline 2237 & 34779 & 0.8090 & 31 & 6 & 15 & $35-34-54$ & $114-39-32$ \\
\hline 2237 & 34786 & 0.9722 & 31 & & & $35-34-57$ & $114-39-36$ \\
\hline 2237 & 34793 & 0.7500 & 31 & 10 & 14.2 & $35-34-58$ & $114-39-34$ \\
\hline 2237 & 34795 & 0.2222 & 31 & 10 & 14.3 & $35-34-52$ & $114-39-35$ \\
\hline 2237 & 34821 & 0.7153 & 31 & 8 & 17 & $35-34-58$ & $114-39-31$ \\
\hline 2237 & 34851 & 0.6875 & 31 & 10 & 18.2 & $35-35-00$ & 114-39-37 \\
\hline 2237 & 34852 & 0.1632 & 31 & 10 & 19.8 & $35-34-56$ & $114-39-38$ \\
\hline 2237 & 34877 & 0.7431 & 31 & 5 & 22.2 & $35-34-58$ & $114-39-34$ \\
\hline 2237 & 34905 & 0.7743 & 31 & 9 & 27 & $35-34-57$ & $114-39-35$ \\
\hline 2237 & 34961 & 0.6528 & 31 & 7 & 27.3 & $35-34-57$ & $114-39-35$ \\
\hline 2237 & 34989 & 0.6424 & 31 & 6 & 21 & $35-34-56$ & $114-39-34$ \\
\hline 2237 & 35046 & 0.7153 & 31 & 6 & 13.9 & $35-34-56$ & $114-39-34$ \\
\hline 2246 & 34661 & 0.4965 & 6 & 1 & & $35-55-57$ & $114-42-38$ \\
\hline 2246 & 34662 & 0.6875 & 6 & 9 & & $35-56-03$ & $114-42-51$ \\
\hline 2246 & 34674 & 0.7188 & 11 & & 13.3 & $35-51-50$ & $114-40-33$ \\
\hline 2246 & 34688 & 0.6458 & 11 & & & & \\
\hline 2246 & 34712 & 0.3403 & 11 & 2 & 12.7 & $35-51-48$ & $114-40-32$ \\
\hline 2246 & 34724 & 0.6597 & 11 & & & & \\
\hline 2246 & 34737 & 0.7500 & 11 & 2 & 12.7 & $35-51-47$ & $114-40-34$ \\
\hline 2246 & 34752 & 0.5903 & 11 & & & & \\
\hline 2246 & 34759 & 0.6597 & 11 & 1 & 12.8 & $35-51-47$ & $114-40-34$ \\
\hline 2246 & 34768 & 0.4215 & 11 & 1 & 12.5 & $35-51-47$ & $114-40-34$ \\
\hline 2246 & 34773 & 0.5757 & 11 & 2 & 12.9 & $35-51-47$ & $114-40-33$ \\
\hline 2246 & 34779 & 0.6667 & 11 & 1 & 12.8 & $35-51-47$ & $114-40-35$ \\
\hline 2246 & 34786 & 0.8299 & 11 & & & $35-51-47$ & $114-40-34$ \\
\hline 2246 & 34793 & 0.6458 & 11 & 1 & 13 & $35-51-49$ & $114-40-35$ \\
\hline 2246 & 34795 & 0.3021 & 11 & 1 & 12.7 & $35-51-46$ & $114-40-34$ \\
\hline 2246 & 34821 & 0.5833 & 11 & 2 & 13.5 & $35-51-47$ & $114-40-32$ \\
\hline 2246 & 34851 & 0.5278 & 11 & 1 & 13.6 & $35-51-48$ & $114-40-32$ \\
\hline 2246 & 34852 & 0.3438 & 11 & 1 & 13.7 & $35-51-49$ & $114-40-35$ \\
\hline 2246 & 34877 & 0.5972 & 11 & 1 & 14.1 & $35-51-48$ & $114-40-34$ \\
\hline 2246 & 34905 & 0.6389 & 11 & 1 & 14.2 & $35-51-45$ & $114-40-33$ \\
\hline
\end{tabular}




\begin{tabular}{|c|c|c|c|c|c|c|c|c|}
\hline LAKE MOH & AVE RAZOF & BACK SUC & KER TELEN & METRY STU & DY & Vov 1 & 994 to July & 1997 \\
\hline Fish ID\# & DATE & TIME & WP & SHORE & TEMP & $C$ & LAT. & LONG. \\
\hline & (JULIAN) & $(24-h r)$ & & $1-10=X 10 M$ & & & & \\
\hline & & & & $11=.100 \mathrm{~m}$ & & & & \\
\hline 2246 & 34961 & 0.5417 & 11 & 2 & & 14.5 & $35-51-48$ & $114-40-34$ \\
\hline 2246 & 34989 & 0.5313 & 11 & 1 & & 14.4 & $35-51-47$ & $114-40-34$ \\
\hline 2246 & 35046 & 0.6215 & 11 & 1 & & 13.9 & $35-51-49$ & $114-40-36$ \\
\hline 2246 & 35088 & 0.5104 & 11 & 2 & & 13.4 & $35-51-46$ & $114-40-35$ \\
\hline 2255 & 34661 & 0.5833 & 18 & 1 & & & $35-46-38$ & $114-41-52$ \\
\hline 2255 & 34662 & 0.6528 & 18 & & & 14.1 & & \\
\hline 2255 & 34676 & 0.3458 & 18 & 2 & & 13.1 & $35-46-36$ & $114-41-54$ \\
\hline 2255 & 34709 & 0.7569 & 18 & 2 & & 12.5 & $35-46-40$ & $114-41-52$ \\
\hline 2255 & 34712 & 0.2917 & 18 & 3 & & 12.7 & $35-46-37$ & $114-41-53$ \\
\hline 2255 & 34722 & 0.6090 & 18 & 2 & & 12.3 & $35-46-37$ & $114-41-52$ \\
\hline 2255 & 34726 & 0.1250 & 18 & 2 & & 12.5 & $35-46-38$ & $114-41-54$ \\
\hline 2255 & 34737 & 0.7986 & 18 & 2 & & 12.9 & $35-46-36$ & $114-41-53$ \\
\hline 2255 & 34752 & 0.6111 & 18 & & & & & \\
\hline 2255 & 34759 & 0.6875 & 18 & 1 & & 13 & $35-46-38$ & $114-41-52$ \\
\hline 2255 & 34768 & 0.3924 & 18 & 2 & & 12.8 & $35-46-39$ & $114-41-55$ \\
\hline 2255 & 34773 & 0.6299 & 18 & 2 & & 13.3 & $35-46-37$ & $114-41-58$ \\
\hline 2255 & 34779 & 0.6944 & 18 & 2 & & 13.2 & $35-46-39$ & $114-41-35$ \\
\hline 2255 & 34793 & 0.6806 & 18 & 2 & & 13.4 & $35-2$ & $114-41-54$ \\
\hline 2255 & 34795 & 0.2743 & 18 & 2 & & 13.1 & $35-46-39$ & $114-41-56$ \\
\hline 2255 & 34821 & 0.6285 & 18 & 2 & & 14.1 & $35-46-37$ & $114-41-53$ \\
\hline 2255 & 34851 & 0.5590 & 18 & 2 & & 14.3 & $35-4$ & $114-41-55$ \\
\hline 2255 & 34852 & 0.3056 & 18 & 2 & & 14 & $35-46-38$ & $114-41-55$ \\
\hline 2255 & 34877 & 0.6285 & 18 & 2 & & 14.7 & $35-46-38$ & $114-41-55$ \\
\hline 2255 & 34905 & 0.6667 & 18 & 2 & & 15.5 & $35-46-39$ & $114-41-55$ \\
\hline 2255 & 34961 & 0.5833 & 18 & 2 & & 15.8 & $35-46-37$ & $114-41-55$ \\
\hline 2255 & 34989 & 0.5625 & 18 & 2 & & 14.7 & $35-46-38$ & $114-41-55$ \\
\hline 2255 & 35046 & 0.6528 & 18 & 2 & & 14 & $35-46-37$ & $114-41-55$ \\
\hline 2264 & 34661 & 0.6042 & 31 & 1 & & & $35-35-17$ & $114-39-18$ \\
\hline 2264 & 34662 & 0.6042 & 31 & 9 & & 12.3 & $35-35-03$ & $114-39-36$ \\
\hline 2264 & 34662 & 0.8056 & 31 & & & & & \\
\hline 2264 & 34674 & 0.8611 & 30 & 9 & & & $35-3$ & $114-39-27$ \\
\hline 2264 & 34676 & 0.2604 & 30 & 11 & & 12.3 & $35-35-28$ & $114-39-17$ \\
\hline 2264 & 34687 & 0.6201 & 31 & 11 & & 11.6 & $35-$ & $114-39-26$ \\
\hline 2264 & 34688 & 0.0000 & 30 & & & & & \\
\hline 2264 & 34690 & 0.1042 & 31 & 11 & & 11.8 & $35-35-38$ & $114-39-25$ \\
\hline 2264 & 34709 & 0.8889 & 30 & 11 & & 12.1 & $35-35-41$ & $114-39-20$ \\
\hline 2264 & 34712 & 0.1924 & 31 & 11 & & 12.2 & $35-$ & $114-39-24$ \\
\hline 2264 & 34724 & 0.7458 & 31 & & & & & \\
\hline 2264 & 34744 & 0.7222 & 31 & 11 & & 13.1 & $35-35-47$ & $114-39-23$ \\
\hline 2264 & 34752 & 0.6667 & 30 & & & & & \\
\hline 2264 & 34759 & 0.7708 & 31 & 11 & & 13.4 & $35-$ & $114-39-25$ \\
\hline 2264 & 34768 & 0.3125 & 31 & 11 & & 13.3 & $35-$ & $114-39-30$ \\
\hline 2264 & 34773 & 0.7292 & 30 & & & 13.1 & $35-35-36$ & $114-39-26$ \\
\hline 2264 & 34779 & 0.7847 & 30 & 11 & & 13.8 & $35-35-44$ & $114-39-20$ \\
\hline 2264 & 34786 & 0.9722 & 30 & & & 12.9 & $35-35-31$ & $114-39-28$ \\
\hline 2264 & 34793 & 0.7431 & 30 & 11 & & 13.5 & $35-35-39$ & $114-39-25$ \\
\hline 2264 & 34795 & 0.2257 & 30 & 11 & & 13.7 & $35-35-31$ & $114-39-24$ \\
\hline 2264 & 34821 & 0.7014 & 30 & 11 & & 14.4 & $35-35-39$ & $114-39-21$ \\
\hline 2264 & 34851 & 0.6701 & 30 & 11 & & 14.8 & $35-35-38$ & $114-39-26$ \\
\hline 2264 & 34852 & 0.1806 & 30 & 11 & & 14.8 & $35-35-38$ & $114-39-22$ \\
\hline
\end{tabular}


LAKE MOHAVE RAZORBACK SUCKER TELEMETRY STUPY Nov 1994 to July 1997

\begin{tabular}{|c|c|c|c|c|c|c|c|}
\hline Fish ID\# & DATE & TIME & WP & SHORE & TEMP C & LAT. & LONG. \\
\hline & (JULIAN) & $(24-h r)$ & & $1-10=X 10 M$ & & & \\
\hline & & & & $11=.100 \mathrm{~m}$ & & & \\
\hline 2264 & 34877 & 0.7326 & 30 & 11 & 15.1 & $35-35-39$ & $114-39-27$ \\
\hline 2264 & 34905 & 0.7569 & 30 & 11 & 16.6 & $35-35-41$ & $114-39-26$ \\
\hline 2264 & 34961 & 0.6458 & 30 & 11 & 16.4 & $35-35-40$ & $114-39-25$ \\
\hline 2264 & 34989 & 0.6285 & 30 & 11 & 15.1 & $35-35-39$ & $114-39-26$ \\
\hline 2264 & 35046 & 0.7049 & 30 & 11 & 13.8 & $35-35-39$ & $114-39-25$ \\
\hline 2273 & 34661 & 0.6042 & 31 & 1 & & $35-35-17$ & 114-39-18 \\
\hline 2273 & 34662 & 0.6042 & 31 & 1 & 13.6 & $35-35-15$ & $114-39-21$ \\
\hline 2273 & 34662 & 0.8042 & 31 & & & & \\
\hline 2273 & 34759 & 0.8125 & 32 & 3 & 15.4 & $35-34-40$ & $114-41-11$ \\
\hline 2273 & 34768 & 0.2500 & 32 & 1 & 13.9 & $35-34-37$ & $114-41-07$ \\
\hline 2273 & 34773 & 0.7639 & 32 & 5 & 14 & $35-34-37$ & $114-41-14$ \\
\hline 2273 & 34778 & 0.6250 & 32 & 2 & 16.3 & $35-34-39$ & $114-41-13$ \\
\hline 2273 & 34780 & 0.5694 & 34 & 10 & 15.3 & $35-33-32$ & $114-40-08$ \\
\hline 2273 & 34781 & 0.1354 & 32 & 10 & 14.7 & $35-34-47$ & $114-40-01$ \\
\hline 2273 & 34795 & 0.2014 & 32 & 3 & 14.2 & $35-34-23$ & $114-40-50$ \\
\hline 2273 & 34806 & 0.6563 & 32 & 5 & & $35-34-22$ & $114-40-55$ \\
\hline 2273 & 34808 & 0.6771 & 32 & 4 & & $35-34-22$ & $114-40-53$ \\
\hline 2273 & 34809 & 0.0938 & 32 & 11 & 13.8 & $35-34-29$ & $114-40-57$ \\
\hline 2273 & 34821 & 0.7257 & 32 & 3 & 17.1 & $35-34-21$ & $114-40-54$ \\
\hline 2273 & 34823 & 0.1215 & 32 & 2 & 18.9 & $35-34-21$ & $114-40-54$ \\
\hline 2273 & 34834 & 0.6354 & 32 & 1 & 17.8 & $35-34-21$ & $114-40-55$ \\
\hline 2273 & 34836 & 0.8021 & 32 & 1 & 17 & $35-34-20$ & $114-40-57$ \\
\hline 2273 & 34837 & 0.0972 & 32 & 1 & 17.9 & $35-34-20$ & $114-40-57$ \\
\hline 2273 & 34850 & 0.8646 & 32 & 1 & 21.9 & $35-34-19$ & $114-40-57$ \\
\hline 2273 & 34852 & 0.1458 & 32 & 1 & 21.2 & $35-34-18$ & $114-41-00$ \\
\hline 2273 & 34862 & 0.6424 & 32 & 1 & 22.8 & $35-34-23$ & $114-40-57$ \\
\hline 2273 & 34864 & 0.6458 & 32 & 1 & 23.7 & $35-34-18$ & $114-40-59$ \\
\hline 2273 & 34866 & 0.0938 & 32 & 1 & 21.7 & $35-34-20$ & $114-40-58$ \\
\hline 2273 & 34879 & 0.2500 & 35 & 4 & 24.5 & $35-32-32$ & $114-40-25$ \\
\hline 2273 & 34891 & 0.6563 & 35 & 2 & 27.8 & $35-32-06$ & $114-40-22$ \\
\hline 2273 & 34892 & 0.6458 & 35 & 3 & 27.6 & $35-32-12$ & $114-40-23$ \\
\hline 2273 & 34894 & 0.0868 & 35 & 3 & 26.9 & $35-32-27$ & $114-40-23$ \\
\hline 2273 & 34905 & 0.7778 & 32 & 3 & 28.1 & $35-34-23$ & $114-40-55$ \\
\hline 2273 & 34907 & 0.1354 & 32 & 2 & 26.9 & $35-34-19$ & $114-40-55$ \\
\hline 2273 & 34919 & 0.6667 & 32 & 10 & 26.4 & $35-34-34$ & $114-40-59$ \\
\hline 2273 & 34920 & 0.5625 & 32 & 10 & 24.3 & $35-34-36$ & $114-41-03$ \\
\hline 2273 & 34921 & 0.0938 & 32 & 11 & 22.2 & $35-34-52$ & $114-40-46$ \\
\hline 2273 & 34935 & 0.1215 & 32 & 11 & 21.2 & $35-34-49$ & $114-40-36$ \\
\hline 2273 & 34948 & 0.5938 & 35 & 11 & 25.7 & $35-32-41$ & $114-40-11$ \\
\hline 2273 & 34949 & 0.5938 & 33 & 10 & 18.3 & $35-34-19$ & $114-39-44$ \\
\hline 2273 & 34950 & 0.2431 & 33 & 8 & 25 & $35-34-13$ & 114-39-35 \\
\hline 2273 & 34961 & 0.6667 & 32 & 6 & 25.8 & $35-34-35$ & $114-39-44$ \\
\hline 2273 & 34963 & 0.1319 & 32 & 1 & 26.4 & $35-34-34$ & 114-39-34 \\
\hline 2273 & 34974 & 0.6285 & 35 & 11 & 17.3 & $35-32-07$ & $114-39-18$ \\
\hline 2273 & 34975 & 0.6771 & 35 & 11 & 16.9 & $35-31-56$ & $114-39-17$ \\
\hline 2273 & 34976 & 0.1111 & 35 & 2 & 22.7 & $35-32-34$ & 114-39-09 \\
\hline 2273 & 34988 & 0.8368 & 36 & 6 & 21.3 & $35-31-25$ & 114-39-19 \\
\hline 2273 & 34991 & 0.1076 & 36 & 3 & 20.7 & $35-31-37$ & $114-39-10$ \\
\hline 2273 & 35003 & 0.6181 & 36 & 5 & 15.4 & $35-31-35$ & $114-39-16$ \\
\hline 2273 & 35004 & 0.5972 & 35 & 11 & 15.3 & $35-32-01$ & $114-39-18$ \\
\hline
\end{tabular}


LAKE MOHAVE RAZORBACK SUCKER TELEMETRY STUDY Nov 1994 to July 1997

\begin{tabular}{|c|c|c|c|c|c|c|c|}
\hline ish ID\# & DATE & TIME & WP & SHORE & TEMP C & LAT. & LONG. \\
\hline & (JULIAN) & (24-hr) & & $1-10=X 10 M$ & & & \\
\hline & & & & $11=.100 \mathrm{~m}$ & & & \\
\hline 2273 & 35016 & 0.9097 & 40 & 11 & 18.2 & $35-27-57$ & $114-39-42$ \\
\hline 2273 & 35032 & 0.5625 & 41 & 11 & 16.4 & $35-27-43$ & $114-38-53$ \\
\hline 2273 & 35044 & 0.7257 & 70 & 4 & 15.8 & $35-12-54$ & $114-34-15$ \\
\hline 2273 & 35048 & 0.2604 & 70 & 4 & 15.5 & $35-12-55$ & 114-34-15 \\
\hline 2273 & 35088 & 0.6667 & 36 & 7 & 12.4 & $35-31-38$ & 114-39-09 \\
\hline 2273 & 35173 & 0.7083 & 39 & 10 & 1290 & $35-28-48$ & $114-40-08$ \\
\hline 2273 & 35185 & 0.7014 & 39 & 8 & 1269 & $35-28-29$ & $114-40-03$ \\
\hline 2273 & 35535 & 0.589583 & 5 & & & 355617 & 1144322 \\
\hline 2273 & 35598 & 0.520833 & 5 & & & & \\
\hline 2327 & 34661 & 0.5625 & 18 & 1 & & $35-46-38$ & $114-41-52$ \\
\hline 2327 & 34674 & 0.7569 & 16 & & 13.1 & $35-48-23$ & $114-42-41$ \\
\hline 2327 & 34676 & 0.3542 & 16 & 2 & 12.9 & $35-48-19$ & $114-42-44$ \\
\hline 2327 & 34688 & 0.6806 & 16 & & & & \\
\hline 2327 & 34712 & 0.3056 & 16 & 3 & 12.7 & $35-48-17$ & $114-42-52$ \\
\hline 2327 & 34724 & 0.6806 & 16 & & & & \\
\hline 2327 & 34737 & 0.7847 & 16 & 8 & 12.9 & $35-48-25$ & $114-42-42$ \\
\hline 2327 & 34752 & 0.6042 & 16 & & & & \\
\hline 2327 & 34759 & 0.6806 & 16 & 2 & 13.1 & $35-48-20$ & $114-42-49$ \\
\hline 2327 & 34768 & 0.4000 & 16 & 1 & 13.1 & $35-48-18$ & $114-42-49$ \\
\hline 2327 & 34773 & 0.6118 & 16 & 2 & 13.6 & $35-48-20$ & $114-42-48$ \\
\hline 2327 & 34779 & 0.6875 & 16 & 1 & 13.2 & $35-48-18$ & $114-42-49$ \\
\hline 2327 & 34786 & 0.8542 & 16 & & & $35-48-22$ & $114-42-45$ \\
\hline 2327 & 34793 & 0.6701 & 16 & 1 & 13.8 & $35-48-17$ & $114-42-50$ \\
\hline 2327 & 34795 & 0.2813 & 16 & 1 & 13.1 & $35-48-18$ & $114-42-50$ \\
\hline 2327 & 34821 & 0.6111 & 16 & 2 & 14.5 & $35-48-19$ & $114-42-51$ \\
\hline 2327 & 34851 & 0.5486 & 16 & 1 & 14.7 & $35-48-18$ & $114-42-48$ \\
\hline 2327 & 34852 & 0.3229 & 16 & 1 & 14.1 & $35-48-21$ & $114-42-52$ \\
\hline 2327 & 34877 & 0.6181 & 16 & 1 & 15.1 & $35-48-16$ & $114-42-48$ \\
\hline 2327 & 34905 & 0.6597 & 16 & 1 & 15.5 & $35-48-17$ & $114-42-49$ \\
\hline 2327 & 34961 & 0.5729 & 16 & 2 & 15.5 & $35-48-19$ & $114-42-48$ \\
\hline 2327 & 34989 & 0.5556 & 16 & 1 & 15 & $35-48-20$ & $114-42-54$ \\
\hline 2327 & 35046 & 0.6424 & 16 & 1 & 14 & $35-48-17$ & $114-42-49$ \\
\hline 2327 & 35088 & 0.5347 & 16 & 1 & 13.3 & $35-48-19$ & $114-42-48$ \\
\hline 2354 & 34661 & 0.6042 & 31 & 1 & & $35-35-17$ & $114-39-18$ \\
\hline 2354 & 34662 & 0.6042 & 31 & 1 & & $35-35-15$ & $114-39-21$ \\
\hline 2354 & 34676 & 0.2500 & 31 & 9 & 12.9 & $35-35-15$ & $114-39-21$ \\
\hline 2354 & 34687 & 0.6042 & 31 & 2 & 12.1 & $35-35-16$ & $114-39-20$ \\
\hline 2354 & 34688 & 0.7389 & 31 & & & & \\
\hline 2354 & 34690 & 0.1125 & 31 & 2 & 11.9 & $35-35-16$ & $114-39-24$ \\
\hline 2354 & 34709 & 0.9028 & 31 & 2 & 12.2 & $35-35-18$ & $114-39-24$ \\
\hline 2354 & 34712 & 0.1806 & 31 & & 12.2 & $35-35-16$ & $114-39-20$ \\
\hline 2354 & 34724 & 0.7361 & 32 & & & & \\
\hline 2354 & 34737 & 0.8750 & 31 & 2 & 12.9 & $35-35-16$ & $114-39-21$ \\
\hline 2354 & 34744 & 0.7153 & 31 & 2 & 13.3 & $35-35-19$ & $114-39-22$ \\
\hline 2354 & 34752 & 0.6729 & 31 & & & & \\
\hline 2354 & 34759 & 0.7847 & 31 & 2 & 14.2 & $35-35-16$ & $114-39-23$ \\
\hline 2354 & 34768 & 0.2931 & 31 & 1 & 13.7 & $35-35-17$ & $114-39-24$ \\
\hline 2354 & 34773 & 0.7465 & 31 & 2 & 13.7 & $35-35-15$ & $114-39-23$ \\
\hline 2354 & 34779 & 0.8021 & 31 & 1 & 15.1 & $35-35-17$ & $114-39-21$ \\
\hline 2354 & 34793 & 0.7465 & 31 & 1 & 14 & $35-35-17$ & $114-39-20$ \\
\hline
\end{tabular}




\begin{tabular}{|c|c|c|c|c|c|c|c|}
\hline \multicolumn{8}{|c|}{ LAKE MOHAVE RAZORBACK SUCKER TELEMETRY STUDY } \\
\hline Fish ID\# & DATE & TIME & WP & SHORE & TEMP $\mathrm{C}$ & LAT. & LONG. \\
\hline & (JULIAN) & $(24-h r)$ & & $1-10=X 10 M$ & & & \\
\hline & & & & $11=.100 \mathrm{~m}$ & & & \\
\hline 2354 & 34795 & 0.2222 & 31 & 1 & & $35-35-17$ & $114-39-20$ \\
\hline 2354 & 34821 & 0.7083 & 31 & 2 & 16.6 & $35-35-16$ & $114-39-21$ \\
\hline 2354 & 34851 & 0.6840 & 31 & 1 & 16.4 & $35-35-20$ & $114-39-24$ \\
\hline 2354 & 34852 & 0.1701 & 31 & 1 & 17.4 & $35-35-17$ & $114-39-20$ \\
\hline 2354 & 34877 & 0.7431 & 31 & 1 & 19.1 & $35-35-17$ & $114-39-23$ \\
\hline 2354 & 34905 & 0.7708 & 31 & 1 & 25.2 & $35-35-17$ & $114-39-21$ \\
\hline 2354 & 34961 & 0.6493 & 31 & 1 & & $35-35-17$ & $114-39-22$ \\
\hline 2354 & 34989 & 0.6389 & 31 & 1. & 19.7 & $35-35-17$ & $114-39-21$ \\
\hline 2354 & 35046 & 0.7083 & 31 & 1 & 14.1 & $35-35-17$ & $114-39-22$ \\
\hline 2363 & 34660 & 0.6285 & 54 & 1 & & $35-24-29$ & $114-39-40$ \\
\hline 2363 & 34673 & 0.7083 & 55 & 11 & 12 & $35-24-27$ & $114-39-16$ \\
\hline 2363 & 34677 & 0.2778 & 53 & 11 & 12.2 & $35-25-11$ & $114-39-54$ \\
\hline 2363 & 34686 & 0.6458 & 54 & 11 & 11.4 & $35-24-43$ & $114-39-31$ \\
\hline 2363 & 34688 & 0.3750 & 53 & & & & \\
\hline 2363 & 34689 & 0.1250 & 54 & 11 & 11.5 & $35-24-43$ & $114-39-47$ \\
\hline 2363 & 34708 & 0.7500 & 54 & 11 & 11.4 & $35-24-46$ & $114-39-46$ \\
\hline 2363 & 34711 & 0.3333 & 54 & 11 & 11.4 & $35-24-42$ & $114-39-50$ \\
\hline 2363 & 34724 & 0.3750 & 54 & & & & \\
\hline 2363 & 34736 & 0.7639 & 54 & 11 & 11.7 & $35-24-45$ & $114-39-50$ \\
\hline 2363 & 34745 & 0.3542 & 54 & 11 & 12.7 & $35-24-37$ & $114-39-31$ \\
\hline 2363 & 34752 & 0.3382 & 54 & & & & \\
\hline 2363 & 34753 & 0.1181 & 54 & 11 & 12.6 & $35-24-47$ & $114-39-44$ \\
\hline 2363 & 34758 & 0.7292 & 54 & 11 & 12.8 & $35-24-45$ & $114-39-46$ \\
\hline 2363 & 34767 & 0.2694 & 54 & 11 & 13.3 & $35-24-40$ & $114-39-44$ \\
\hline 2363 & 34772 & 0.5639 & 54 & 11 & 13.9 & $35-24-40$ & $114-39-46$ \\
\hline 2363 & 34780 & 0.7153 & 54 & 11 & 14 & $35-24-39$ & $114-39-42$ \\
\hline 2363 & 34792 & 0.7222 & 54 & 11 & 14.2 & $35-24-38$ & $114-39-42$ \\
\hline 2363 & 34796 & 0.1667 & 54 & 11 & 14.3 & $35-24-35$ & $114-39-44$ \\
\hline 2363 & 34801 & 0.6563 & 54 & 11 & 15 & $35-24-39$ & $114-39-43$ \\
\hline 2363 & 34820 & 0.7535 & 54 & 11 & 14.8 & $35-24-39$ & $114-39-46$ \\
\hline 2363 & 34824 & 0.2188 & 54 & 11 & 15.2 & $35-24-36$ & $114-39-44$ \\
\hline 2363 & 34850 & 0.7604 & 54 & 11 & 15.6 & $35-24-41$ & $114-39-39$ \\
\hline 2363 & 34853 & 0.2153 & 54 & 11 & 15.5 & $35-24-40$ & $114-39-37$ \\
\hline 2363 & 34876 & 0.7083 & 54 & 11 & 16 & $35-24-39$ & $114-39-41$ \\
\hline 2363 & 34904 & 0.7604 & 54 & 11 & 16.4 & $35-24-37$ & $114-39-40$ \\
\hline 2363 & 34932 & 0.7535 & 54 & 11 & 16.8 & $35-24-38$ & $114-39-40$ \\
\hline 2363 & 34960 & 0.7535 & 54 & 11 & 17 & $35-24-38$ & $114-39-44$ \\
\hline 2363 & 34988 & 0.7361 & 54 & 11 & 16.3 & $35-24-39$ & $114-39-44$ \\
\hline 2363 & 35016 & 0.8194 & 54 & 11 & 15.9 & $35-24-39$ & $114-39-45$ \\
\hline 2363 & 35044 & 0.8021 & 54 & 11 & 14.6 & $35-24-40$ & $114-39-45$ \\
\hline 2426 & 34660 & 0.6389 & 54 & 1 & & $35-24-29$ & $114-39-40$ \\
\hline 2435 & 34660 & 0.6771 & 66 & 1 & & $35-17-36$ & $114-35-12$ \\
\hline 2435 & 34662 & 0.4167 & 65 & & & $35-17-29$ & $114-35-12$ \\
\hline 2435 & 34752 & 0.2917 & 66 & 2 & 13.4 & $35-17-13$ & $114-35-10$ \\
\hline 2435 & 34758 & 0.6736 & 67 & 2 & 15.5 & $35-16-46$ & $114-35-16$ \\
\hline 2435 & 34767 & 0.3389 & 66 & 2 & 14.3 & $35-16-48$ & $114-35-16$ \\
\hline 2435 & 34772 & 0.4764 & 66 & 2 & 15.1 & $35-16-46$ & $114-35-15$ \\
\hline 2435 & 34780 & 0.7535 & 66 & 2 & 15.5 & $35-16-48$ & $114-35-15$ \\
\hline 2435 & 34792 & 0.6632 & 66 & 2 & 16.3 & $35-16-47$ & $114-35-16$ \\
\hline 2435 & 34796 & 0.2222 & 66 & 2 & 16.2 & $35-16-47$ & $114-35-15$ \\
\hline
\end{tabular}


LAKE MOHAVE RAZORBACK SUCKER TELEMETRY STUPY Nov 1994 to July 1997

\begin{tabular}{|c|c|c|c|c|c|c|c|}
\hline Fish ID\# & DATE & TIME & WP & SHORE & TEMP C & LAT. & LONG. \\
\hline & (JULIAN) & (24-hr) & & $1-10=\mathrm{X} 10 \mathrm{M}$ & & & \\
\hline & & & & $11=.100 \mathrm{~m}$ & & & \\
\hline 2444 & 34660 & 0.7083 & 66 & 1 & & $35-17-36$ & $114-35-12$ \\
\hline 2444 & 34662 & 0.4167 & 65 & & & $35-17-29$ & $114-35-12$ \\
\hline 2444 & 34711 & 0.4167 & 71 & 10 & 11 & $35-12-07$ & $114-34-08$ \\
\hline 2444 & 34723 & 0.6319 & 71 & 10 & 11.1 & $35-12-05$ & $144-34-07$ \\
\hline 2444 & 34725 & 0.1771 & 71 & & & & \\
\hline 2444 & 34736 & 0.6667 & 71 & 10 & 11.8 & $35-12-07$ & $114-34-07$ \\
\hline 2444 & 34745 & 0.4167 & 71 & 10 & 12 & $35-12-29$ & $114-33-58$ \\
\hline 2444 & 34752 & 0.2639 & 71 & & & & \\
\hline 2444 & 34758 & 0.6590 & 71 & 10 & 12.7 & $35-12-06$ & 114-34-12 \\
\hline 2444 & 34767 & 0.3625 & 71 & 8 & 13 & $35-12-08$ & $114-34-05$ \\
\hline 2444 & 34772 & 0.4340 & 71 & 10 & 13.3 & $35-12-04$ & $114-34-10$ \\
\hline 2444 & 34780 & 0.7743 & 71 & 10 & 13.7 & $35-12-09$ & $114-34-08$ \\
\hline 2444 & 34787 & 0.5764 & 71 & & & $35-12-09$ & $114-34-08$ \\
\hline 2444 & 34792 & 0.6424 & 71 & 10 & 15 & $35-12-07$ & $114-34-08$ \\
\hline 2444 & 34796 & 0.2396 & 71 & 10 & 15 & $35-12-09$ & $114-34-10$ \\
\hline 2444 & 34801 & 0.6076 & 71 & 10 & 15.1 & $35-12-08$ & $114-34-07$ \\
\hline 2444 & 34820 & 0.6528 & 71 & 10 & 15 & $35-12-08$ & $114-34-07$ \\
\hline 2444 & 34824 & 0.2951 & 71 & 10 & 15 & $35-12-08$ & $114-34-09$ \\
\hline 2444 & 34850 & 0.6771 & 71 & 10 & 16 & $35-12-07$ & $114-34-07$ \\
\hline 2444 & 34853 & 0.2743 & 71 & 10 & 16 & $35-12-08$ & $114-34-10$ \\
\hline 2444 & 34876 & 0.6458 & 71 & 10 & 16.3 & $35-12-08$ & $114-34-09$ \\
\hline 2444 & 34904 & 0.6597 & 71 & 10 & 16.5 & $35-12-08$ & $114-34-12$ \\
\hline 2444 & 34932 & 0.6632 & 71 & 10 & 17.3 & $35-12-08$ & $114-34-11$ \\
\hline 2444 & 34960 & 0.6563 & 71 & 10 & 17.3 & $35-12-07$ & $114-34-10$ \\
\hline 2444 & 34988 & 0.6632 & 71 & 10 & 18.7 & $35-12-06$ & $114-34-10$ \\
\hline 2444 & 35016 & 0.7257 & 71 & 10 & 16.4 & $35-12-06$ & $114-34-11$ \\
\hline 2444 & 35044 & 0.7083 & 71 & 10 & 15.7 & $35-12-07$ & $114-34-08$ \\
\hline 2444 & 35087 & 0.5243 & 71 & 10 & 12.1 & $35-12-08$ & $114-34-11$ \\
\hline 2453 & 34661 & 0.4861 & 6 & 1 & & $35-55-57$ & $114-42-38$ \\
\hline 2453 & 34662 & 0.6875 & 6 & & & $35-55-51$ & $114-42-34$ \\
\hline 2453 & 34688 & 0.6319 & 9 & & & & \\
\hline 2453 & 34709 & 0.6875 & 8 & 2 & 12.7 & $35-54-01$ & $114-41-55$ \\
\hline 2453 & 34712 & 0.3681 & 9 & 1 & 12.5 & $35-54-00$ & $114-41-59$ \\
\hline 2453 & 34724 & 0.6458 & 8 & & & & \\
\hline 2453 & 34737 & 0.7292 & 8 & 2 & 12.6 & $35-54-02$ & $114-41-57$ \\
\hline 2453 & 34751 & 0.6528 & 8 & 1 & 12.9 & $35-54-25$ & $114-41-37$ \\
\hline 2453 & 34752 & 0.5750 & 8 & & & & \\
\hline 2453 & 34754 & 0.1458 & 8 & 1 & 12.4 & $35-53-56$ & $114-41-57$ \\
\hline 2453 & 34759 & 0.6319 & 8 & 1 & 12.9 & $35-54-02$ & $114-41-58$ \\
\hline 2453 & 34768 & 0.4403 & 8 & 1 & 12.1 & $35-54-01$ & $114-41-59$ \\
\hline 2453 & 34773 & 0.5514 & 8 & 1 & 13 & $35-54-04$ & $114-41-51$ \\
\hline 2453 & 34779 & 0.6493 & 8 & 1 & 12.6 & $35-54-00$ & $114-41-58$ \\
\hline 2453 & 34786 & 0.8056 & 8 & & & $35-54-02$ & $114-41-53$ \\
\hline 2453 & 34793 & 0.6319 & 8 & 2 & 13.1 & $35-54-00$ & $114-42-00$ \\
\hline 2453 & 34795 & 0.3160 & 8 & 1 & 12.6 & $35-54-03$ & $114-41-59$ \\
\hline 2453 & 34821 & 0.5521 & 8 & 1 & 13.2 & $35-54-02$ & $114-41-59$ \\
\hline 2453 & 34851 & 0.5000 & 8 & 1 & 13.6 & $35-54-02$ & $114-41-57$ \\
\hline 2453 & 34852 & 0.3611 & 8 & 1 & 13.4 & 35-54-01 & $114-41-59$ \\
\hline 2453 & 34877 & 0.5833 & 8 & 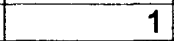 & 14.1 & $35-54-03$ & $114-42-00$ \\
\hline 2453 & 34905 & 0.6181 & 8 & 1 & 14.4 & $35-54-03$ & $114-42-01$ \\
\hline
\end{tabular}


LAKE MOHAVE RAZORBACK SUCKER TELEMETRY STUPY Nov 1994 to July 1997

\begin{tabular}{|c|c|c|c|c|c|c|c|}
\hline ish ID\# & DATE & TIME & WP & SHORE & TEMP $\mathrm{C}$ & LAT. & LONG. \\
\hline & (JULIAN) & (24-hr) & & $1-10=X 10 M$ & & & \\
\hline & & & & $11=.100 \mathrm{~m}$ & & & \\
\hline 2453 & 34961 & 0.5278 & 8 & 1 & 14.5 & $35-54-01$ & $114-41-59$ \\
\hline 2453 & 34989 & 0.5104 & 8 & 1 & 14.5 & $35-54-02$ & $114-42-00$ \\
\hline 2525 & 34660 & 0.6944 & 66 & 1 & & $35-17-36$ & $114-35-12$ \\
\hline 2525 & 34662 & 0.4167 & 65 & & & $35-17-29$ & $114-35-12$ \\
\hline 2534 & 34661 & 0.5694 & 18 & 1 & & $35-46-38$ & $114-41-52$ \\
\hline 2534 & 34662 & 0.6528 & 18 & & & $35-46-39$ & $114-42-05$ \\
\hline 2534 & 34662 & 0.7500 & 18 & & & & \\
\hline 2534 & 34674 & 0.7667 & 18 & & 13.2 & $35-46-32$ & $114-42-01$ \\
\hline 2534 & 34688 & 0.6875 & 18 & & & & \\
\hline 2534 & 34709 & 0.7639 & 18 & 9 & 12.5 & $35-46-35$ & $114-41-56$ \\
\hline 2534 & 34712 & 0.2986 & 18 & 11 & 12.6 & $35-46-29$ & $114-41-59$ \\
\hline 2534 & 34722 & 0.6181 & 18 & 10 & 12.3 & $35-46-34$ & $114-42-00$ \\
\hline 2534 & 34724 & 0.6875 & 18 & 10 & & & \\
\hline 2534 & 34726 & 0.1319 & 18 & 4 & 12.5 & $35-46-31$ & $144-42-03$ \\
\hline 2534 & 34737 & 0.7917 & 18 & 6 & 13.3 & $35-46-34$ & $114-41-59$ \\
\hline 2534 & 34752 & 0.6111 & 18 & 5 & & & \\
\hline 2534 & 34759 & 0.6944 & 18 & 4 & 12.8 & $35-46-31$ & $114-42-07$ \\
\hline 2534 & 34768 & 0.3903 & 18 & 6 & 12.7 & $35-46-30$ & $114-42-06$ \\
\hline 2534 & 34773 & 0.6319 & 18 & & 12.9 & $35-46-28$ & $114-42-05$ \\
\hline 2534 & 34779 & 0.6944 & 18 & 9 & 13 & $35-46-31$ & $114-42-07$ \\
\hline 2534 & 34786 & 0.8819 & 18 & & & $35-46-31$ & $114-42-07$ \\
\hline 2534 & 34793 & 0.6840 & 18 & 5 & 13 & $35-46-28$ & $114-42-04$ \\
\hline 2534 & 34795 & 0.2708 & 18 & 5 & 13.1 & $35-46-35$ & $114-42-00$ \\
\hline 2534 & 34821 & 0.6319 & 18 & 5 & 13.9 & $35-46-30$ & $114-42-04$ \\
\hline 2534 & 34851 & 0.5625 & 18 & 4 & 13.9 & $35-46-28$ & $114-42-06$ \\
\hline 2534 & 34852 & 0.3056 & 18 & 5 & 13.9 & $35-46-28$ & $114-42-06$ \\
\hline 2534 & 34877 & 0.6285 & 18 & 8 & 14.4 & $35-46-30$ & $114-42-04$ \\
\hline 2534 & 34905 & 0.6701 & 18 & 8 & 14.7 & $35-46-29$ & $114-42-03$ \\
\hline 2534 & 34961 & 0.5833 & 18 & 8 & 14.8 & $35-46-28$ & $114-42-03$ \\
\hline 2534 & 34989 & 0.5660 & 18 & 8 & 14.5 & $35-46-29$ & $114-42-04$ \\
\hline 2534 & 35046 & 0.6563 & 18 & 6 & 13.7 & $35-46-26$ & $114-42-04$ \\
\hline 2543 & 34661 & 0.6042 & 31 & 1 & & $35-35-17$ & $114-39-18$ \\
\hline 2543 & 34674 & 0.8472 & 30 & 1 & 13.1 & $35-35-51$ & $114-39-27$ \\
\hline 2543 & 34709 & 58 & 30 & 11 & 12.1 & 35- & $114-39-23$ \\
\hline 2543 & 34712 & 0.1944 & 31 & 11 & 12.1 & $35-35-36$ & $114-39-26$ \\
\hline 2543 & 34724 & 0.7396 & 30 & & & & \\
\hline 2543 & 34737 & 0.8750 & 30 & 11 & 12.3 & $35-35-33$ & $114-39-25$ \\
\hline 2543 & 34752 & 0.6667 & 30 & & & & \\
\hline 2543 & 34759 & 0.7778 & 31 & 11 & 13.4 & $35-35-33$ & $114-39-25$ \\
\hline 2543 & 34768 & 0.3153 & 31 & 11 & 13.2 & $35-35-37$ & 114-39-24 \\
\hline 2543 & 34773 & 0.7431 & 31 & & 13 & $35-35-31$ & $114-39-22$ \\
\hline 2543 & 34779 & 0.7917 & 30 & 11 & 13.9 & $35-35-36$ & $114-39-20$ \\
\hline 2543 & 34786 & 0.9722 & 30 & & & $35-35-31$ & $114-39-28$ \\
\hline 2543 & 34793 & 0.7396 & 30 & 11 & 13.4 & $35-35-39$ & $114-39-25$ \\
\hline 2543 & 34795 & 0.2257 & 30 & 11 & 13.7 & $35-35-38$ & $114-39-19$ \\
\hline 2543 & 34821 & 0.7049 & 30 & 11 & 14.5 & $35-35-35$ & $114-39-20$ \\
\hline 2543 & 34851 & 0.6701 & 30 & 11 & 14.9 & $35-35-35$ & $114-39-27$ \\
\hline 2543 & 34852 & 0.1771 & 30 & 11 & 14.9 & $35-35-37$ & $114-39-22$ \\
\hline 2543 & 34877 & 0.7396 & 30 & 11 & 15.2 & $35-35-36$ & $114-39-25$ \\
\hline 2543 & 34905 & 0.7569 & 30 & 11 & 16.7 & $35-35-34$ & $114-39-22$ \\
\hline
\end{tabular}




\begin{tabular}{|c|c|c|c|c|c|c|c|}
\hline LAKE MOH & AVE RAZO & RBACK SUG & KER TELEN & AETRY STU & Nov 1 & 994 to Jul & 1997 \\
\hline Fish ID\# & DATE & TIME & WP & SHORE & TEMP $\mathrm{C}$ & LAT. & LONG. \\
\hline & (JULIAN) & (24-hr) & & $1-10=\times 10 M$ & & & \\
\hline & & & & $11=.100 \mathrm{~m}$ & & & \\
\hline 2543 & 34961 & 0.6458 & 30 & 11 & 16.4 & $35-35-34$ & $114-39-23$ \\
\hline 2543 & 34989 & 0.6354 & 30 & 11 & 15.4 & $35-35-35$ & $114-39-24$ \\
\hline 2543 & 35046 & 0.7083 & 30 & 11 & 14.3 & $35-35-35$ & $114-39-24$ \\
\hline 2633 & 34661 & 0.5069 & 6 & 1 & & $35-55-57$ & $114-42-38$ \\
\hline 2633 & 34662 & 0.6944 & 6 & & & & \\
\hline 2633 & 34676 & 0.3819 & 13 & 1 & 13.1 & $35-51-11$ & $114-42-09$ \\
\hline 2633 & 34688 & 0.6667 & 13 & & & & \\
\hline 2633 & 34712 & 0.3264 & 13 & 2 & 12.6 & $35-51-10$ & $114-42-08$ \\
\hline 2633 & 34737 & 0.7639 & 13 & 3 & 12.8 & $35-51-12$ & $114-42-08$ \\
\hline 2633 & 34752 & 0.5972 & 13 & & & & \\
\hline 2633 & 34759 & 0.6667 & 13 & 2 & 12.9 & $35-51-14$ & $114-42-09$ \\
\hline 2633 & 34768 & 0.4167 & 13 & 1 & 12.6 & $35-51-14$ & $114-42-10$ \\
\hline 2633 & 34773 & 0.5903 & 13 & 2 & 13.4 & $35-51-08$ & $114-42-10$ \\
\hline 2633 & 34779 & 0.6736 & 13 & 1 & 12.8 & $35-51-11$ & $114-42-09$ \\
\hline 2633 & 34793 & 0.6563 & 13 & 1 & 14.6 & $35-51-12$ & $114-42-12$ \\
\hline 2633 & 34795 & 0.2951 & 13 & 1 & 12.9 & $35-51-13$ & $114-42-09$ \\
\hline 2633 & 34821 & 0.5903 & 13 & 2 & 14.5 & $35-51-15$ & $114-42-12$ \\
\hline 2633 & 34851 & 0.5347 & 13 & 1 & 14.6 & $35-51-11$ & $114-42-11$ \\
\hline 2633 & 34852 & 0.3368 & 13 & 1 & 13 & $35-51-12$ & $114-42-09$ \\
\hline 2633 & 34864 & 0.4931 & 13 & 1 & 14.8 & $35-51-13$ & $114-42-09$ \\
\hline 2633 & 34877 & 0.6076 & 13 & 1 & 14.9 & $35-51-13$ & $114-42-12$ \\
\hline 2633 & 34905 & 0.6424 & 13 & 1 & 15.6 & $35-51-13$ & $114-42-12$ \\
\hline 2633 & 34961 & 0.5625 & 13 & 2 & 16.3 & $35-51-13$ & $114-42-10$ \\
\hline 2633 & 34989 & 0.5417 & 13 & 2 & 17 & $35-51-12$ & $114-42-11$ \\
\hline 2633 & 35046 & 0.6285 & 13 & 1 & 16.3 & $35-51-13$ & $114-42-11$ \\
\hline 2633 & 35088 & 0.5243 & 13 & 2 & 16.5 & $35-51-13$ & $114-42-10$ \\
\hline 3335 & 34661 & 0.5903 & 18 & 1 & & $35-46-38$ & $114-41-52$ \\
\hline 3335 & 34662 & 0.7500 & 18 & & & & \\
\hline 3335 & 34674 & 0.7917 & 22 & 9 & & $35-42-26$ & $114-41-58$ \\
\hline 3335 & 34676 & 0.3215 & 23 & 2 & 12.9 & $35-42-21$ & $114-41-56$ \\
\hline 3335 & 34688 & 0.7014 & 22 & & & & \\
\hline 3335 & 34709 & 0.8056 & 23 & 2 & 12.4 & $35-42-20$ & $114-41-52$ \\
\hline 3335 & 34712 & 0.2639 & 23 & 2 & 12.4 & $35-42-17$ & $114-41-55$ \\
\hline 3335 & 34724 & 0.7014 & 22 & & & & \\
\hline 3335 & 34737 & 0.8194 & 23 & 2 & 13 & $35-42-13$ & $114-41-55$ \\
\hline 3335 & 34752 & 0.6319 & 23 & & & & \\
\hline 3335 & 34759 & 0.7222 & 22 & 1 & 13.5 & $35-42-16$ & $114-41-57$ \\
\hline 3335 & 34768 & 0.3604 & 23 & 2 & 13.3 & $35-42-19$ & $114-41-58$ \\
\hline 3335 & 34773 & 0.6736 & 22 & 2 & 13.2 & $35-42-17$ & $114-41-57$ \\
\hline 3335 & 34779 & 0.7153 & 22 & 1 & 14.1 & $35-42-18$ & $114-41-58$ \\
\hline 3335 & 34786 & 0.9028 & 22 & & & $35-42-01$ & $114-41-45$ \\
\hline 3335 & 34793 & 0.7014 & 22 & 1 & 13.6 & $35-42-19$ & $114-41-58$ \\
\hline 3335 & 34795 & 0.2569 & 23 & 1 & 13.5 & $35-42-18$ & $114-41-57$ \\
\hline 3335 & 34821 & 0.6493 & 22 & 1 & 14.7 & $35-42-19$ & $114-41-59$ \\
\hline 3335 & 34851 & 0.6181 & 23 & 1 & 14.7 & $35-42-21$ & $114-41-58$ \\
\hline 3335 & 34852 & 0.2396 & 23 & 1 & 14.6 & $35-42-19$ & $114-41-58$ \\
\hline 3335 & 34877 & 0.6806 & 22 & 1 & 15.2 & $35-42-19$ & $114-42-00$ \\
\hline 3335 & 34905 & 0.7118 & 23 & 1 & & $35-42-18$ & $114-41-57$ \\
\hline 3335 & 34961 & 0.6042 & 22 & 1 & 17.9 & $35-42-20$ & $114-41-57$ \\
\hline 3335 & 34989 & 0.5833 & 23 & 1 & 15.7 & $35-42-19$ & $114-41-58$ \\
\hline
\end{tabular}




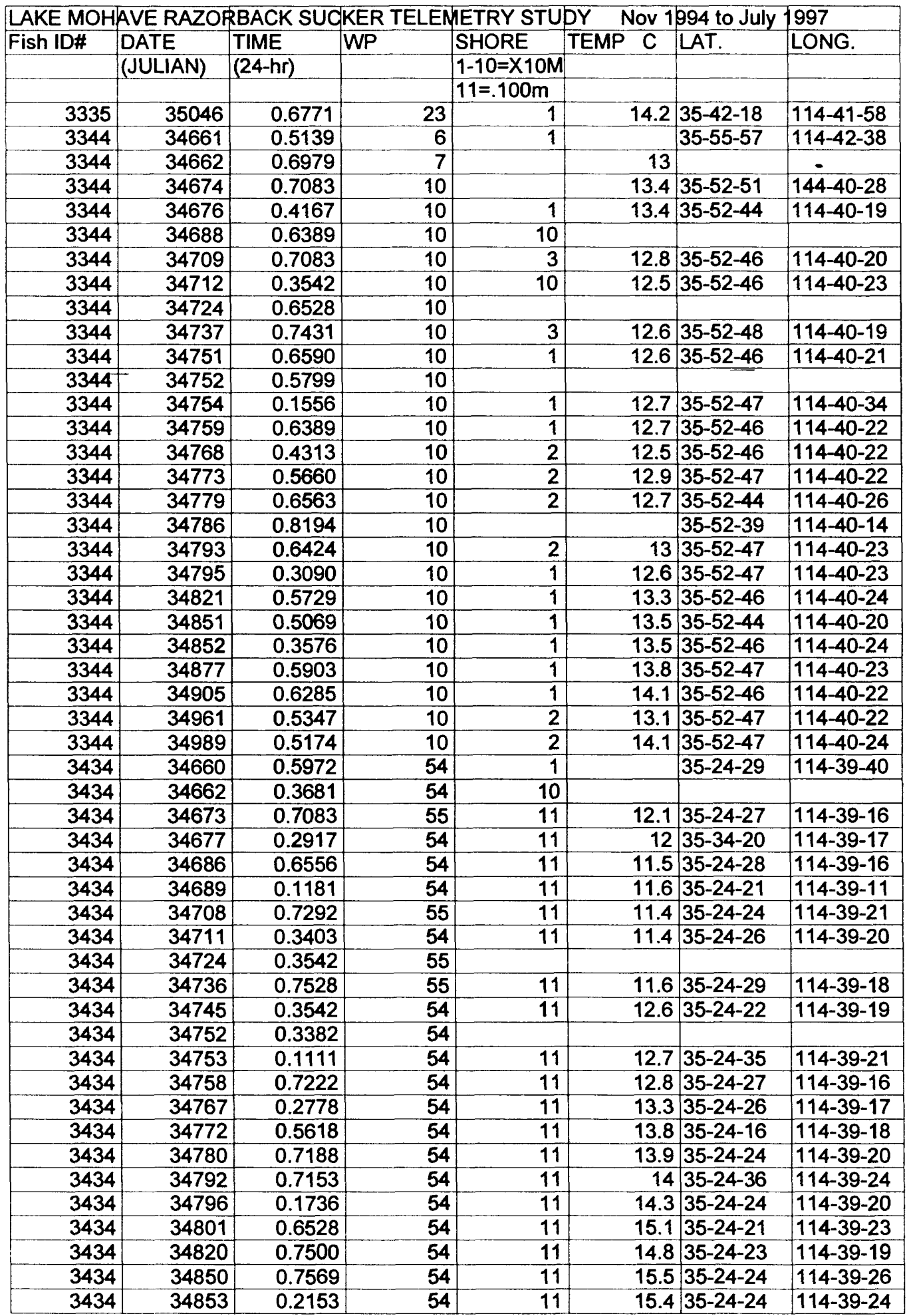




\begin{tabular}{|c|c|c|c|c|c|c|c|}
\hline LAKE MOH & AVE RAZOF & RBACK SUC & KER TELEN & METRY STU & Nov 1 & 994 to Jul & 1997 \\
\hline Fish ID\# & DATE & TIME & WP & SHORE & TEMP C & LAT. & LONG. \\
\hline & (JULIAN) & (24-hr) & & $1-10=X 10 M$ & & & \\
\hline & & & & $11=.100 \mathrm{~m}$ & & & \\
\hline 3434 & 34876 & 0.7083 & 54 & 11 & 16.2 & $35-24-27$ & $114-39-20$ \\
\hline 3434 & 3490 & 0. & 54 & 11 & 16.6 & 24 & $114-39-16$ \\
\hline 3434 & 34932 & 0.7465 & 54 & 11 & 17.1 & $35-24-24$ & $114-39-16$ \\
\hline 3434 & 34960 & 0.7431 & 54 & 11 & 17.1 & $35-24-25$ & $114-39-16$ \\
\hline 3434 & 38 & 0.7292 & 54 & 11 & 16.3 & -24 & $114-39-16$ \\
\hline 3434 & 35016 & 0.8160 & 54 & 11 & 15.9 & -24 & $114-39-16$ \\
\hline 3434 & 35044 & 0.7917 & 54 & 11 & 14.5 & $35-24-25$ & $114-39-17$ \\
\hline
\end{tabular}




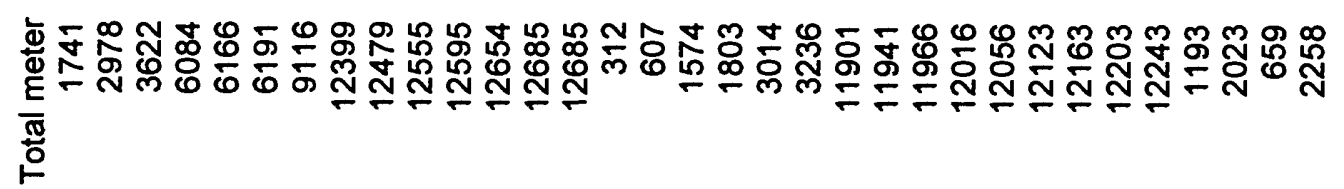

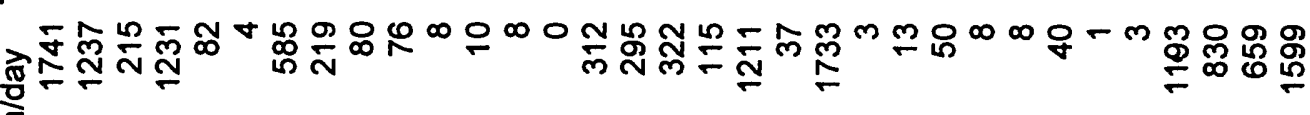
है

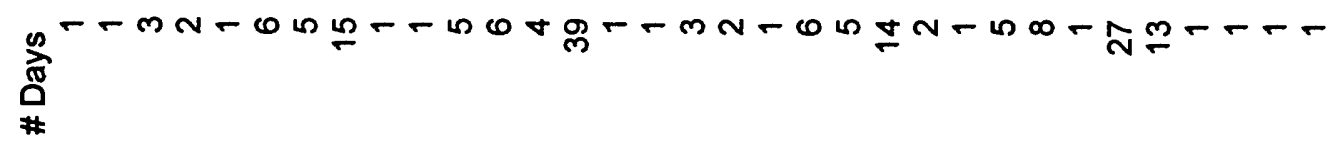
凹

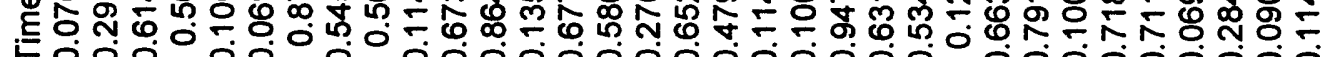
蛋

入o

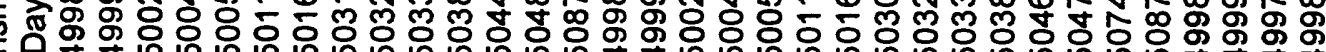

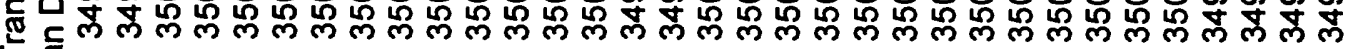
鰝

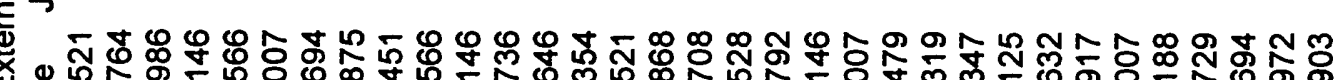
山ै

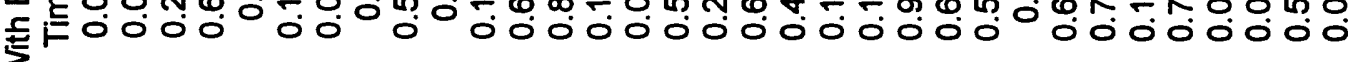

党

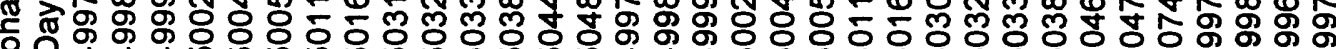

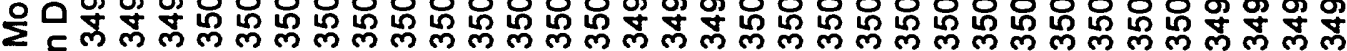
产 兽 可 $\frac{\alpha}{\alpha}$

대내

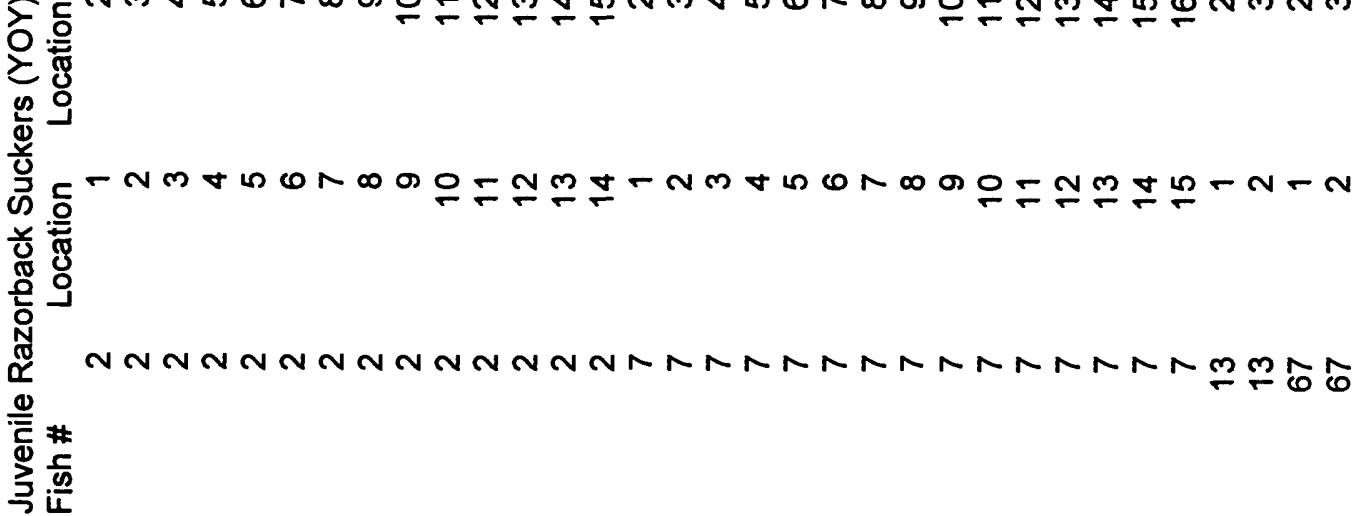




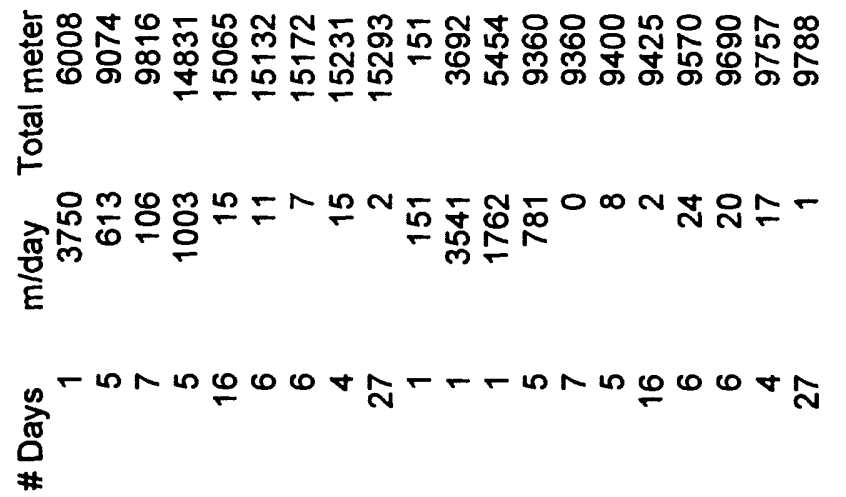

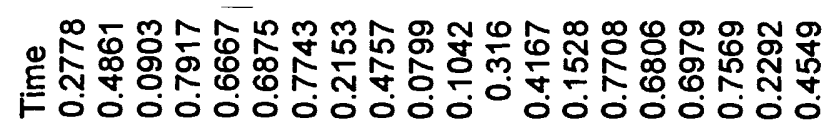

$$
\text { 足 }
$$

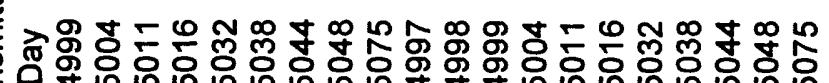

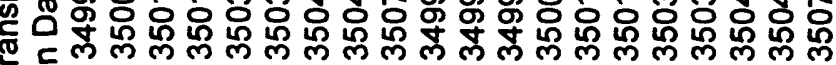

$=\frac{5}{\overline{3}}$

ত

ำ س

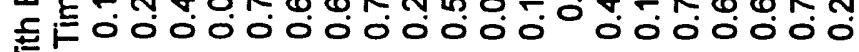
3

()

ส

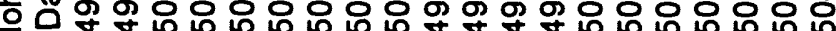

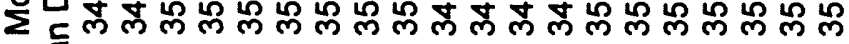

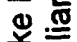

空

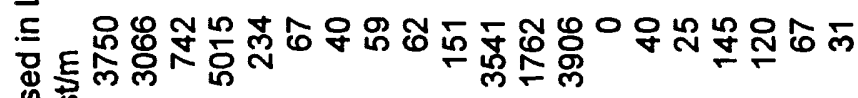$$
\stackrel{\mathbb{\mathscr { X }}}{\mathbb{\mathscr { W }}}
$$

$\widetilde{\alpha}$

₹ᄃ

응

象

윽

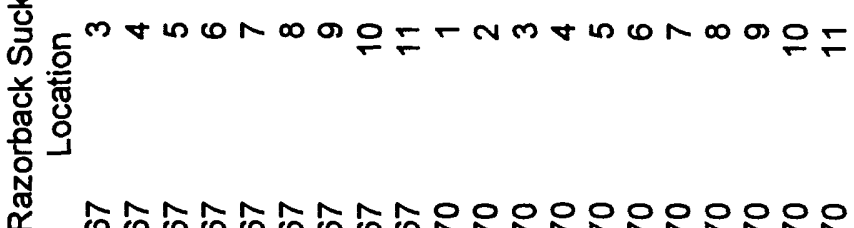

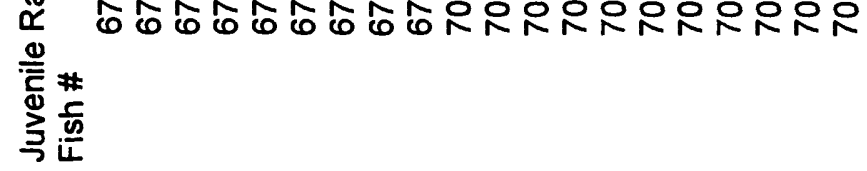


Appendix C. Temperature and Depth Data 


\begin{tabular}{|c|c|c|c|c|c|}
\hline \multicolumn{4}{|c|}{ Temperature Data --Lake Mohave -- 1995} & \multicolumn{2}{|l|}{ Date $=$ Julian } \\
\hline Date & 34823 & Date & 34823 & Date & 34823 \\
\hline Fish \# & 348 & Fish \# & 366 & Fish \# & 258 \\
\hline Waypoint & 32 & Waypoint & 32 & Waypoint & 32 \\
\hline Depth $(m)$ & Temp (C) & Depth $(m)$ & Temp (C) & Depth (m) & Temp (C) \\
\hline 0 & 19.5 & 0 & 19.5 & 0 & 18.8 \\
\hline 1 & 19.5 & 1 & 19.5 & 1 & - 18.9 \\
\hline 3 & 19.2 & 3 & 19.1 & 3 & 18.5 \\
\hline 5 & 18.1 & & & 5 & 17.7 \\
\hline 7 & 17.8 & Date & 34823 & 7 & 17.1 \\
\hline 9 & 17.5 & $\begin{array}{l}\text { Fish \# } \\
\text { Waypoint }\end{array}$ & $\begin{array}{r}339 \\
29\end{array}$ & $\begin{array}{r}9 \\
11\end{array}$ & $\begin{array}{l}16.8 \\
16.2\end{array}$ \\
\hline Date & 34823 & Depth (m) & Temp (C) & 13 & 15.5 \\
\hline Fish \# & 88 & 0 & 18.2 & & \\
\hline Waypoint & 29 & 1 & 18.3 & Date & 34823 \\
\hline Depth $(m)$ & Temp (C) & 3 & 18.2 & Fish \# & 2228 \\
\hline 0 & 18.6 & 5 & 17.6 & Waypoint & 27 \\
\hline 1 & 18.6 & 7 & 17 & Depth $(m)$ & Temp (C) \\
\hline 3 & 18.5 & 9 & 16.1 & 0 & 18.1 \\
\hline 5 & 17.3 & 11 & 15.3 & 1 & 18.1 \\
\hline 7 & 16.8 & & & 3 & 16.7 \\
\hline 9 & 16.2 & Date & 34823 & 5 & 16.5 \\
\hline 11 & 15.9 & Fish \# & 276 & & \\
\hline 13 & 15.1 & Waypoint & 25 & Date & 34836 \\
\hline 15 & 15 & Depth (m) & Temp (C) & Fish \# & 276 \\
\hline & & 0 & 17.1 & Waypoint & 24 \\
\hline Date & 34836 & 1 & 17.1 & Depth $(m)$ & Temp (C) \\
\hline Fish \# & 375 & 3 & 16.9 & 0 & 16.7 \\
\hline Waypoint & 25 & 5 & 15.8 & 1 & 16.5 \\
\hline Depth $(m)$ & Temp (C) & 7 & 15.1 & 3 & 15.8 \\
\hline 0 & 17.2 & 9 & 14.6 & 5 & 15.6 \\
\hline 1 & 17 & 11 & 14.5 & 7 & 15.6 \\
\hline 3 & 15.9 & 13 & 14.4 & 9 & 15.2 \\
\hline 5 & 15.5 & & & 11 & 15 \\
\hline 7 & 15.1 & Date & 34836 & 13 & 14.7 \\
\hline 9 & 14.7 & Fish \# & 339 & 15 & 14.4 \\
\hline 11 & 14.4 & Waypoint & 26 & & \\
\hline 13 & 14.4 & Depth (m) & Temp (C) & Date & 34836 \\
\hline 15 & 14.4 & 0 & 18.1 & Fish \# & 88 \\
\hline & & 1 & 17.7 & Waypoint & 27 \\
\hline Date & 34836 & 3 & 17 & Depth $(m)$ & Temp (C) \\
\hline Fish \# & 2228 & 5 & 16.7 & 0 & 19 \\
\hline Waypoint & 29 & 7 & 16.5 & 1 & 18.6 \\
\hline Depth $(m)$ & Temp (C) & 9 & 15.6 & 3 & 17.4 \\
\hline 0 & 18.7 & 11 & 14.9 & 5 & 17 \\
\hline 1 & 18.7 & 13 & 14.8 & 7 & 16.8 \\
\hline 3 & 18.4 & 15 & 14.6 & 9 & 16.4 \\
\hline 5 & 18 & 17 & 14.4 & 11 & 14.5 \\
\hline 7 & 17.7 & & & & \\
\hline 9 & 17.2 & Date & 34836 & Date & 34836 \\
\hline 11 & 16.1 & Fish \# & 348 & Fish \# & 2273 \\
\hline 13 & 15.7 & Waypoint & 30 & Waypoint & 33 \\
\hline 15 & 14.6 & Depth $(m)$ & Temp (C) & Depth $(m)$ & Temp (C) \\
\hline 17 & 14.6 & 0 & 18.7 & 0 & 17.6 \\
\hline
\end{tabular}




\begin{tabular}{|c|c|c|c|c|c|}
\hline \multicolumn{4}{|c|}{ Temperature Data --Lake Mohave -- 1995} & \multicolumn{2}{|l|}{ Date $=$ Julian } \\
\hline & & . & 18.7 & 1 & 17.6 \\
\hline Date & 34836 & 3 & 18.5 & 3 & 17.6 \\
\hline Fish \# & 366 & 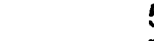 & 18.2 & & \\
\hline Waypoint & 32 & i & 18 & Date & 34850 \\
\hline Depth $(m)$ & Temp (C) & S & 17 & Fish \# & 2273 \\
\hline 0 & 18.8 & 1 & 15.8 & Waypoint & 33 \\
\hline 1 & 18.2 & 1 & 15.3 & Depth $(m)$ & Temp (C) \\
\hline 3 & 17.9 & 1 & 15 & 0 & 21.6 \\
\hline & & 1 & 14.8 & 1 & 21.6 \\
\hline Date & 34851 & & & 3 & 20.8 \\
\hline Fish \# & 348 & Date & 34851 & & \\
\hline Waypoint & 22 & Fish \# & $366-285$ & Date & 34851 \\
\hline Depth $(m)$ & Temp (C) & Waypoint & 33 & Fish \# & 2273 \\
\hline 0 & 19.2 & Depth $(m)$ & Temp (C) & Waypoint & 33 \\
\hline 1 & 19 & & 22.1 & Depth $(m)$ & Temp (C) \\
\hline 3 & 18.2 & & 22.1 & 0 & 21.5 \\
\hline 5 & 17.6 & & 22.1 & 1 & 21.5 \\
\hline 7 & 14.6 & & 21.7 & & \\
\hline 9 & 14.5 & & 21.5 & Date & 34852 \\
\hline & & & 21 & Fish \# & 88 \\
\hline Date & 34852 & 1 & 16.5 & Waypoint & 23 \\
\hline Fish \# & 2228 & 1 & 15.6 & Depth $(m)$ & Temp (C) \\
\hline Waypoint & 22 & & & 0 & 18.6 \\
\hline Depth (m) & Temp (C) & Date & 34852 & 1 & 18.5 \\
\hline 0 & 18.2 & Fish \# & 348 & 3 & 17.8 \\
\hline 1 & 18.2 & Waypoint & 21 & 5 & 17 \\
\hline 3 & 17.5 & Depth (m) & Temp (C) & 7 & 16.4 \\
\hline 5 & 16.9 & & 17.7 & 9 & 15 \\
\hline 7 & 15 & & 17.6 & 11 & 14.6 \\
\hline 9 & 14.5 & & 17.3 & & \\
\hline & & & 14.8 & Date & 34852 \\
\hline Date & 34852 & & & Fish \# & 276 \\
\hline Fish \# & 339 & Date & 34853 & Waypoint & 21 \\
\hline Waypoint & 20 & Fish \# & 465 & Depth (m) & Temp (C) \\
\hline Depth (m) & Temp (C) & Waypoint & 49 & 0 & 17.7 \\
\hline 0 & 17.5 & Depth $(m)$ & Temp (C) & 1 & 17.4 \\
\hline 1 & 17.5 & & 21.5 & 3 & 16.2 \\
\hline 3 & 17.4 & & 21.5 & 5 & 14.3 \\
\hline 5 & 15 & & 21.5 & 7 & 14.2 \\
\hline 7 & 14.2 & & 21.2 & 9 & 14.2 \\
\hline 9 & 14.2 & & & 11 & 14.2 \\
\hline 11 & 14.2 & Date & 34862 & & \\
\hline & & Fish \# & 2273 & Date & 34863 \\
\hline Date & 34864 & Waypoint & 33 & Fish \# & 88 \\
\hline Fish \# & 339 & Depth (m) & Temp (C) & Waypoint & 23 \\
\hline Waypoint & 20 & & 23 & Depth $(m)$ & Temp (C) \\
\hline Depth $(m)$ & Temp (C) & & 23 & 0 & 20.5 \\
\hline 0 & 19.3 & & 23 & 1 & 20.4 \\
\hline 1 & 19.2 & & & 3 & 19.6 \\
\hline 3 & 18.7 & Date & 34864 & 5 & 19.2 \\
\hline 5 & 17.4 & Fish \# & 2228 & 7 & 17.4 \\
\hline 7 & 15.5 & Waypoint & 21 & 9 & 16.6 \\
\hline 9 & 15.06 & Depth $(m)$ & Temp (C) & & \\
\hline
\end{tabular}




\begin{tabular}{|c|c|c|c|c|c|}
\hline \multicolumn{4}{|c|}{ Temperature Data --Lake Mohave -- 1995} & \multicolumn{2}{|l|}{ Date $=J u l i a n$} \\
\hline Date & 34879 & 1 & 24.6 & & \\
\hline Fish \# & $348-339$ & 3 & 24.4 & Date & 34880 \\
\hline Waypoint & 22 & 5 & 22.2 & Fish \# & 465 \\
\hline Depth $(m)$ & Temp (C) & 7 & 15.9 & Waypoint & 63 \\
\hline 0 & 24.5 & 9 & 15.1 & Depth $(m)$ & Temp (C) \\
\hline 1 & 24.5 & 11 & 15 & 0 & 24.3 \\
\hline 3 & 24.3 & & & 1 & 24.4 \\
\hline 5 & 17.2 & Date & 34891 & 3 & 24.4 \\
\hline 7 & 15.6 & Fish \# & 2273 & 5 & 24.4 \\
\hline 9 & 15.4 & Waypoint & 34 & 7 & 24.4 \\
\hline 11 & 14.9 & Depth $(m)$ & Temp (C) & 9 & 24.3 \\
\hline 13 & 14.9 & 0 & 27.8 & 11 & 24.2 \\
\hline & & 1 & 27.8 & 13 & 20.7 \\
\hline Date & 34892 & 3 & 27.8 & 15 & 18.4 \\
\hline Fish \# & $339-$ & & & & \\
\hline Waypoint & 17 & Date & 34892 & Date & 34892 \\
\hline Depth $(m)$ & Temp (C) & Fish \# & 348 & Fish \# & 384 \\
\hline 0 & 20.4 & Waypoint & 23 & Waypoint & 32 \\
\hline 1 & 21.3 & Depth $(m)$ & Temp (C) & Depth $(m)$ & Temp (C) \\
\hline 3 & 21 & 0 & 26.5 & 0 & 27.5 \\
\hline 5 & 19.1 & 1 & 26.5 & 1 & 27.5 \\
\hline 7 & 17.6 & 3 & 26.5 & 3 & 27.5 \\
\hline 9 & 16.7 & 5 & 26.1 & 5 & 27.4 \\
\hline 11 & 15.8 & 7 & 26.1 & 7 & 27.4 \\
\hline 13 & 15.5 & & & 9 & 27.2 \\
\hline 15 & 15.3 & $\begin{array}{l}\text { Date } \\
\text { Fish \# }\end{array}$ & $\begin{array}{r}34892 \\
375\end{array}$ & 11 & 22.5 \\
\hline Date & 34892 & Waypoint & 33 & Date & 34892 \\
\hline Fish \# & 2273 & Depth $(m)$ & Temp (C) & Fish \# & 88 \\
\hline Waypoint & 35 & 0 & 27.1 & Waypoint & 37 \\
\hline Depth $(m)$ & Temp (C) & 1 & 27.1 & Depth (m) & Temp (C) \\
\hline 0 & 27.3 & 3 & 27.1 & 0 & 28 \\
\hline 1 & 27.3 & 5 & 27 & 1 & 28 \\
\hline 3 & 27.3 & 7 & 27 & 3 & 27.9 \\
\hline 5 & 27.3 & 9 & 26.6 & 5 & 27.7 \\
\hline & & 11 & 20.5 & 7 & 27.6 \\
\hline Date & 34892 & 13 & 19.2 & 9 & 27.5 \\
\hline Fish \# & 465 & 15 & 18.2 & & \\
\hline Waypoint & 53 & 17 & 17.8 & Date & 34893 \\
\hline Depth $(m)$ & Temp (C) & & & Fish \# & 2273 \\
\hline 0 & 26.6 & Date & 34893 & Waypoint & 34 \\
\hline 1 & 26.6 & Fish \# & 348 & Depth $(m)$ & Temp (C) \\
\hline 3 & 26.7 & Waypoint & $?$ & 0 & 26.7 \\
\hline 5 & 26.6 & Depth $(m)$ & Temp (C) & 1 & 26.7 \\
\hline 7 & 26.6 & 0 & 25.4 & 3 & 26.7 \\
\hline 9 & 26.6 & 1 & 25.4 & & \\
\hline 11 & 24.5 & 3 & 25.4 & Date & 34904 \\
\hline 13 & 20.5 & 5 & 25.3 & Fish \# & 375 \\
\hline 15 & 18.8 & 7 & 24.1 & Waypoint & 53 \\
\hline 17 & 17.5 & 9 & 19.2 & Depth $(m)$ & Temp (C) \\
\hline & & 11 & 18 & 0 & 27.9 \\
\hline Date & 34905 & & & 1 & 28.5 \\
\hline Fish \# & 2228 & Date & 34904 & 3 & 27.7 \\
\hline
\end{tabular}




\begin{tabular}{|c|c|c|c|c|c|}
\hline \multicolumn{4}{|c|}{ Temperature Data --Lake Mohave -- 1995} & \multicolumn{2}{|l|}{ Date $=$ Julian } \\
\hline Waypoint & 19 & Fish \# & 465 & & 27.7 \\
\hline Depth (m) & Temp (C) & Waypoint & 46 & 7 & 27.6 \\
\hline 0 & 24.9 & Depth $(m)$ & Temp (C) & 9 & 26.8 \\
\hline 1 & 23.3 & 0 & 27.7 & 11 & 26.2 \\
\hline 3 & 21 & 1 & 27.8 & 13 & 20.1 \\
\hline 5 & 18.2 & 3 & 27.8 & 15 & 18.7 \\
\hline 7 & 17.6 & 5 & 27.7 & 17 & 18.2 \\
\hline 9 & 17.2 & 7 & 27.6 & 19 & 17.8 \\
\hline & & 9 & 26.6 & 21 & 17.7 \\
\hline Date & 34905 & 11 & 25.1 & 23 & 17.6 \\
\hline Fish \# & 339 & 13 & 20 & & \\
\hline Waypoint & 20 & 15 & 18.4 & Date & 34905 \\
\hline Depth $(m)$ & Temp (C) & & & Fish \# & 348 \\
\hline 0 & 26.9 & Date & _34905 & Waypoint & 22 \\
\hline 1 & 26.9 & Fish \# & 88 & Depth $(m)$ & Temp (C) \\
\hline 3 & 25.2 & Waypoint & 35 & 0 & 27.6 \\
\hline 5 & 20.7 & Depth $(m)$ & Temp (C) & 1 & 27.6 \\
\hline 7 & 19.3 & 0 & 27.7 & 3 & 27.4 \\
\hline & & 1 & 27.7 & 5 & 27.3 \\
\hline Date & 34907 & 3 & 27.7 & 7 & 25 \\
\hline Fish \# & 88 & 5 & 27.7 & & \\
\hline Waypoint & 36 & 7 & 27.6 & Date & 34907 \\
\hline Depth (m) & Temp (C) & 9 & 27.6 & Fish \# & 384 \\
\hline 0 & 28 & 11 & 21.4 & Waypoint & 32 \\
\hline 1 & 27.9 & 13 & 19 & Depth $(m)$ & Temp (C) \\
\hline 3 & 27.9 & 15 & 17.7 & 0 & 28 \\
\hline 5 & 27.8 & 17 & 17.4 & 1 & 28 \\
\hline 7 & 27.7 & 19 & 17.1 & 3 & 28 \\
\hline 9 & 27.6 & & & 5 & 28 \\
\hline 11 & 22.7 & Date & 34907 & 7 & 27.6 \\
\hline 13 & 20 & Fish \# & 2273 & 9 & 24.7 \\
\hline 15 & 18.4 & Waypoint & 32 & 11 & 19.4 \\
\hline 17 & 17.8 & Depth $(m)$ & Temp (C) & 13 & 18.2 \\
\hline 19 & 17.4 & 0 & 27.6 & 15 & 18 \\
\hline 21 & 17 & 1 & 27.6 & 17 & 17.8 \\
\hline & & 3 & 27.5 & & \\
\hline Date & 34907 & & & Date & 34907 \\
\hline Fish \# & 366 & Date & 34907 & Fish \# & 339 \\
\hline Waypoint & 25 & Fish \# & 348 & Waypoint & 20 \\
\hline Depth $(m)$ & Temp (C) & Waypoint & 23 & Depth $(m)$ & Temp (C) \\
\hline 0 & 27.2 & Depth $(m)$ & Temp (C) & 0 & 26.3 \\
\hline 1 & 27.3 & 0 & 26.9 & 1 & 26.4 \\
\hline 3 & 27.3 & 1 & 26.9 & 3 & 26.3 \\
\hline 5 & 27.3 & 3 & 26.9 & 5 & 25.2 \\
\hline 7 & 24 & 5 & 26.9 & 7 & 16.1 \\
\hline & & 7 & 21.3 & 9 & 15.2 \\
\hline Date & 34908 & 8 & 18 & 11 & 14.8 \\
\hline Fish \# & 88 & & & 13 & 14.8 \\
\hline Waypoint & 40 & Date & 34908 & 15 & 14.7 \\
\hline $\operatorname{Depth}(m)$ & Temp (C) & Fish \# & 276 & 17 & 14.7 \\
\hline 0 & 29.4 & Waypoint & 46 & & \\
\hline 1 & 29.4 & Depth $(m)$ & Temp (C) & Date & 34908 \\
\hline 3 & 28.2 & 0 & 27.9 & Fish \# & 375 \\
\hline
\end{tabular}




\begin{tabular}{|c|c|c|c|c|c|}
\hline \multicolumn{4}{|c|}{ Temperature Data --Lake Mohave -- 1995} & \multicolumn{2}{|l|}{ Date $=$ Julian } \\
\hline 5 & 28 & 1 & 27.9 & Waypoint & 46 \\
\hline 7 & 27.9 & 3 & 27.9 & Depth $(m)$ & Temp (C) \\
\hline 9 & 25.4 & 5 & 27.9 & 0 & 27.7 \\
\hline 11 & 19.9 & 7 & 27.8 & 1 & 27.7 \\
\hline 13 & 19 & 9 & 24.3 & 3 & 27.7 \\
\hline 15 & 18.3 & 11 & 20 & 5 & - $\quad 27.7$ \\
\hline 17 & 18 & & & 7 & 27.7 \\
\hline 19 & 17.8 & Date & 34908 & 9 & 22.42 \\
\hline 21 & 17.8 & Fish \# & 2273 & 11 & 20 \\
\hline 23 & 17.8 & Waypoint & 32 & 13 & 18.6 \\
\hline 25 & 17.4 & Depth $(m)$ & Temp (C) & 15 & 18.3 \\
\hline & & 0 & 29.4 & 17 & 18.2 \\
\hline Date & 34920 & 1 & 29.4 & 19 & 17.9 \\
\hline Fish \# & 2228 & 3 & 29.4 & 21 & 17.7 \\
\hline Waypoint & 14 & 5 & 29.4 & 23 & 17.4 \\
\hline Depth (m) & Temp (C) & 7 & 28.4 & 25 & 17.3 \\
\hline 0 & 15.4 & 9 & 22.6 & & \\
\hline 1 & 15.2 & & & Date & 34920 \\
\hline 3 & 14.3 & Date & 34920 & Fish \# & 2273 \\
\hline 5 & 14.2 & Fish \# & 339 & Waypoint & 32 \\
\hline & & Waypoint & 23 & Depth (m) & Temp (C) \\
\hline Date & 34920 & Depth $(m)$ & Temp (C) & 0 & 29.4 \\
\hline Fish \# & 348 & 0 & 29 & 1 & 29.4 \\
\hline Waypoint & 22 & 1 & 29 & 3 & 29.4 \\
\hline Depth (m) & Temp (C) & 3 & 28.9 & 5 & 29.4 \\
\hline 0 & 28.8 & 5 & 27.4 & 7 & 29.3 \\
\hline 1 & 28.7 & 7 & 19 & & \\
\hline 3 & 28.7 & & & Date & 34920 \\
\hline 5 & 28.1 & Date & 34920 & Fish \# & 88 \\
\hline 7 & 17.3 & Fish \# & 384 & Waypoint & 35 \\
\hline 9 & 15.7 & Waypoint & 46 & Depth (m) & Temp (C) \\
\hline & & Depth (m) & Temp (C) & 0 & 29.3 \\
\hline Date & 34920 & 0 & 29.8 & 1 & 29.3 \\
\hline Fish \# & 465 & 1 & 29.8 & 3 & 29.3 \\
\hline Waypoint & 46 & 3 & 29.8 & 5 & 29.2 \\
\hline Depth (m) & Temp (C) & 5 & 29.8 & 7 & 29.1 \\
\hline 0 & 29.7 & 7 & 29.7 & 9 & 22.2 \\
\hline 1 & 29.7 & 9 & 24.8 & 11 & 19 \\
\hline 3 & 29.7 & 11 & 19.5 & 13 & 17.7 \\
\hline 5 & 29.7 & 13 & 18.3 & 15 & 17.2 \\
\hline 7 & 29.6 & & & 17 & 17.1 \\
\hline 9 & 22 & Date & 34920 & 19 & 16.7 \\
\hline 11 & 18.9 & Fish \# & $375-276$ & & \\
\hline 13 & 17.8 & Waypoint & 53 & Date & 34922 \\
\hline & & Depth (m) & Temp (C) & Fish \# & 276 \\
\hline Date & 34920 & 0 & 29.6 & Waypoint & $?$ \\
\hline Fish \# & 2273 & 1 & 29.6 & Depth $(m)$ & Temp (C) \\
\hline Waypoint & 32 & 3 & 29.6 & 0 & 29.2 \\
\hline Depth $(m)$ & Temp (C) & 5 & 29.6 & 1 & 29.2 \\
\hline 0 & 29.3 & 7 & 29.6 & 3 & 29.2 \\
\hline 1 & 29.3 & 9 & 22.2 & 5 & 29.2 \\
\hline 3 & 29.3 & 11 & 19.1 & 7 & 29.2 \\
\hline 5 & 29.3 & 13 & 17.9 & 9 & 22.1 \\
\hline
\end{tabular}




\begin{tabular}{|c|c|c|c|c|c|}
\hline \multicolumn{4}{|c|}{ Temperature Data --Lake Mohave -- 1995} & \multicolumn{2}{|l|}{ Date $=$ Julian } \\
\hline 7 & 29.2 & 1 & 17.6 & 11 & 20 \\
\hline & & 1 & 17.4 & 13 & 18.1 \\
\hline Date & 34932 & 1 & 17.2 & 15 & 17.9 \\
\hline Fish \# & 384 & 2 & 17.1 & 17 & 17.8 \\
\hline Waypoint & 53 & & & 19 & 17.7 \\
\hline Depth (m) & Temp (C) & Date & 34932 & 21 & 17.5 \\
\hline 0 & 28.9 & Fish \# & 465 & & \\
\hline 1 & 28.9 & Waypoint & 53 & Date & 34932 \\
\hline 3 & 28.5 & Depth (m) & Temp (C) & Fish \# & 276 \\
\hline 5 & 28.1 & & 29.9 & Waypoint & 46 \\
\hline 7 & 28 & & 29 & Depth $(m)$ & Temp (C) \\
\hline 9 & 22.7 & & 28.2 & 0 & 29.3 \\
\hline 11 & 19.3 & & 28.1 & 1 & 29.3 \\
\hline 13 & 18.3 & & 28 & 3 & 28.4 \\
\hline 15 & 18.1 & & & 5 & 28.1 \\
\hline 17 & 18 & Date & 34932 & 7 & 28 \\
\hline 19 & 17.7 & Fish \# & 375 & 9 & 23.3 \\
\hline 21 & 17.5 & Waypoint & 46 & 11 & 19.1 \\
\hline 23 & 17.3 & Depth (m) & Temp (C) & 13 & 18.2 \\
\hline & & & 29.8 & 15 & 18.2 \\
\hline Date & 34934 & & 29.8 & 17 & 18 \\
\hline Fish \# & 2228 & & 28.4 & & \\
\hline Waypoint & 12 & & 28.1 & Date & 34934 \\
\hline Depth (m) & Temp (C) & & 28 & Fish \# & 339 \\
\hline 0 & 14.1 & & 23.3 & Waypoint & 17 \\
\hline 15 & 14.1 & 1 & 19.5 & Depth (m) & Temp (C) \\
\hline & & 1 & 18.5 & 0 & 14.3 \\
\hline Date & 34934 & & & 15 & 14.3 \\
\hline Fish \# & 88 & Date & 34935 & & \\
\hline Waypoint & 35 & Fish \# & 2273 & Date & 34935 \\
\hline Depth (m) & Temp (C) & Waypoint & 32 & Fish \# & 88 \\
\hline 0 & 29.3 & Depth $(m)$ & Temp (C) & Waypoint & 36 \\
\hline 1 & 29.3 & & 29.1 & Depth (m) & Temp (C) \\
\hline 3 & 29.2 & & 29.1 & 0 & 28.9 \\
\hline 5 & 28.9 & & 29.1 & 1 & 28.9 \\
\hline 7 & 25.9 & & 28.3 & 3 & 28.9 \\
\hline 9 & 22.5 & & 26.7 & 5 & 28.8 \\
\hline 11 & 20.3 & & 22.8 & 7 & 28.5 \\
\hline 13 & 18.5 & 1 & 17.2 & 9 & 23.1 \\
\hline 15 & 17.5 & 1 & 16.9 & 11 & 19.9 \\
\hline 17 & 16.6 & & & 13 & 18.3 \\
\hline 19 & 16.4 & Date & 34935 & 15 & 17.5 \\
\hline & & Fish \# & 339 & & \\
\hline Date & 34935 & Waypoint & 10 & Date & 34936 \\
\hline Fish \# & 2228 & Depth $(m)$ & Temp (C) & Fish \# & $375-276$ \\
\hline Waypoint & 12 & & 13.9 & Waypoint & 46 \\
\hline Depth (m) & Temp (C) & & 13.8 & Depth (m) & Temp (C) \\
\hline 0 & 14.1 & & & 0 & 28.2 \\
\hline 9 & 13.9 & Date & 34936 & 1 & 28.2 \\
\hline & & Fish \# & 465 & 3 & 28.2 \\
\hline Date & 34936 & Waypoint & 46 & 5 & 28.1 \\
\hline Fish \# & 384 & Depth (m) & Temp (C) & 7 & 27.9 \\
\hline Waypoint & 46 & & 28.1 & 9 & 26.6 \\
\hline
\end{tabular}




\begin{tabular}{|c|c|c|c|c|c|}
\hline & \multicolumn{2}{|l|}{ Date $=$ Julian } \\
\hline \multicolumn{4}{|c|}{ Depth $(m)$ Temp (C) } & 11 & 20.1 \\
\hline 0 & 28 & 3 & 28.1 & 13 & 18.9 \\
\hline 1 & 28.1 & 5 & 28.1 & 15 & 17.8 \\
\hline 3 & 28.1 & 7 & 28 & & \\
\hline 5 & 28.1 & 9 & 26.4 & Date & 34936 \\
\hline 7 & 28 & 11 & 19.9 & Fish \# & 258 \\
\hline \multirow[t]{2}{*}{9} & 26.4 & 13 & 18.5 & Waypoint & 46 \\
\hline & & 15 & 18.4 & Depth $(m)$ & Temp (C) \\
\hline Date & 34948 & & & 0 & 28.1 \\
\hline Fish \# & 2273 & Date & 34936 & 1 & 28.2 \\
\hline Waypoint & 35 & Fish \# & 375 & 3 & 28.2 \\
\hline \multirow{7}{*}{ Depth $(\mathrm{m})$} & Temp (C) & Waypoint & 46 & 5 & 28.2 \\
\hline & 28.5 & Depth $(m)$ & Temp (C) & 7 & 28.1 \\
\hline & 28.6 & 0 & 29.6 & 9 & 26.1 \\
\hline & 28.6 & 1 & 29.6 & 11 & 21 \\
\hline & 28.5 & 3 & 29.5 & 13 & 18.7 \\
\hline & \multirow[t]{2}{*}{28.4} & 5 & 29.4 & 15 & 18 \\
\hline & & 7 & 29.4 & 17 & 17.8 \\
\hline Date & 34949 & 9 & 29.4 & 19 & 17.8 \\
\hline Fish \# & 339 & 11 & 19.8 & 21 & 17.7 \\
\hline Waypoint & 5 & 13 & 19.4 & 23 & 17.3 \\
\hline \multicolumn{6}{|c|}{ Depth (m) Temp (C) } \\
\hline 0 & 14.1 & Date & 34949 & Date & 34949 \\
\hline \multirow[t]{2}{*}{9} & \multirow[t]{2}{*}{14} & Fish \# & 2228 & Fish \# & 348 \\
\hline & & Waypoint & 12 & Waypoint & 22 \\
\hline Date & 34949 & Depth $(m)$ & Temp (C) & Depth (m) & Temp (C) \\
\hline Fish \# & 2273 & 0 & 14.2 & 0 & 28.6 \\
\hline Waypoint & 33 & 11 & 13.9 & 1 & 28.6 \\
\hline \multicolumn{2}{|c|}{ Depth (m) Temp (C) } & & & 3 & 28.4 \\
\hline 0 & 28.9 & Date & 34949 & 5 & 28.2 \\
\hline 1 & 28.9 & Fish \# & 88 & 7 & 26 \\
\hline 3 & 28.9 & Waypoint & 35 & 9 & 17 \\
\hline 5 & 28.9 & Depth $(m)$ & Temp (C) & & \\
\hline 7 & 27.8 & 0 & 28.8 & Date & 34949 \\
\hline 9 & 20.2 & 1 & 28.8 & Fish \# & 276 \\
\hline 11 & 18.6 & 3 & 28.8 & Waypoint & 45 \\
\hline 13 & 18.3 & 5 & 28.8 & Depth $(m)$ & Temp (C) \\
\hline \multirow[t]{2}{*}{15} & \multirow[t]{2}{*}{18} & 7 & 28.7 & 0 & 29.2 \\
\hline & & 9 & 22.1 & 1 & 29.2 \\
\hline Date & 34949 & 11 & 19.5 & 3 & 29.2 \\
\hline Fish \# & 384 & 13 & 18.8 & 5 & 29.2 \\
\hline Waypoint & 46 & 15 & 18.2 & 7 & 29 \\
\hline Depth $(m)$ & Temp (C) & 17 & 17.8 & 9 & 25.2 \\
\hline 0 & 29.2 & 19 & 16.8 & 11 & 20.3 \\
\hline 1 & 29.2 & & & 13 & 19 \\
\hline 3 & 29.2 & Date & 34949 & 15 & 18.2 \\
\hline 5 & 29.2 & Fish \# & 375 & 17 & 17.7 \\
\hline 7 & 28 & Waypoint & 53 & 19 & 17.5 \\
\hline 9 & 23.7 & Depth $(m)$ & Temp (C) & & \\
\hline 11 & 19.5 & 0 & 29.2 & Date & 34949 \\
\hline 13 & 19 & 1 & 29.2 & Fish \# & 465 \\
\hline 15 & 18.7 & 3 & 29.2 & Waypoint & 54 \\
\hline & & 5 & 29.2 & Depth (m) & Temp (C) \\
\hline
\end{tabular}




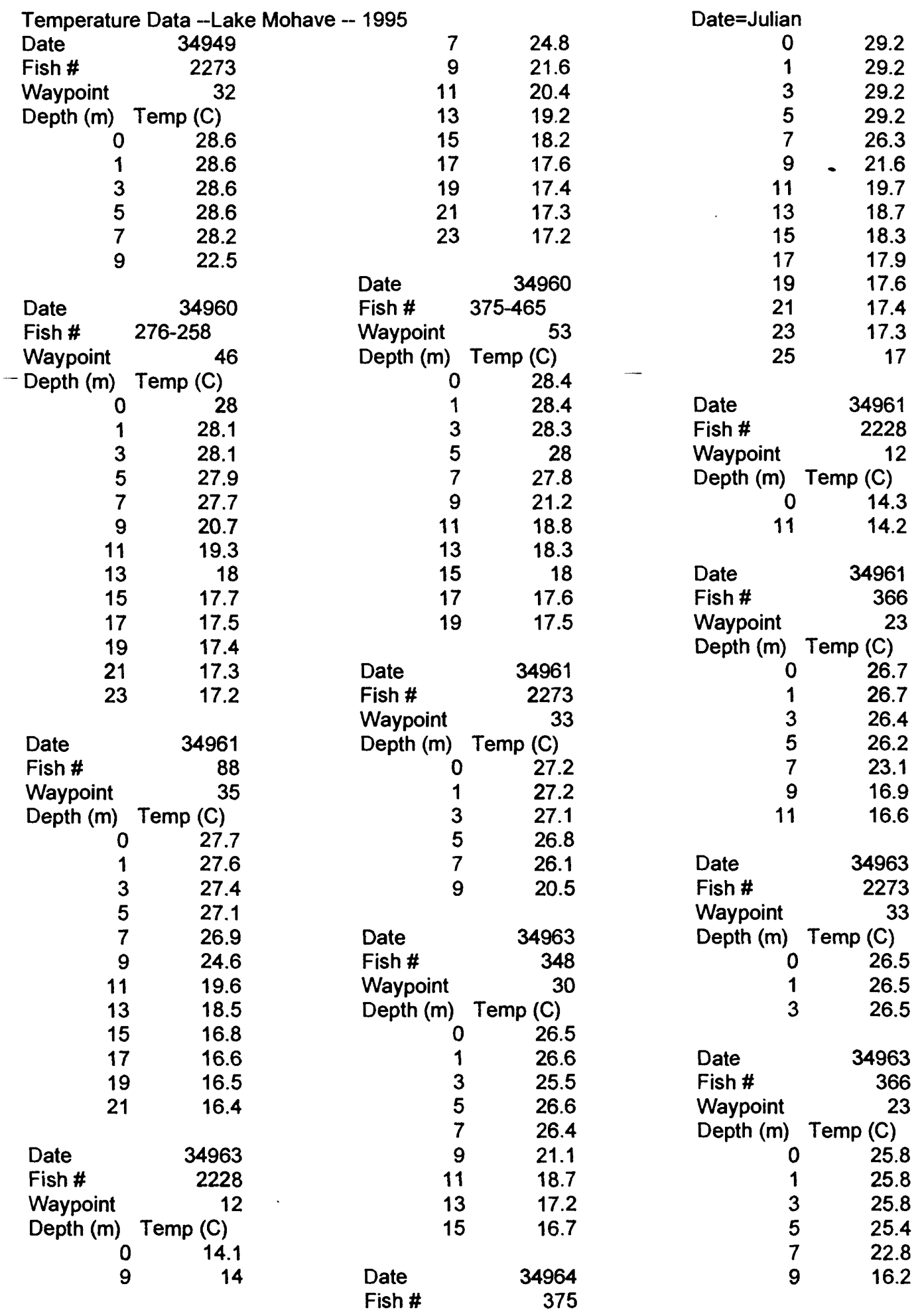




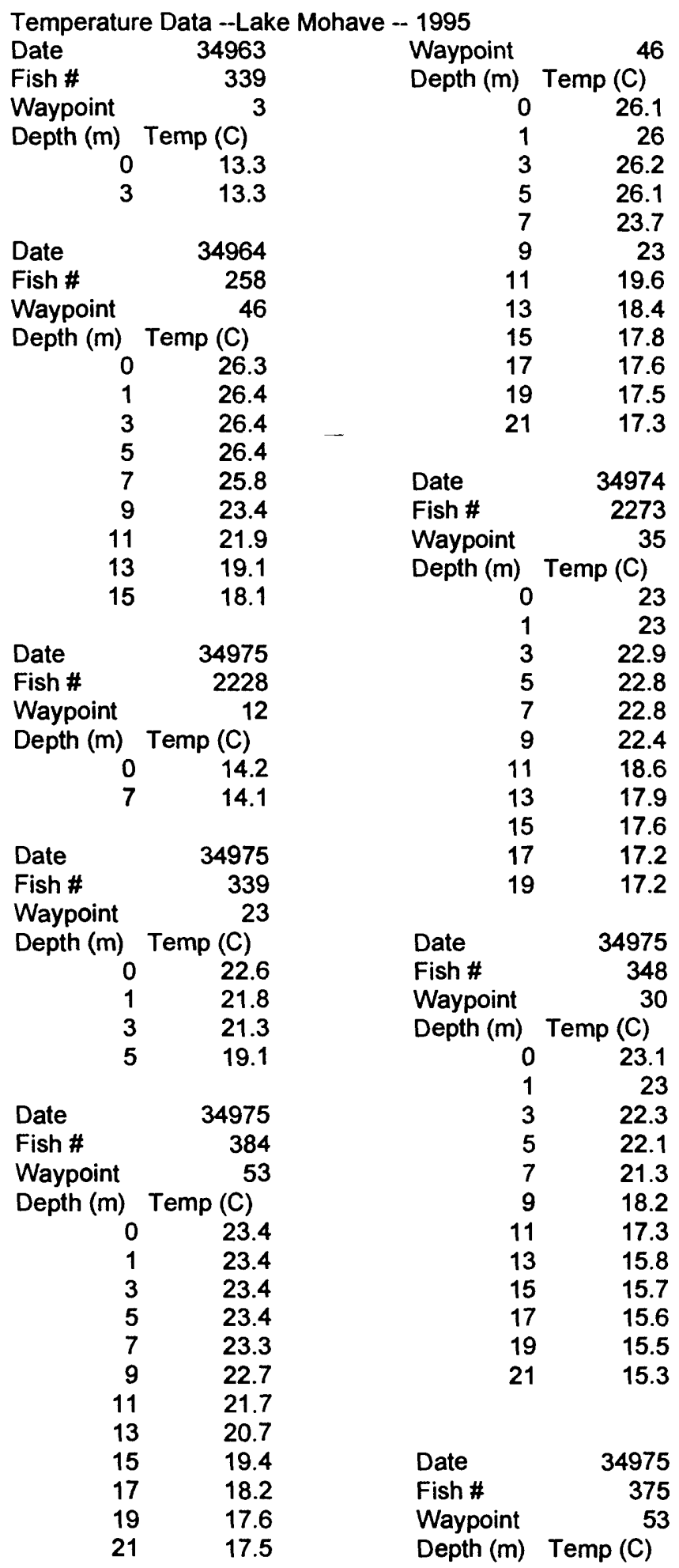

\begin{tabular}{|c|c|}
\hline Date $=$ Juliar & \\
\hline Date & 34964 \\
\hline Fish \# & 276 \\
\hline Waypoint & 53 \\
\hline Depth $(m)$ & Temp (C) \\
\hline 0 & 26.3 \\
\hline 1 & $\begin{array}{l}-\quad 26.4 \\
\end{array}$ \\
\hline 3 & 26.4 \\
\hline 5 & 26.4 \\
\hline 7 & 24.4 \\
\hline 9 & 23.2 \\
\hline Date & 34964 \\
\hline Fish \# & 384 \\
\hline Waypoint & 46 \\
\hline Depth $(m)$ & Temp (C) \\
\hline 0 & 26.2 \\
\hline 1 & 26.2 \\
\hline 3 & 26.2 \\
\hline 5 & 26.2 \\
\hline 7 & 25.2 \\
\hline 9 & 23.3 \\
\hline 11 & 20.6 \\
\hline 13 & 18.4 \\
\hline Date & 34975 \\
\hline Fish \# & 366 \\
\hline Waypoint & 23 \\
\hline Depth $(m)$ & Temp (C) \\
\hline 0 & 22.3 \\
\hline 1 & 21.8 \\
\hline 3 & 21.6 \\
\hline 5 & 19.4 \\
\hline 7 & 15.7 \\
\hline 9 & 15.2 \\
\hline Date & 34975 \\
\hline Fish \# & 88 \\
\hline Waypoint & 35 \\
\hline Depth $(m)$ & Temp (C) \\
\hline 0 & 22.9 \\
\hline 1 & 22.9 \\
\hline 3 & 22.9 \\
\hline 5 & 22.9 \\
\hline 7 & 22.7 \\
\hline 9 & 21.5 \\
\hline 11 & 19.2 \\
\hline 13 & 17.7 \\
\hline 15 & 17.3 \\
\hline 17 & 17.1 \\
\hline 19 & 16.7 \\
\hline Date & 34975 \\
\hline Fish \# & 465 \\
\hline
\end{tabular}




\begin{tabular}{|c|c|c|c|c|c|}
\hline \multicolumn{4}{|c|}{ Temperature Data --Lake Mohave - 1995} & \multirow{3}{*}{$\begin{array}{l}\text { Date=Julian } \\
\text { Waypoint } \\
\text { Depth }(m)\end{array}$} & \multirow{2}{*}{41} \\
\hline & & 0 & 23.4 & & \\
\hline Date & 34975 & 1 & 23.4 & & Temp (C) \\
\hline Fish \# & 2273 & 3 & 23.4 & 0 & 23.3 \\
\hline Waypoint & $?$ & 5 & 23.4 & 1 & 23.3 \\
\hline Depth $(m)$ & Temp (C) & 7 & 22.8 & 3 & 23.3 \\
\hline 0 & 22.2 & 9 & 22.2 & 5 & - $\quad 23.3$ \\
\hline 1 & 22.2 & 11 & 21.9 & 7 & 23.3 \\
\hline 3 & 22.2 & 13 & 20 & 9 & 23.3 \\
\hline 5 & 22.2 & 15 & 18.1 & 11 & 23.2 \\
\hline 7 & 22.2 & 17 & 17.8 & 13 & 22.5 \\
\hline 9 & 20.3 & 19 & 17.6 & 15 & 18.5 \\
\hline 11 & 18.3 & 21 & 17.5 & 17 & 17.6 \\
\hline 13 & 17.5 & & & 19 & 17.6 \\
\hline & & & & 21 & 17.4 \\
\hline Date & 34976 & & & & \\
\hline Fish \# & 88 & & & & \\
\hline Waypoint & 35 & & & & \\
\hline Depth $(m)$ & Temp (C) & & & & \\
\hline 0 & 22.2 & & & & \\
\hline 1 & 22.2 & & & & \\
\hline 3 & 22.2 & & & & \\
\hline 5 & 22.2 & & & & \\
\hline 7 & 22.2 & & & & \\
\hline 9 & 22.1 & & & & \\
\hline 11 & 17.8 & & & & \\
\hline 13 & 17.3 & & & & \\
\hline 15 & 17.1 & & & & \\
\hline 17 & 16.9 & & & & \\
\hline 19 & 16.7 & & & & \\
\hline
\end{tabular}


Appendix D. Individual Movement Maps 


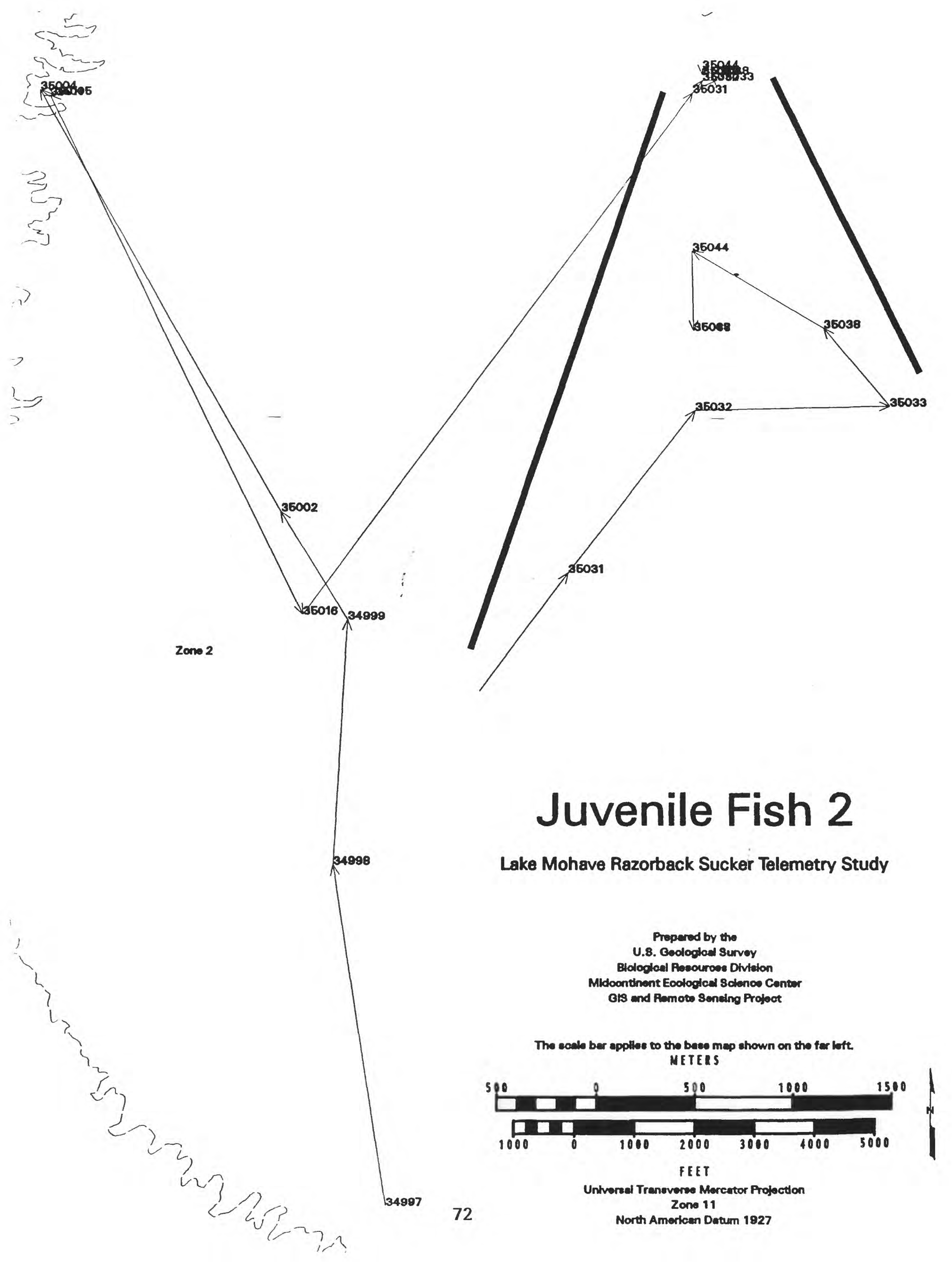




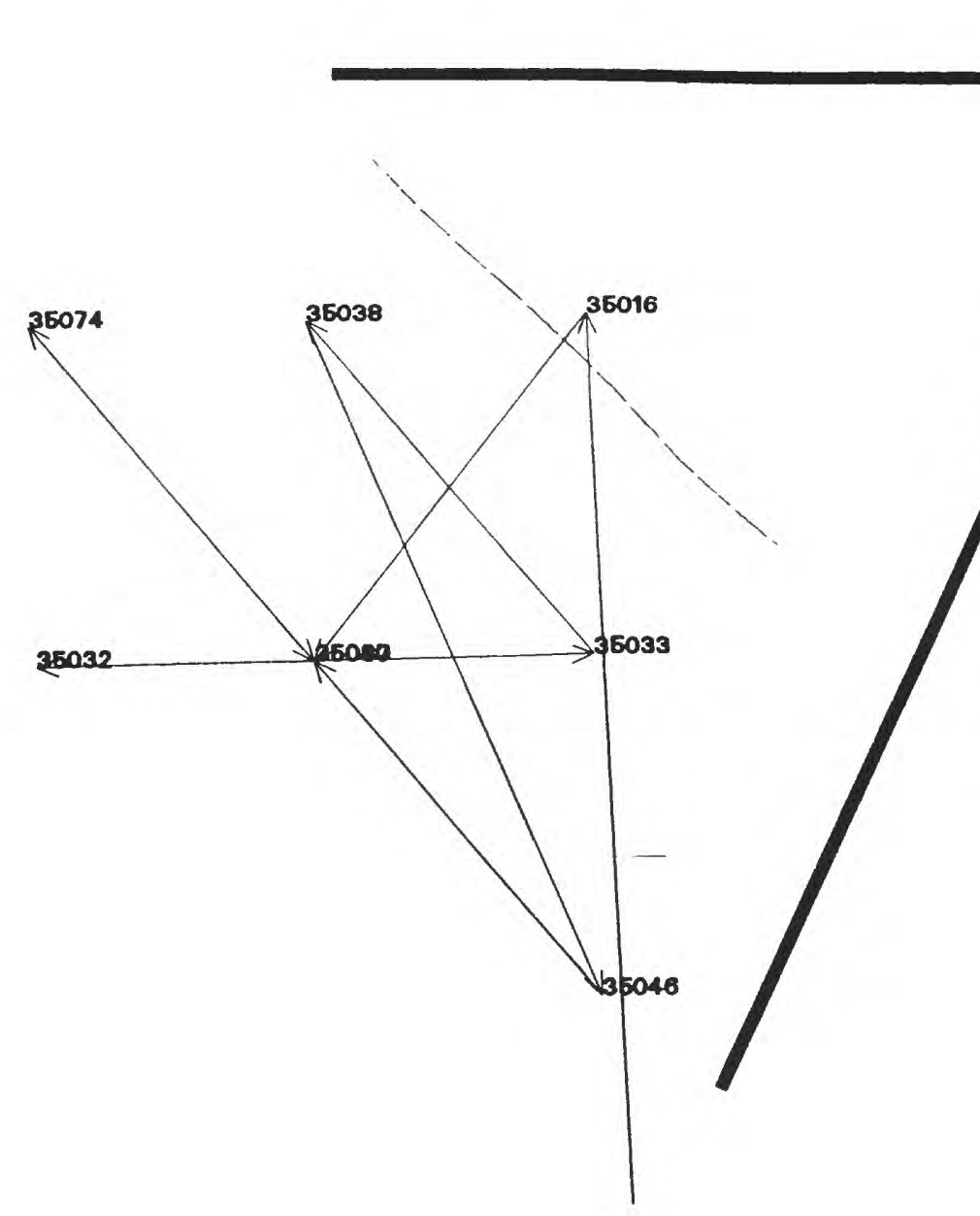

\section{Juvenile Fish 7}

Lake Mohave Razorback Sucker Telemetry Study

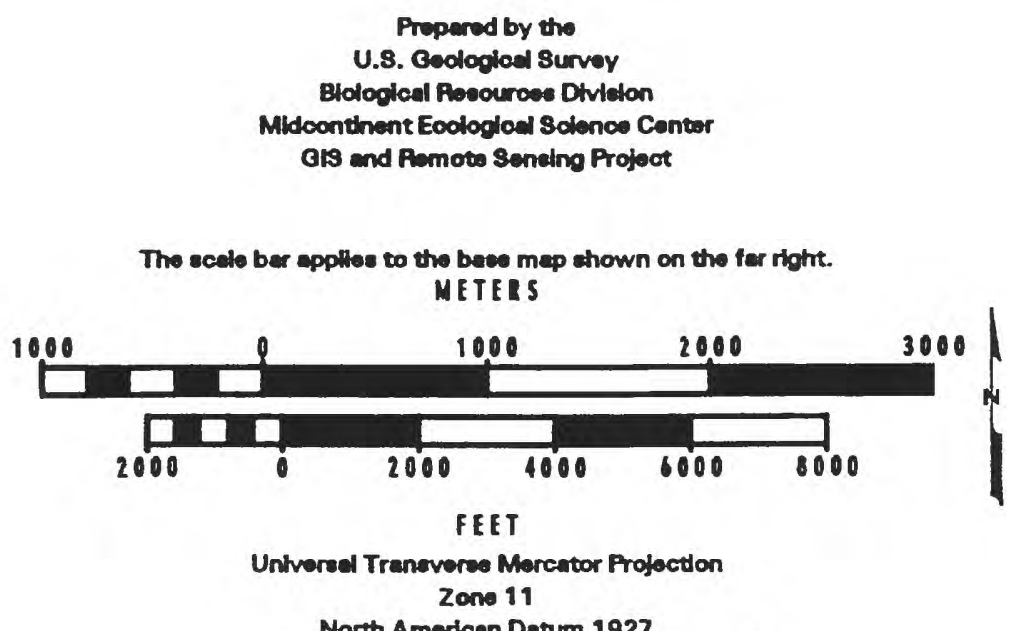




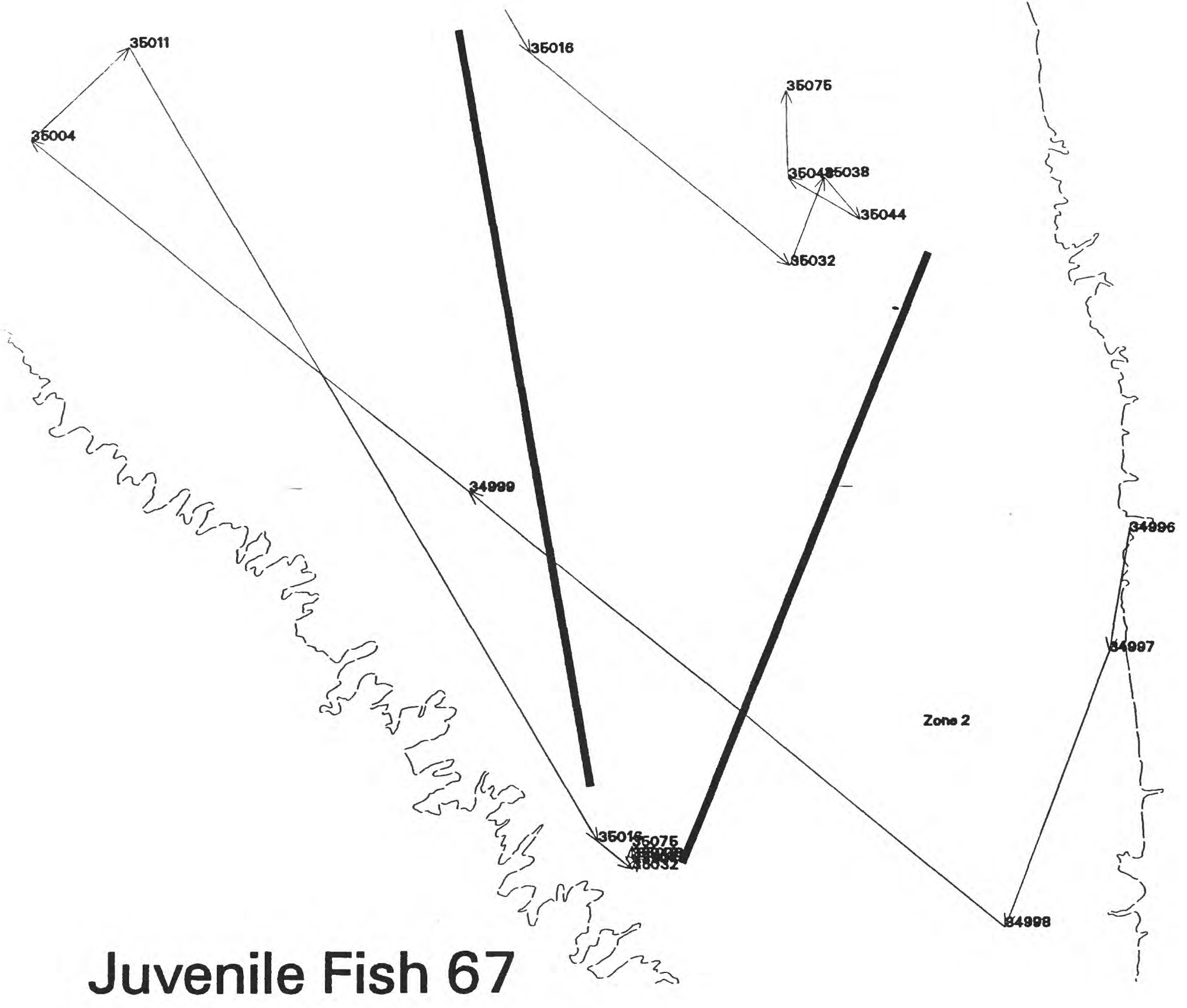

Lake Mohave Razorback Sucker Telemetry Study

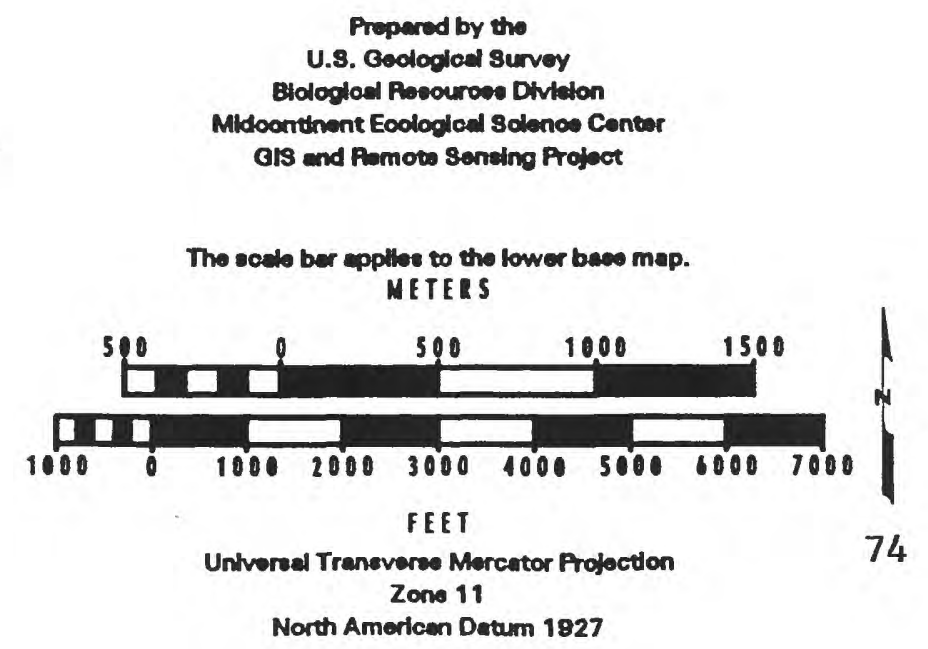




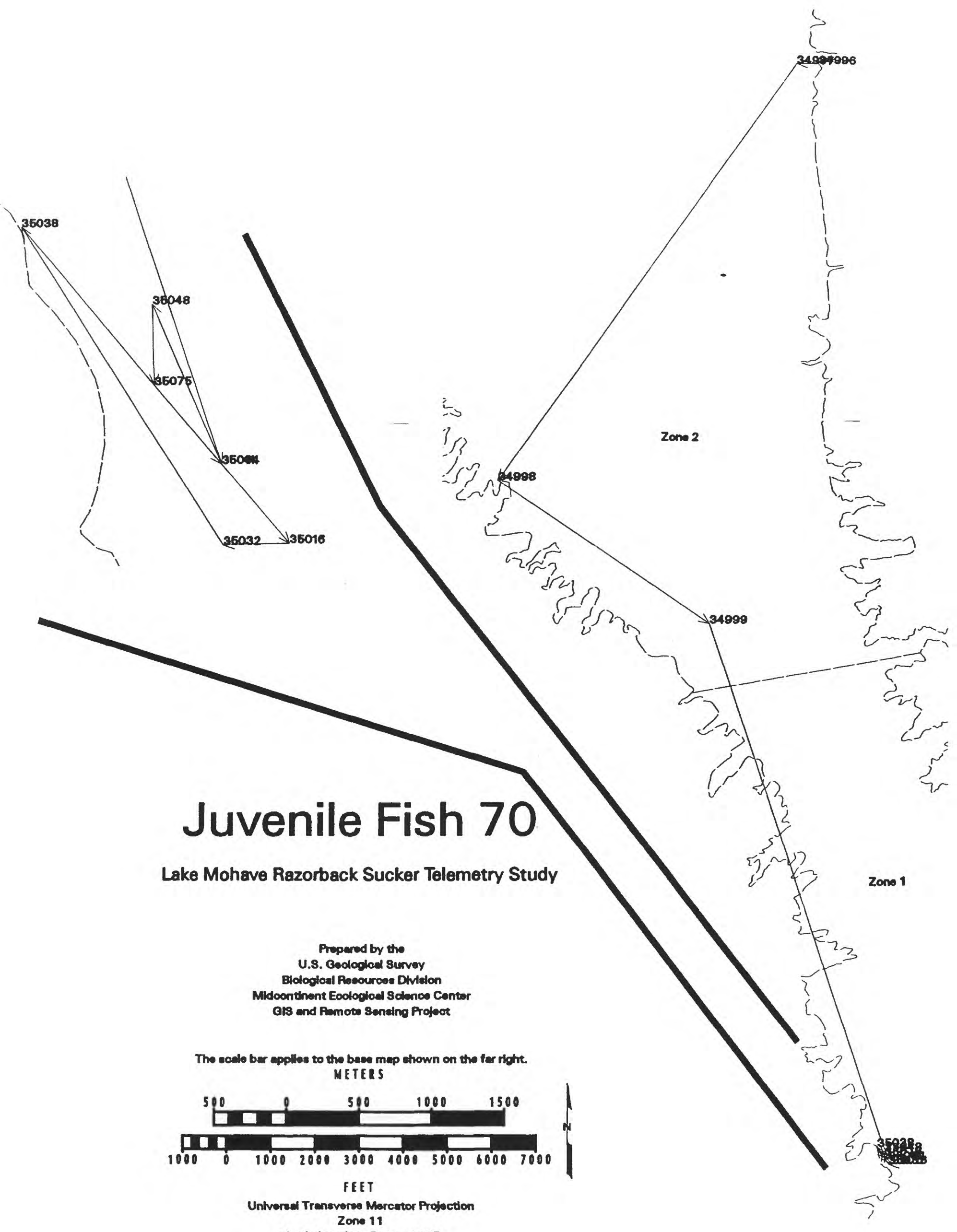

North Americen Datum 1827 


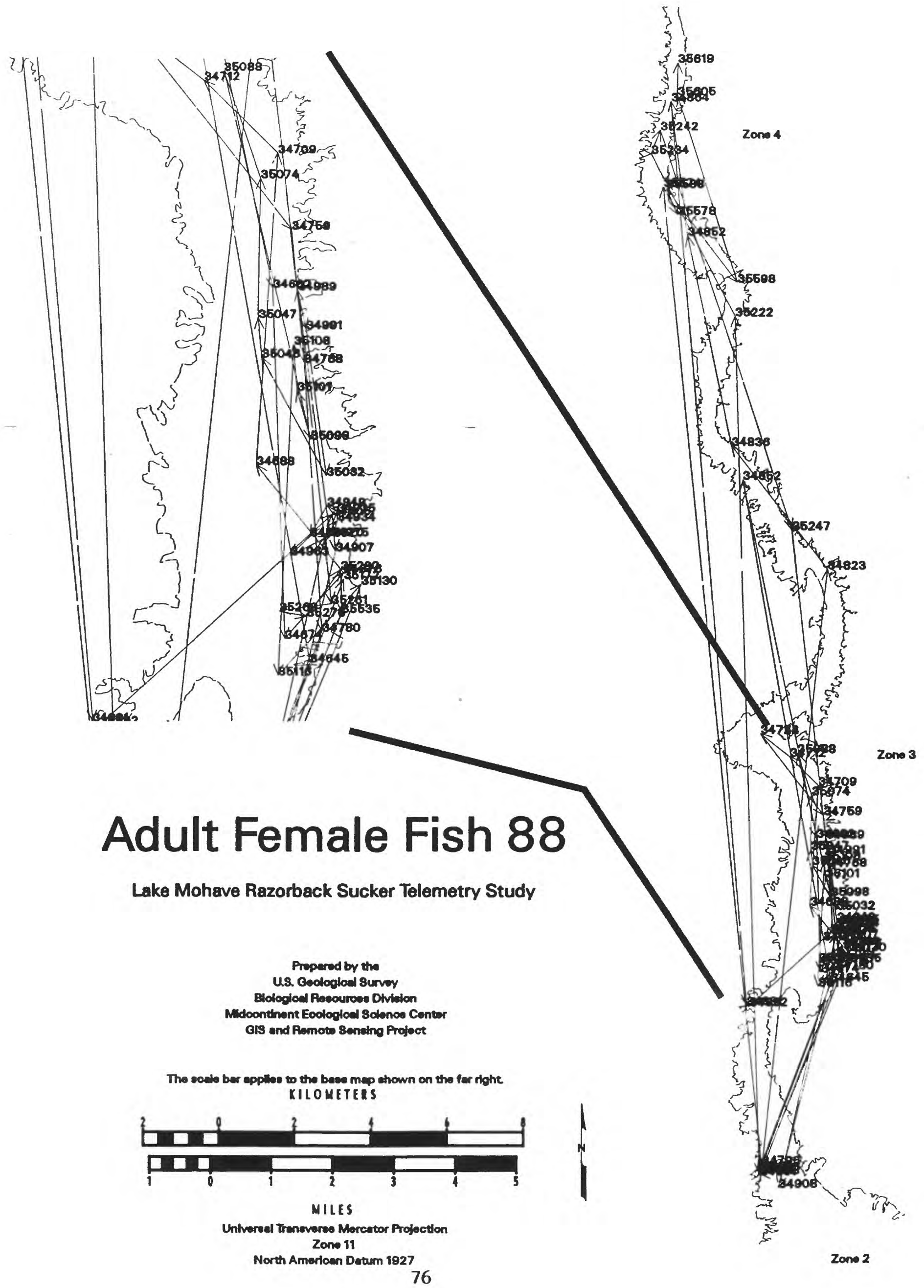



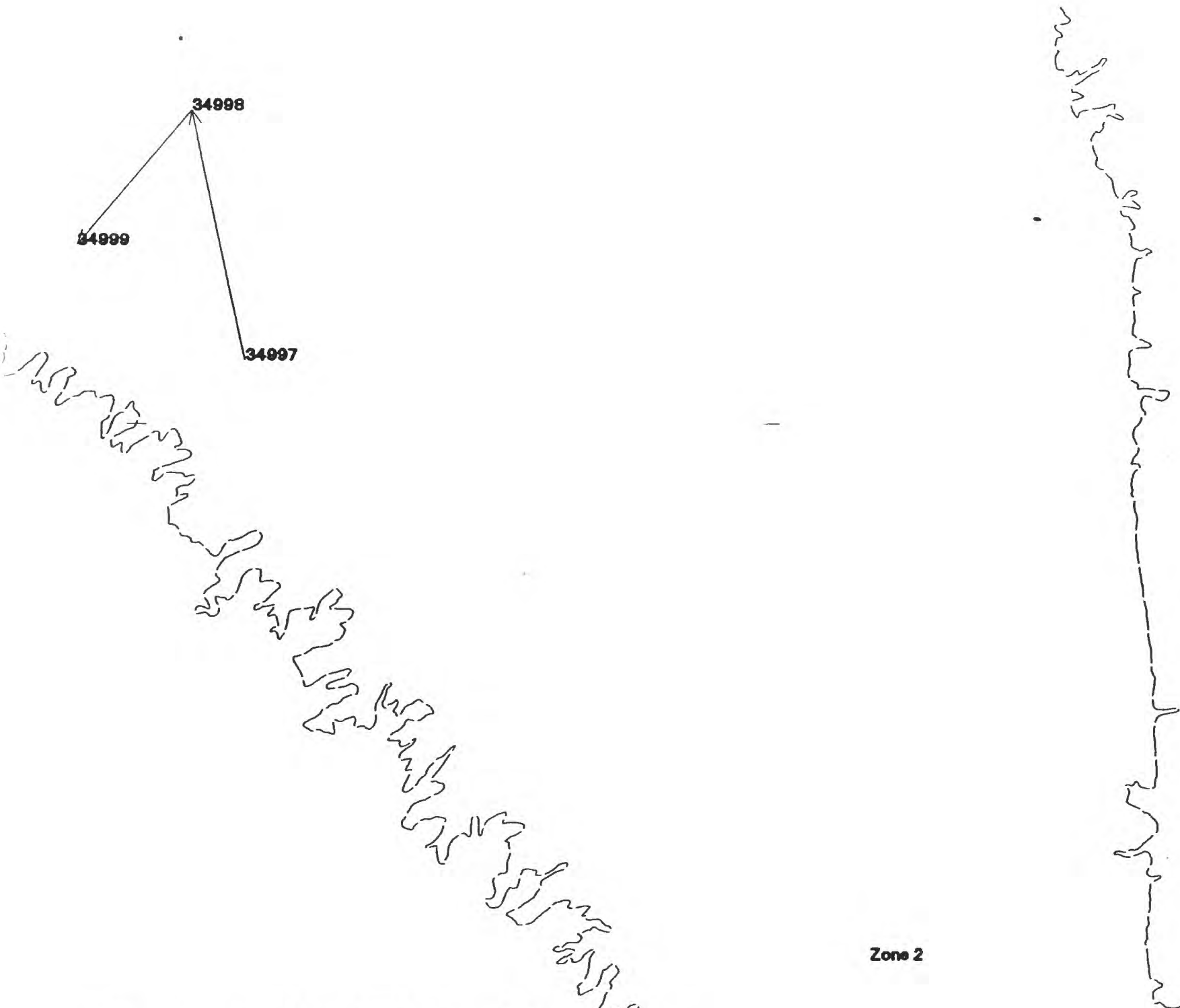

Juvenile Fish 13

Zone 2

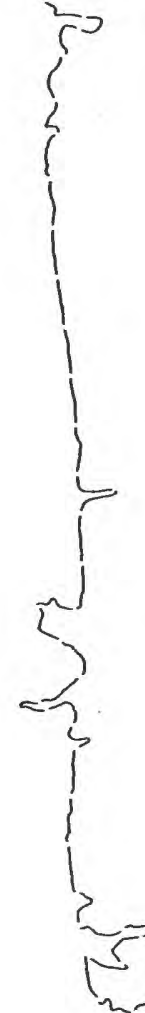

Lake Mohave Razorback Sucker Telemetry Study

Prepared by the

U.S. Goologloel Survey

Biological Rosourcees Diviaion

Midoonthent Eoologloel Solonco Conter

GIS and Remote Seneing Project

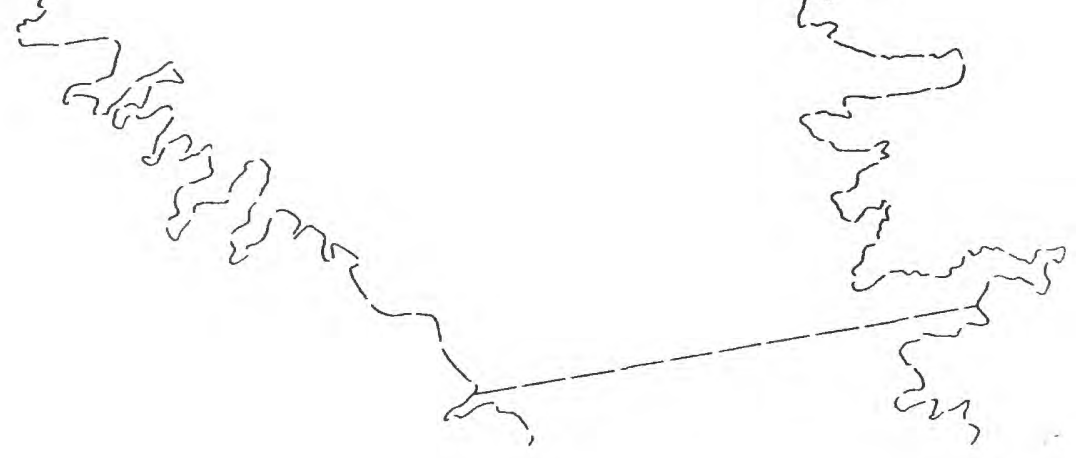

\section{METERS}

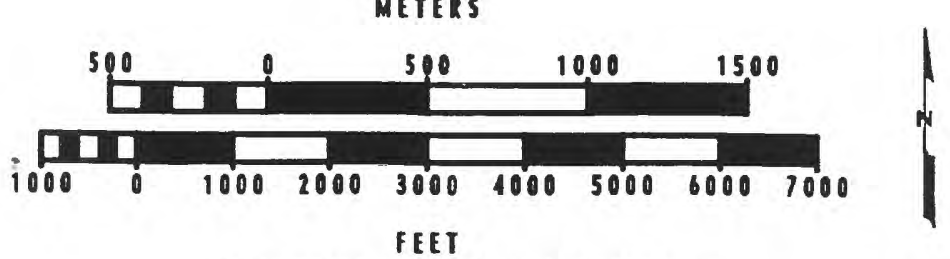

Unlvereal Traneveree Merantor Profoction 

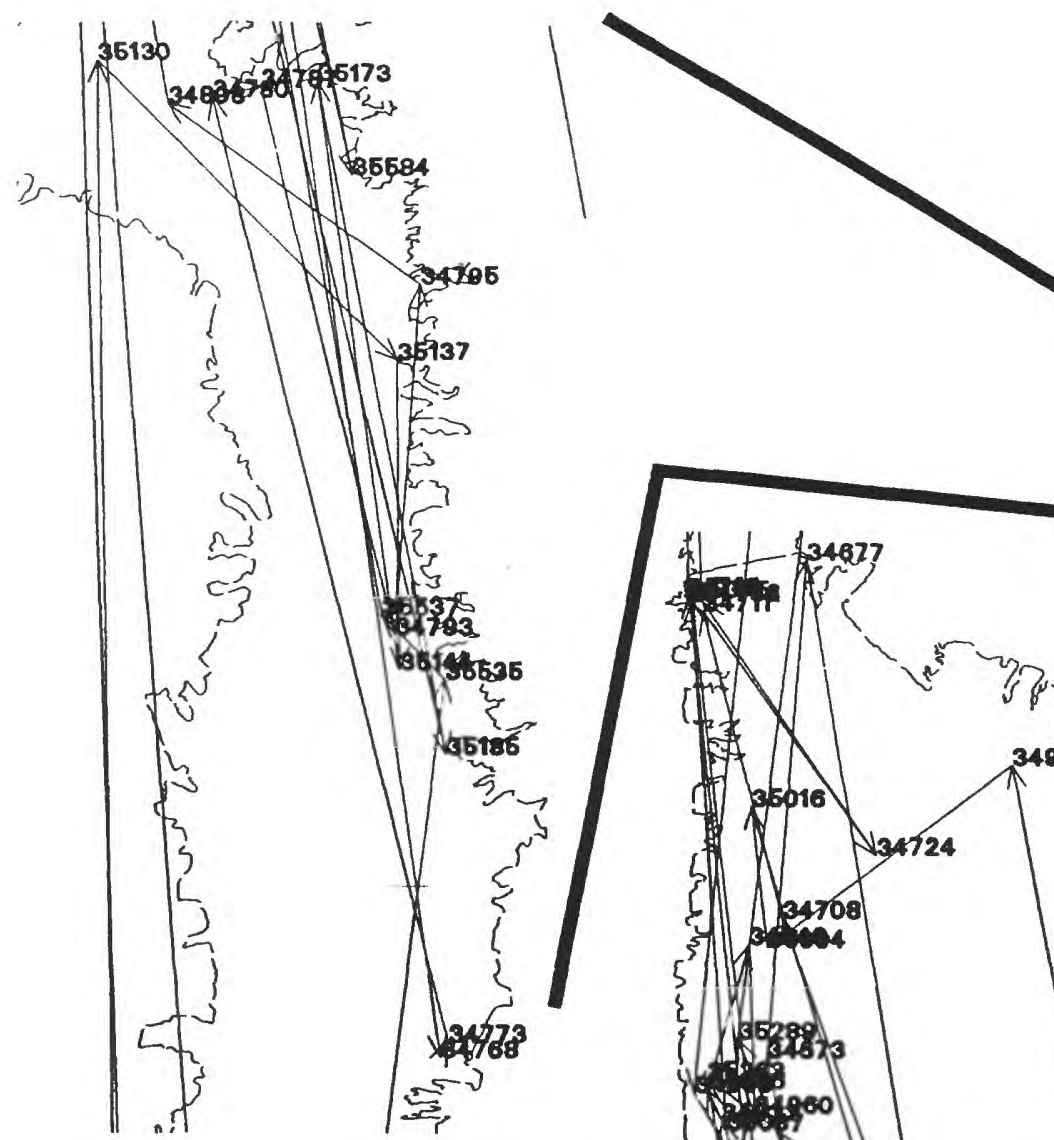


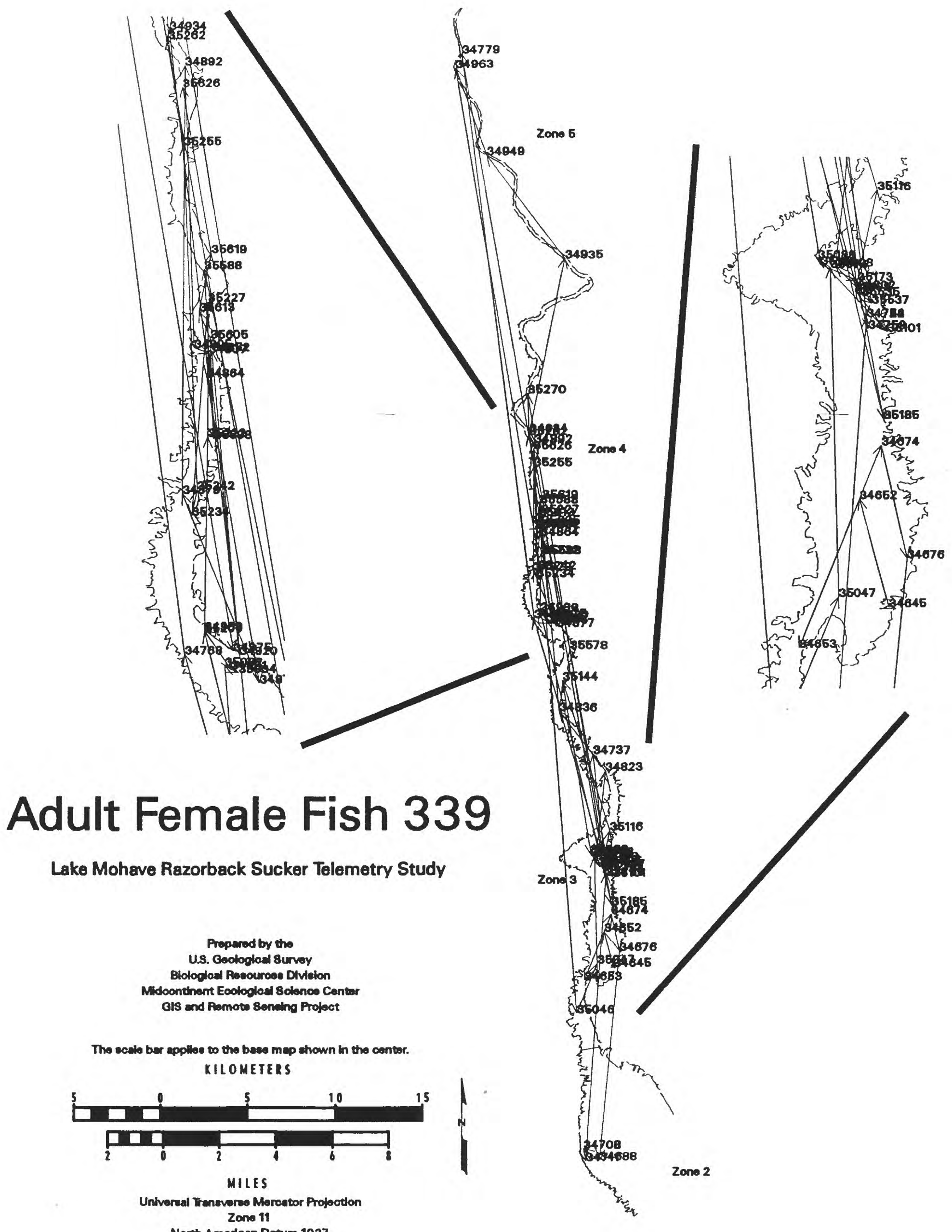




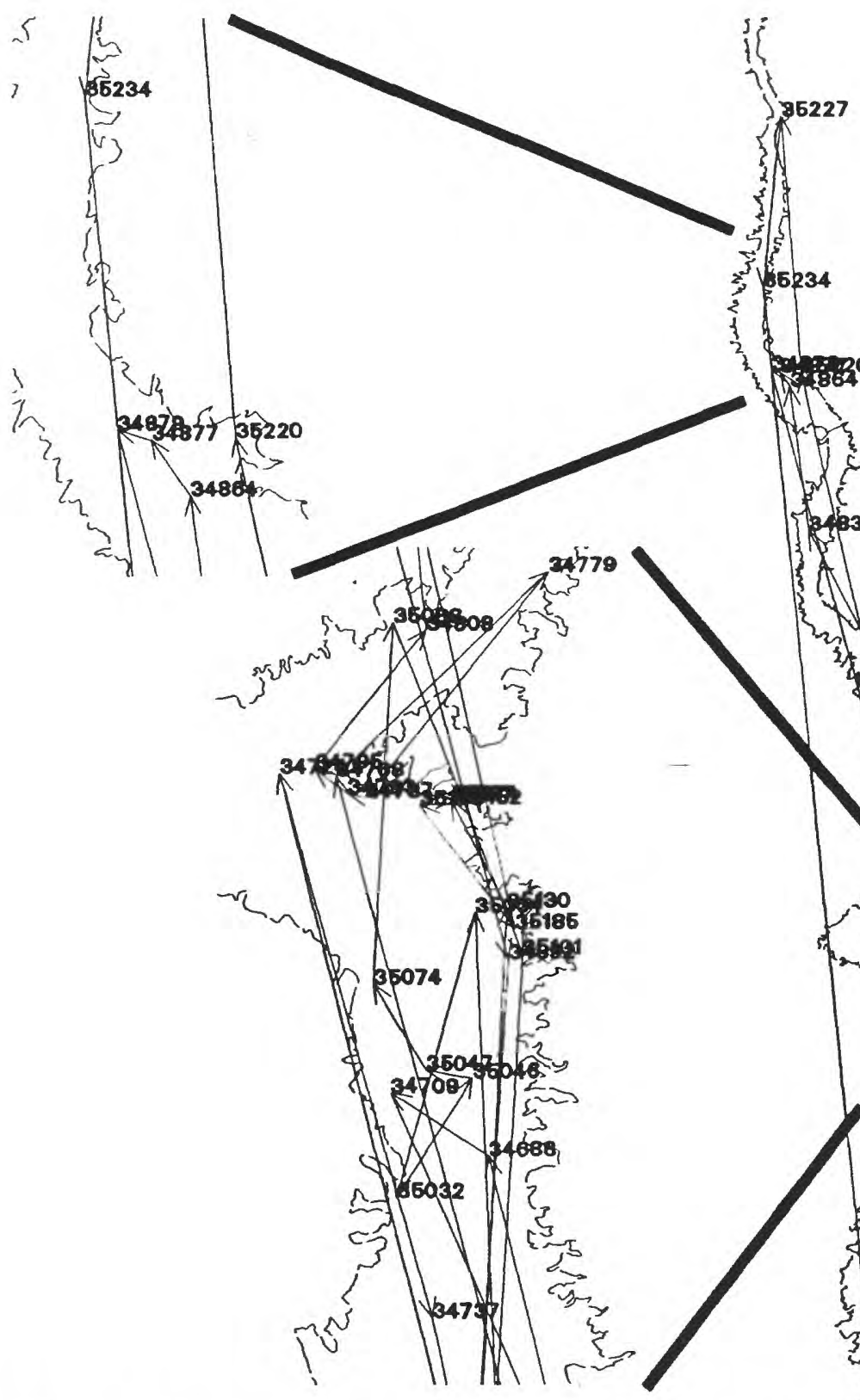

\section{Adult Female Fish 375}

Lake Mohave Razorback Sucker Telemetry Study

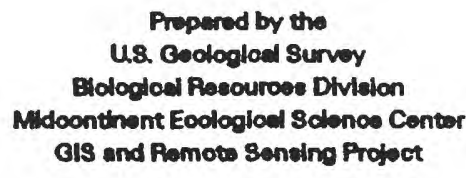

The scale ber epplles to the beee mep chown at the rlght

KILOMETELS
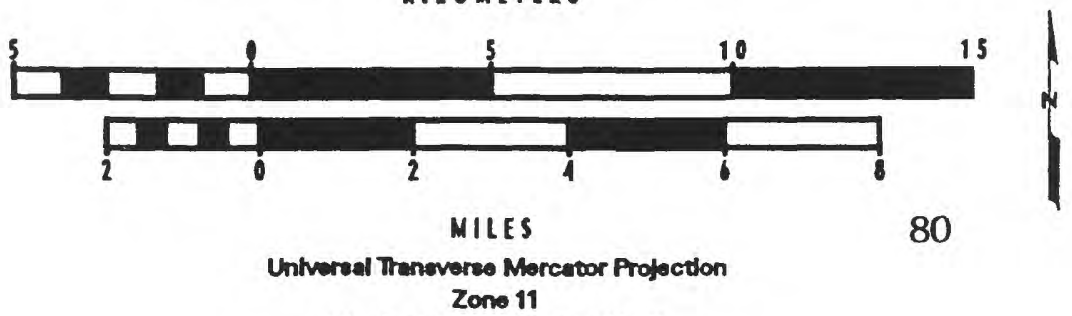

80

North Amortcen Datum 1927 


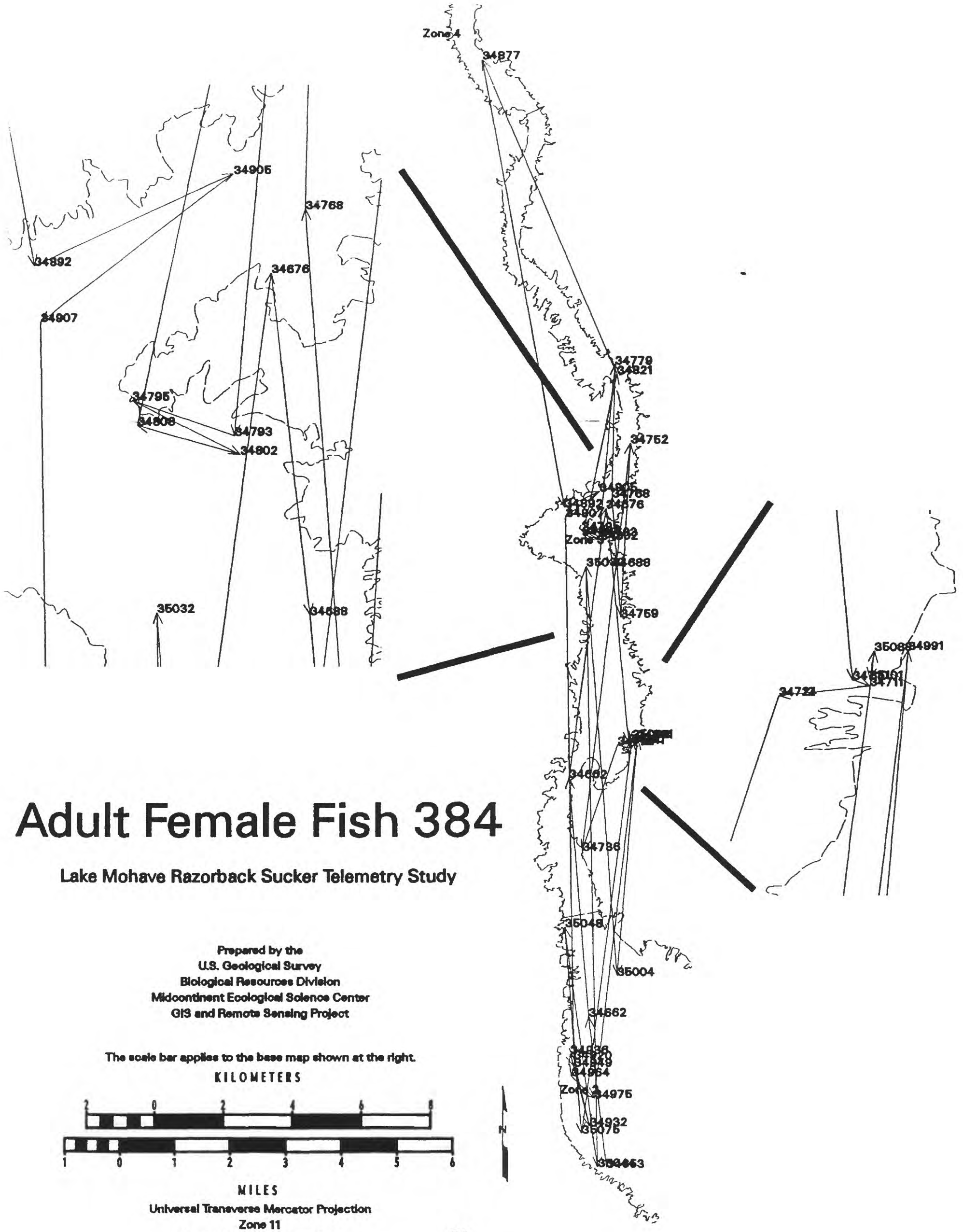




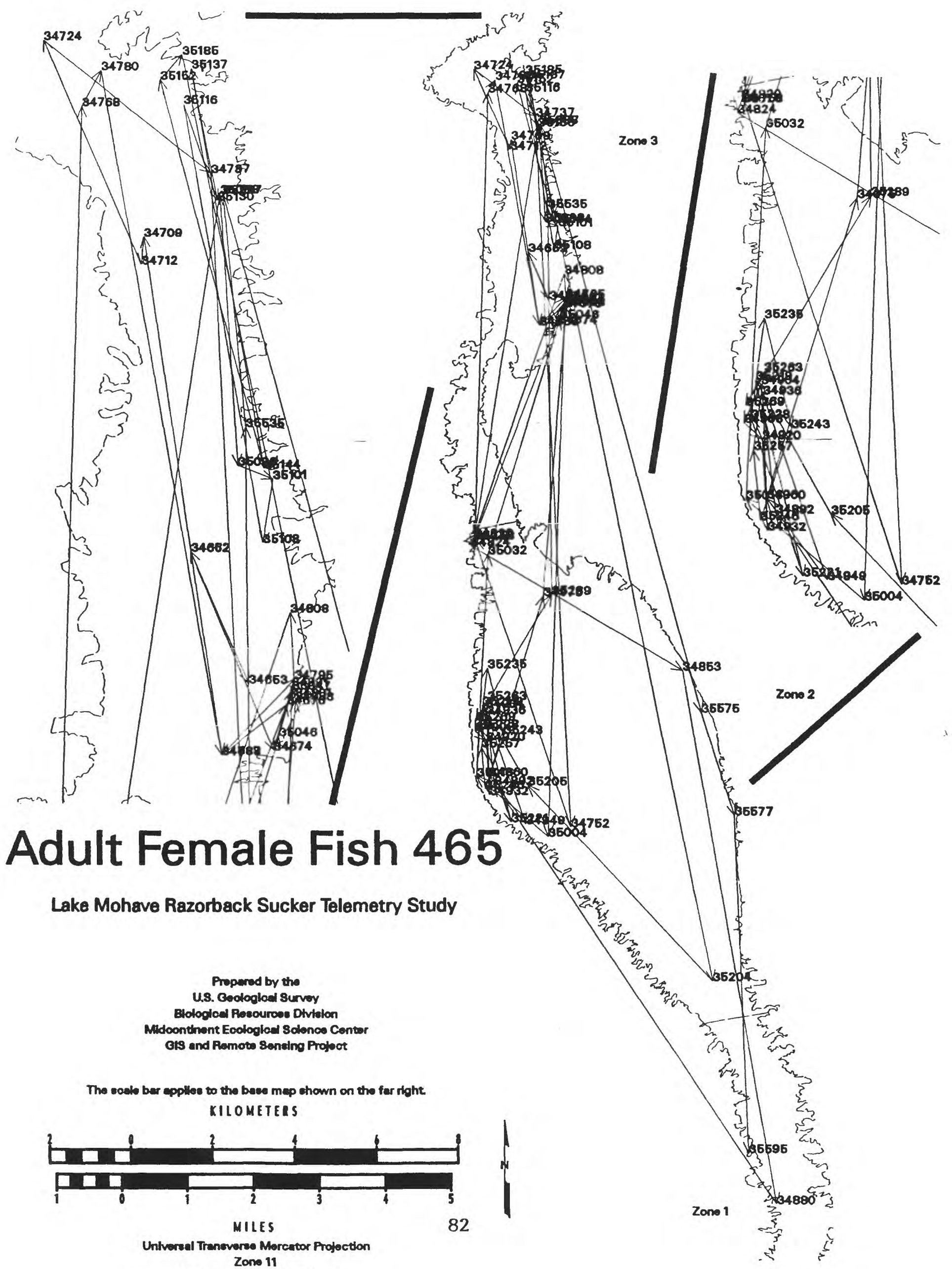

North Americen Detum 1927 


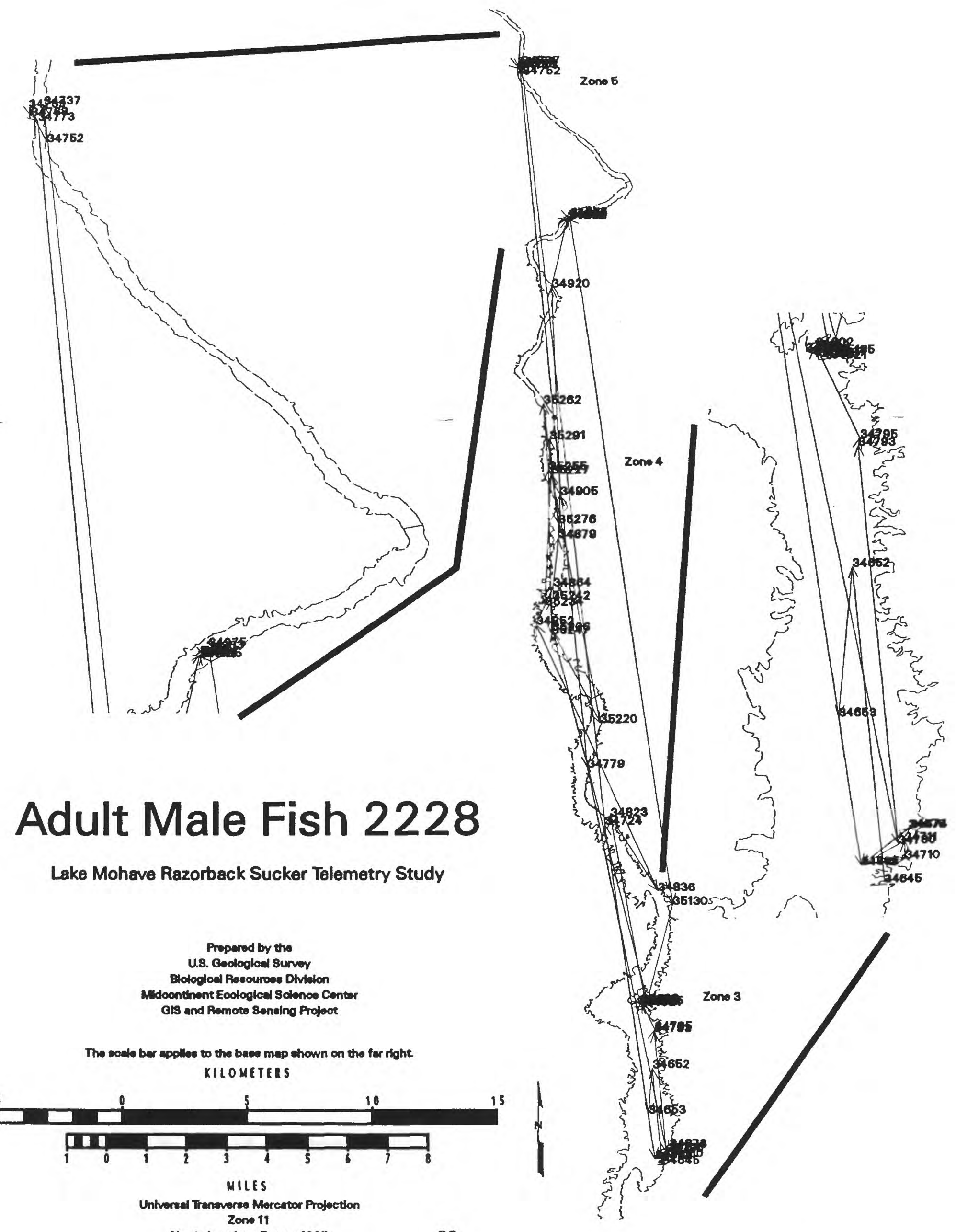

North Amerioan Datum 1927 


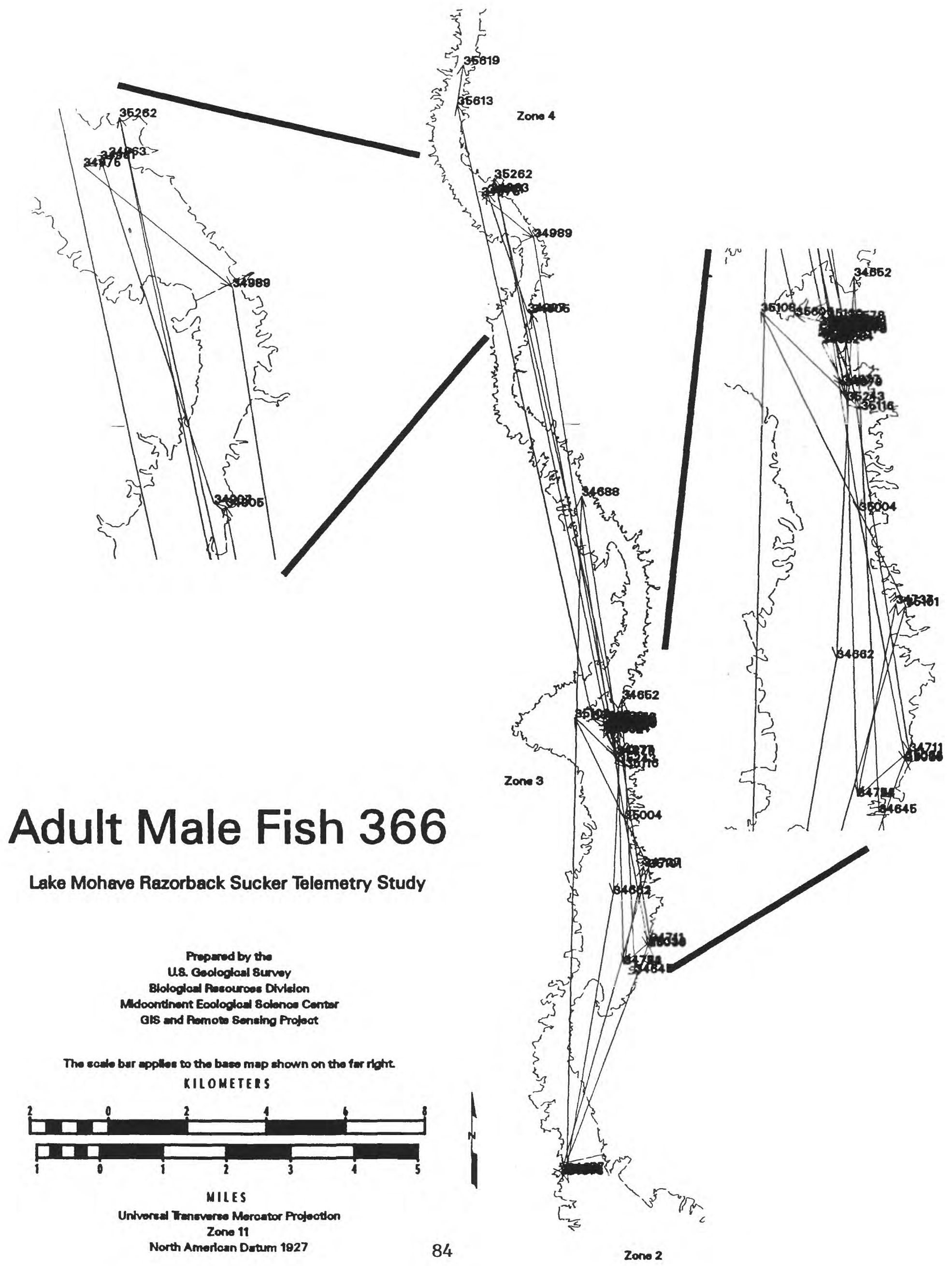




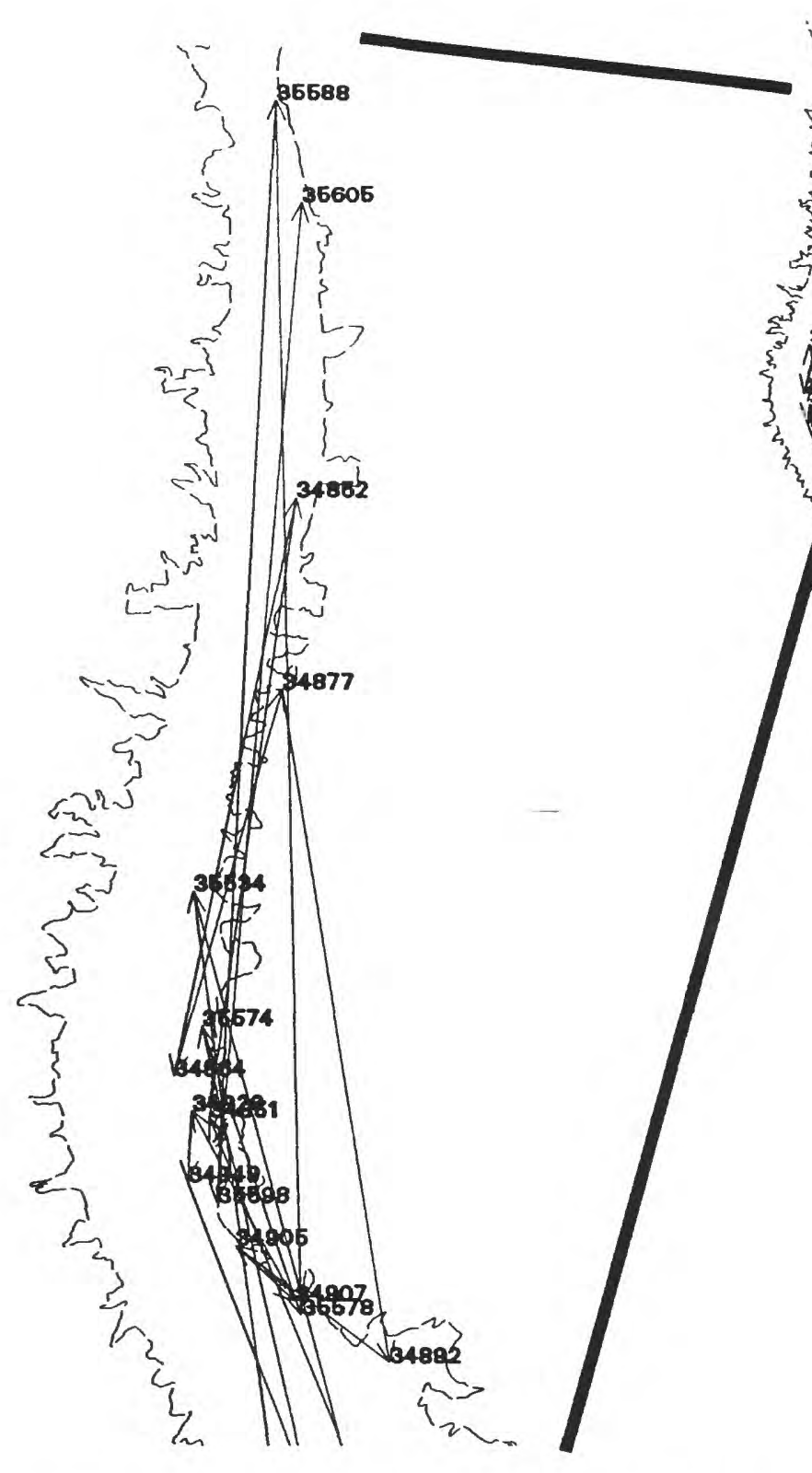

\section{Adult Male Fish 348}

Lake Mohave Razorback Sucker Telemetry Study

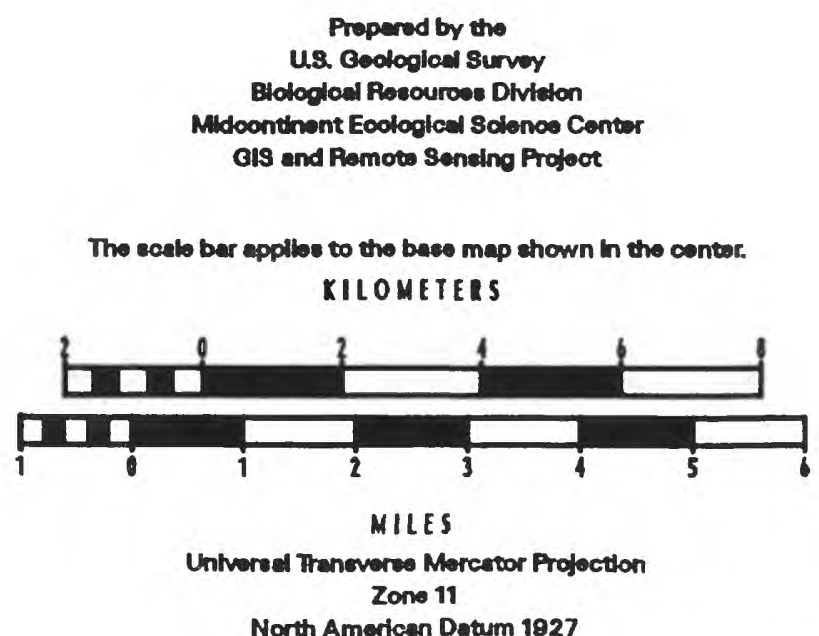




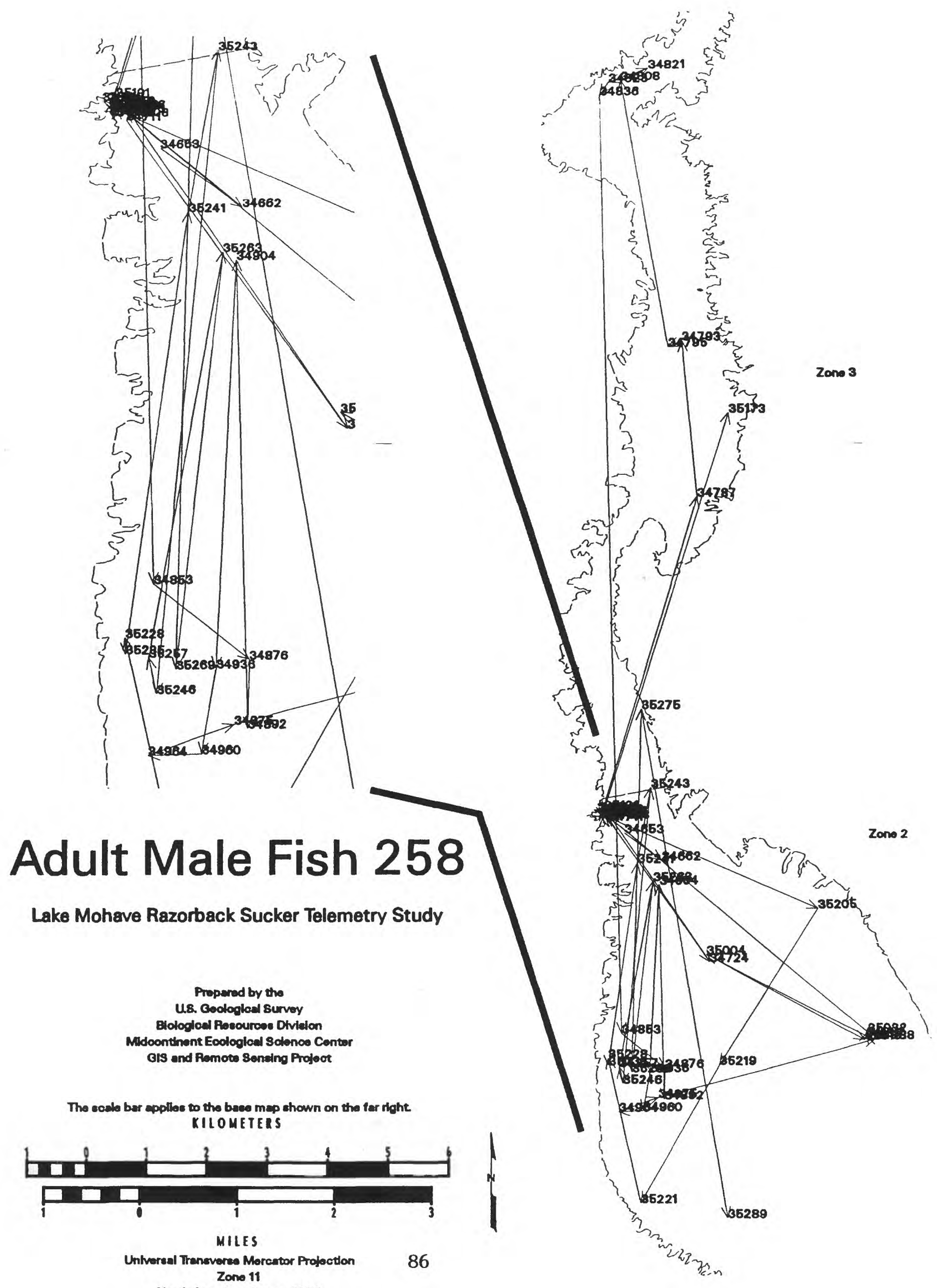




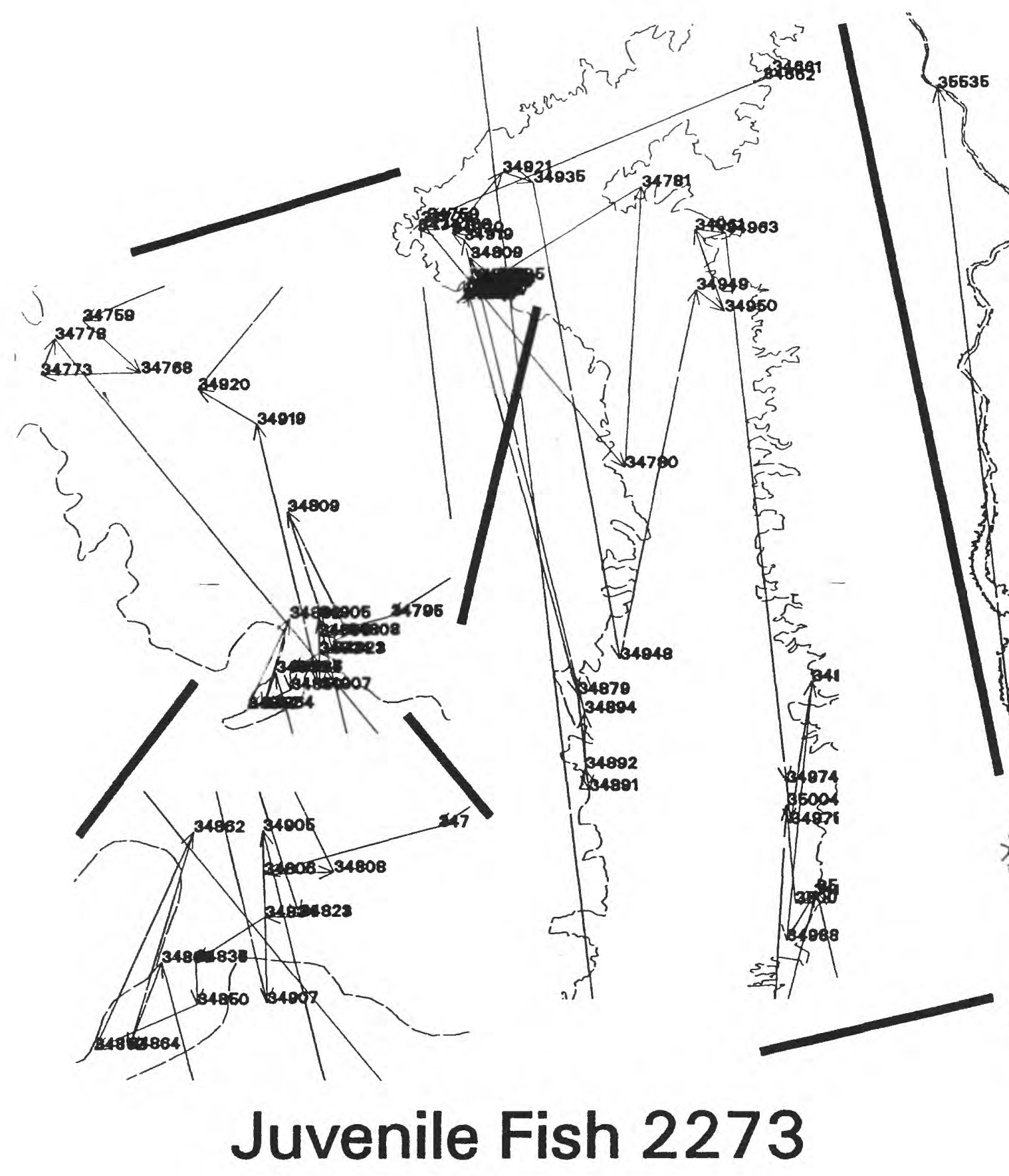

Zone 6

Lake Mohave Razorback Sucker Telemetry Study

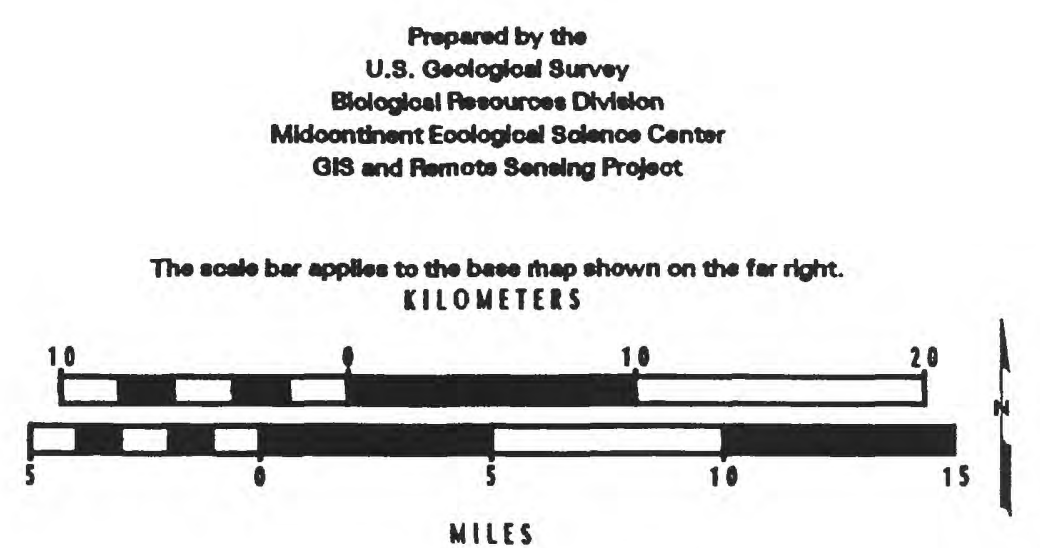

Untversel Traneveres Mercator Projection Zone 11

North Amerloen Datum 1927 


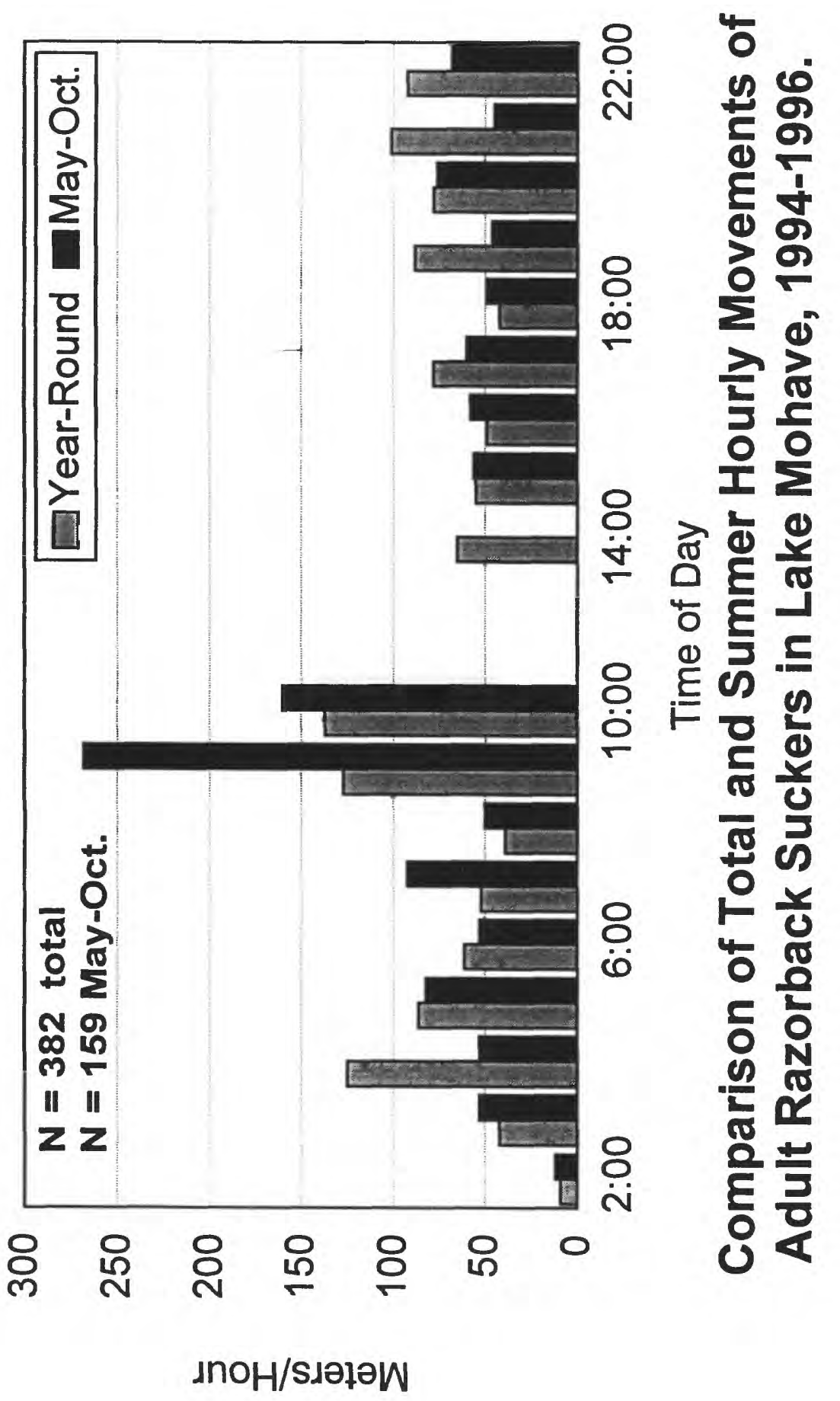

